CHARLENI INÊS SCHERER

O TRABALHO EM SAÚDE BUCAL NA ESTRATÉGIA SAÚDE DA FAMÍLIA: REVISÃO DA LITERATURA E ESTUDO QUALITATIVO NO DISTRITO FEDERAL 


\author{
UNIVERSIDADE DE BRASÍLIA \\ FACULDADE DE CIÊNCIAS DA SAÚDE \\ PROGRAMA DE PÓS-GRADUAÇÃO EM SAÚDE COLETIVA
}

CHARLENI INÊS SCHERER

O TRABALHO EM SAÚDE BUCAL NA ESTRATÉGIA SAÚDE DA FAMÍLIA:
REVISÃO DA LITERATURA E ESTUDO QUALITATIVO NO DISTRITO FEDERAL

Dissertação apresentada como requisito parcial para a obtenção do Título de Mestre em Saúde Coletiva pelo Programa de Pós-Graduação em Saúde Coletiva da Universidade de Brasília.

Orientadora: Magda Duarte dos Anjos Scherer

BRASÍLIA 


\title{
O TRABALHO EM SAÚDE BUCAL NA ESTRATÉGIA SAÚDE DA FAMÍLIA: REVISÃO DA LITERATURA E ESTUDO QUALITATIVO NO DISTRITO FEDERAL
}

\author{
Dissertação apresentada como requisito parcial para a \\ obtenção do Título de Mestre em Saúde Coletiva pelo \\ Programa de Pós-Graduação em Saúde Coletiva da \\ Universidade de Brasília.
}

Aprovado em 12 de dezembro de 2014.

\section{BANCA EXAMINADORA}

Prof. ${ }^{\text {a }}$ Dra. Magda Duarte dos Anjos Scherer - Presidente

Universidade de Brasília

Prof. ${ }^{\text {a }}$ Dra. Daniela Lemos Carcereri

Universidade Federal de Santa Catarina

Prof. a Dra. Elza Maria de Souza

Universidade de Brasília

Prof. ${ }^{a}$ Dra. Dais Gonçalves Rocha

Universidade de Brasília 
Dedico este trabalho aos meus pais, Cassilda Maria Scherer e Zeno Scherer, e ao meu marido, companheiro de todas as horas, Roberto Eduardo Schneiders. 


\section{AGRADECIMENTOS}

À Deus pela vida.

Aos meus pais, que mesmo distantes em Santa Cruz do Sul/RS, por sempre me incentivarem e me apoiarem nos estudos. Em especial, à minha mãe pelas conversas cotidianas e orações.

Ao meu marido, Roberto Eduardo Schneiders, por me proporcionar tranquilidade, paciência, força, companheirismo, carinho, amor e por estar em todos os momentos ao meu lado.

À minha irmã Monica e à querida afilhada Maitê e aos demais familiares por me apoiarem na trajetória de formação acadêmica.

À Professora Dra. Magda Duarte dos Anjos Scherer, que apesar de não ser minha parente, é mais que isso, é amiga e meu espelho profissional. Muito obrigada pela paciência, acolhida, confiança e convívio e pelas orientações fundamentais que tornaram possível a conclusão deste nosso trabalho.

Ao Grupo de Pesquisa do Trabalho em Saúde do Núcleo de Estudos de Saúde Pública (NESP), que me acolheu e me proporciona grandes aprendizados, conhecimentos, reflexões e trocas.

Às amigas e colegas de pesquisa, Erica Lima Costa de Menezes e Eliane Pedroso de Moraes, por me convidarem para participar da Pesquisa Multicêntrica de Saúde Bucal, por a toda contribuição, trocas e apoio pesquisa.

Às estudantes da iniciação científica Lorraine, Ellen e Rayane por toda colaboração e apoio na pesquisa. 
Ao Coordenador-Geral de Gestão da Atenção Básica, Dirceu Ditmar Klitze e à Coordenadora-Adjunta de Gestão da Atenção Básica, Patrícia Araújo Bezerra, por me apoiarem, me valorizarem e me liberarem do trabalho, sempre que necessário, para tornar possível a realização desta conquista.

Às amigas dentistas, Ana Cristina, Alejandra, Carolina, Ellen, Fernanda, Mariângela, Patrícia, Raquel e Suzana, pelo apoio e constantes trocas nos momentos de alegrias e de tensão ao longo do mestrado.

Às amigas e colegas de mestrado, Pauline, Mayara, Maria, Kelly, Aline, Karine e Janaína, por tornarem todos os momentos, ao longo de nossa formação, mais leves, divertidos e produtivos.

Aos colegas e amigos da Coordenação-Geral de Gestão da Atenção Básica e do Ministério da Saúde, pelas amizades, parcerias, compreensão, momentos de desabafo, de descontração e aprendizado diário, em especial às amigas e grandes colegas de trabalho Márcia Helena Leal e Daniela Cristina Moreira Marculino de Figueiredo.

Às Professoras Daniela Lemos Carcereri, Elza Maria de Souza e Dais Gonçalves Rocha por aceitarem o convite em participar da banca de defesa deste mestrado e por todas as contribuições para aprimoramento e qualificação deste trabalho.

Aos gestores da Secretaria de Saúde que permitiram a pesquisa e principalmente ao acolhimento que a pesquisadora responsável recebeu das equipes de Saúde da Família e de Saúde Bucal do Distrito Federal.

Ao Conselho Nacional de Desenvolvimento Científico e Tecnológico (CNPq) pelo apoio financeiro para o desenvolvimento desta pesquisa.

À Universidade de Brasília, por meio do Programa de Pós-Graduação em Saúde Coletiva, aos professores e funcionários, ter me proporcionado uma formação acadêmica gratuita e de qualidade. 
"Seja você quem for, seja qual for a posição social que você tenha na vida, a mais alta ou a mais baixa, tenha sempre como meta muita força, muita determinação e sempre faça tudo com muito amor e com muita fé em Deus, que um dia você chega lá. De alguma maneira você chega lá." 


\section{RESUMO NA LÍNGUA PORTUGUESA}

Introdução: O Brasil Sorridente, maior programa público de saúde bucal do mundo, completa uma década em 2014, sugerindo que nesse espaço de tempo, alterações tenham sido provocadas no trabalho das equipes de saúde bucal na APS, de forma a cumprir com os objetivos de reorientação do modelo de atenção. Objetivo: Analisar o trabalho em saúde bucal na Estratégia Saúde da Família (ESF) à luz das políticas públicas nacionais; bem como, identificar as mudanças efetuadas no trabalho dos profissionais de saúde bucal na atenção primária à saúde no Brasil e analisar como a equipe de saúde bucal se integra à equipe de saúde da família. Método: Realizaram-se duas pesquisas, sendo a primeira, uma revisão de literatura sobre as principais mudanças referentes ao trabalho em saúde bucal na atenção primária à saúde, a partir do lançamento do Programa Brasil Sorridente. Pesquisaram-se os bancos de dados MEDLINE, Lilacs, EMBASE, SciELO, BVS e The Cochrane Library, no período de 2000 a 2013, guiadas por elementos analisadores das mudanças no trabalho. Na segunda investigação, foi realizado um estudo qualitativo que analisa o trabalho em saúde bucal na ESF no Distrito Federal. Os dados foram coletados por meio de observação, análise documental e entrevistas com 19 profissionais que atuavam na ESF no Distrito Federal. A coleta e análise baseou-se em categorias analíticas prévias construídas a partir das políticas públicas nacionais que orientam o trabalho em saúde bucal. Resultados: Na revisão de literatura foram selecionados e analisados 32 estudos, com predomínio de estudos qualitativos, da região nordeste, com trabalhadores, sobretudo o dentista, com foco na integralidade e qualificação da assistência. Os resultados mostram que no trabalho em saúde bucal na ESF predominam características do modelo biomédico hegemônico com ênfase nas ações curativas individuais que convivem com características do modelo preconizado pelas políticas com destaque para a integração dos profissionais da saúde bucal nas reuniões de equipe, nas visitas domiciliares, nas ações intersetoriais e de educação em saúde. No Distrito Federal, no trabalho em saúde bucal na ESF predominam características do modelo biomédico hegemônico com ênfase nas ações curativas individuais que convivem com características do modelo preconizado pelas políticas com destaque para a 
integração dos profissionais da saúde bucal nas reuniões de equipe, nas visitas domiciliares, nas ações intersetoriais e de educação em saúde. Conclusões: Evidenciam-se avanços incipientes nas ações educativas, acolhimento, vínculo e responsabilização. A ampliação do engajamento de gestores e profissionais na compreensão do trabalho e da formação para construir mudanças segundo as singularidades locais, é um caminho promissor. A integração da saúde bucal na equipe de saúde da família é incipiente e limitada por conflitos de normas: de um lado uma normativa que institui o campo comum de atribuições e de outro, a que institui duas equipes distintas.

Palavras-chave: Odontologia em Saúde Pública; Atenção Primária à Saúde; Saúde da Família; Saúde Bucal; Trabalho. 


\section{RESUMO NA LÍNGUA INGLESA}

Introduction: The Brasil Sorridente (Smiling Brazil), the biggest public health program in the world, completes its first decade in 2014, suggesting that in this mean time, changes have been provoked in the work of the APS's oral health teams, in such way to comply with the reorientation objectives from the attention model. Objective: Analyze the oral health work done in the Family Health Strategy (FHS) under the scope of national public policies; as well as identify the changes that took place in the work of oral health professionals for the primary attention to health in Brazil and analyze how the oral health team integrates with the family health team. Method: Two researches took place, the first being a literary review of the main changes referring to the work done in oral health for the primary attention to health, starting with the release of the "Brasil Sorridente" program. The MEDLINE, Lilacs, EMBASE, SciELO, BVS and The Cochrane Library databases were researched, from the period of 2000 to 2013, such researches being guided by analyzing elements that could measure the changes that took place in these works. In the second investigation, a qualitative study was effected, analyzing the oral health work in Distrito Federal's FHS. The data was collected through observation, documental analysis and interviews with 19 professionals that acted in Distrito Federal's FHS. The collection and the analysis based themselves in previous analytical categorias, built from the national public policies that orient the work done in the oral health field. Results: In the literary review, 32 studies were selected and analyzed, with the predominance of qualitative studies, from the Northeast region, with workers, overall the dentist, focusing on the integrality and the qualification of their assistance. The results show that in the oral health work in FHS, characteristics of the hegemonic biomedic model predominate, with emphasis on the individual's healing actions that coexist with the characterists of the model recommended by the policies, highlighting the integration of oral health professionals in the team meetings, in home visits, in the intersectoral actions and of education in health. In Distrito Federal, in the oral health work done at FHS, characterists from the hegemonic biomedical model predominate, with emphasis on the individual healting actions that coexist with characterists of the model recommended by the policies, highlighting the integration of oral health professionals in the team meetings, in the home visits, in the 
intersectoral actions and in health education. Conclusion: Incipient advances are made evident in the educational initiatives; in the reception, bonding and accountability of it. The ampliation of the commitment of professionals and managers in the comprehension of the work being done and of the academic development needed to build changes according to local singularities, is a promissing path. The integration of oral health in the family health team is incipient and limites due to the conflict in general standards: in one side, the normative that institues the common ground of attributions and in the other, the normative that institutes two distinct teams.

Keywords: Public Health Dentistry; Primary Health Care; Family Health; Oral Health; Work. 


\section{LISTA DE FIGURAS}

Figura 1. Regiões administrativas do Distrito Federal com destaque para os locais do estudo

\section{ARTIGO 1. AVANÇOS E DESAFIOS NO TRABALHO EM SAÚDE BUCAL APÓS UMA DÉCADA DE PROGRAMA BRASIL SORRIDENTE}

Figura 1. Linha do tempo, identificando os momentos e normatizações que marcam o incentivo à mudanças no processo de trabalho em saúde bucal na APS no Brasil.

Figura 2. Elementos de análise das mudanças de concepções e práticas em saúde bucal na APS.

Figura 3. Busca, seleção, inclusão e exclusão dos estudos sobre o processo de trabalho na saúde bucal na APS.

\section{ARTIGO 2. O TRABALHO EM SAÚDE BUCAL NA ESTRATÉGIA SAÚDE DA FAMÍLIA: UMA DIFÍCIL INTEGRAÇÃO?}

Figura 1. Elementos de análise das mudanças no trabalho em saúde bucal na APS 58

Figura 2. Síntese do percurso metodológico.

Quadro 1. Fortalezas e fragilidades na integração da equipe de saúde bucal à equipe de saúde da família, segundo as categorias analíticas prévias. 


\section{LISTA DE TABELAS}

ARTIGO 1. AVANÇOS E DESAFIOS NO TRABALHO EM SAÚDE BUCAL APÓS UMA DÉCADA DE PROGRAMA BRASIL SORRIDENTE

Tabela 1. Aspectos gerais dos estudos selecionados, características metodológicas e sujeitos do estudo.

Tabela 2. Estudos selecionados que abordam os elementos analisadores do trabalho em saúde bucal na APS no Brasil apontando desafios e mudanças... 


\section{LISTA DE ABREVIATURAS E SIGLAS}

$\begin{array}{ll}\text { ACS } & \text { Agentes Comunitários de Saúde } \\ \text { APS } & \text { Atenção Primária à Saúde } \\ \text { ASB } & \text { Auxiliar de Saúde Bucal } \\ \text { ATLAS.TI } & \text { Qualitative Research and Solutions } \\ \text { BVS } & \text { Biblioteca Virtual em Saúde } \\ \text { CD } & \text { Cirurgião-Dentista } \\ \text { CEO } & \text { Centro de Especialidade Odontológica } \\ \text { CNPq } & \text { Conselho Nacional de Desenvolvimento Científico e Tecnológico } \\ \text { DF } & \text { Distrito Federal } \\ \text { E } & \text { Enfermeiro } \\ \text { ESF } & \text { Estratégia Saúde da Família } \\ \text { IBGE } & \text { Instituto Brasileiro de Geografia e Estatística } \\ \text { LILACS } & \text { Literatura Latino-Americana e do Caribe em Ciências da Saúde } \\ \text { M } & \text { Médico } \\ \text { MS } & \text { Ministério da Saúde } \\ \text { NASF } & \text { Núcleo de Apoio à Saúde da Família } \\ \text { PMAQ } & \text { Programa Nacional de Melhoria do Acesso e da Qualidade } \\ \text { PNAB } & \text { Política Nacional de Atenção Básica } \\ \text { PNAD } & \text { Pesquisa Nacional por Amostra de Domicílios } \\ \text { PNSB } & \text { Política Nacional de Saúde Bucal } \\ \text { SciELO } & \text { Scientific Electronic Library Online } \\ \text { SUS } & \text { Sistema Único de Saúde } \\ \text { TE } & \text { Técnico de Enfermagem } \\ \text { TSB } & \text { Técnico de Saúde Bucal } \\ \text { UBS } & \text { Unidade Básica de Saúde } \\ \text { UF } & \text { Unidade Federativa } \\ & \\ \text { SA } & \end{array}$




\section{SUMÁRIO}

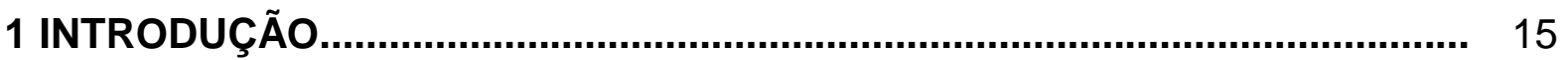

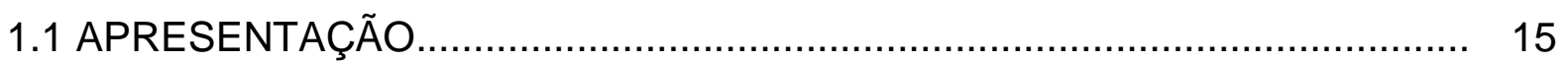

1.2 A SAÚDE BUCAL NA ESTRATÉGIA SAÚDE DA FAMÍLIA........................... 16

1.3 A ESTRATÉGIA SAÚDE DA FAMÍLIA COMO INOVAÇÃO TECNOLÓGICA

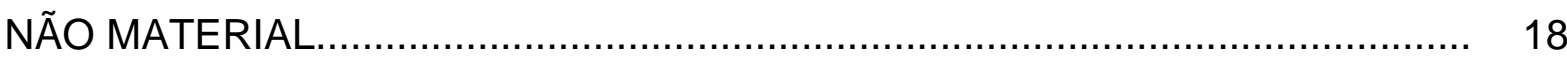

1.4 O TRABALHO EM SAÚDE: O MODO DE OPERACIONALIZAÇÃO DAS POLÍTICAS PÚBLICAS..................................................................................... 19

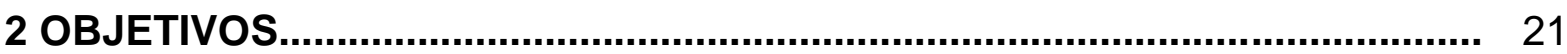

2.1 OBJETIVO GERAL........................................................................ 21

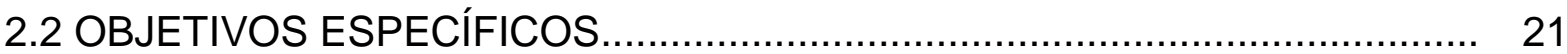

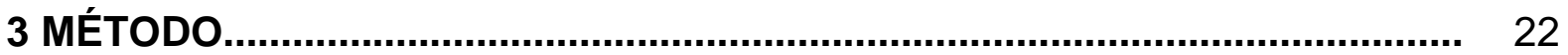

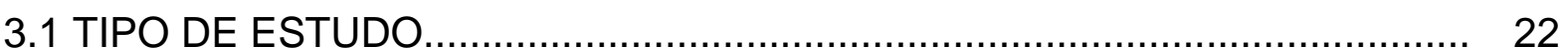

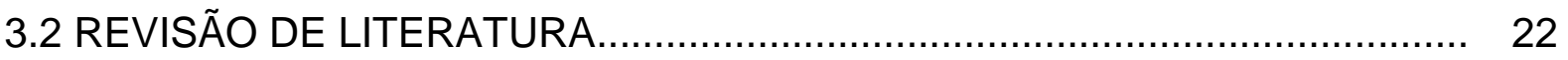

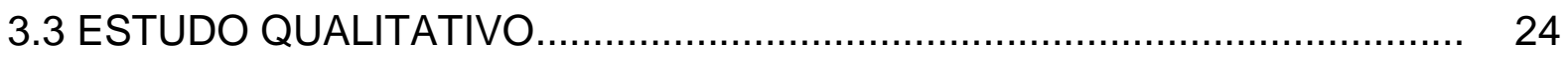

3.3.1 Local e sujeitos do estudo...................................................................... 24

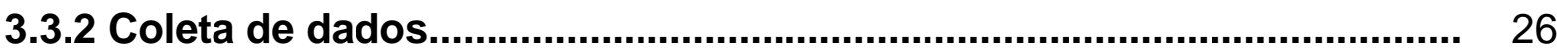

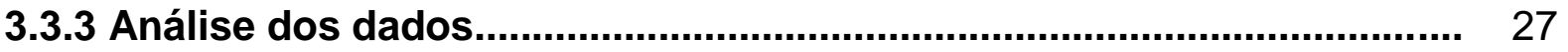

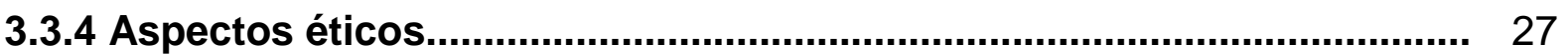

4 RESULTADOS E DISCUSSÃO.................................................................. 28

4.1. ARTIGO 1 - AVANÇOS E DESAFIOS NO TRABALHO EM SAÚDE BUCAL APÓS UMA DÉCADA DE PROGRAMA BRASIL SORRIDENTE....................... 29

4.2. ARTIGO 2 - O TRABALHO EM SAÚDE BUCAL NA ESTRATÉGIA SAÚDE DA FAMÍLIA: UMA DIFÍCIL INTEGRAÇÃO? .................................................... 54

5 CONCLUSÕES.................................................................................... 82

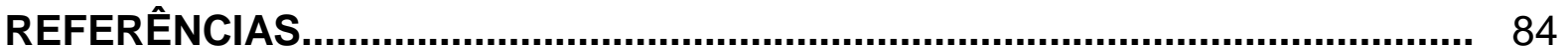

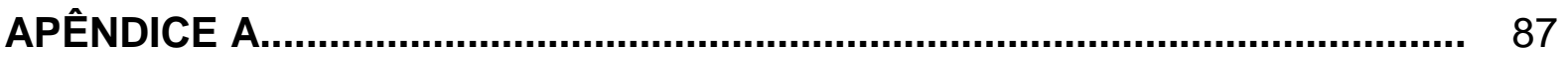

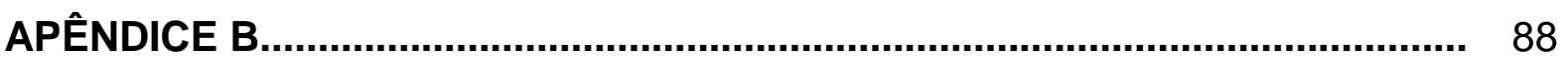

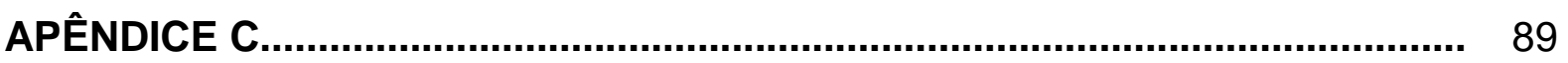

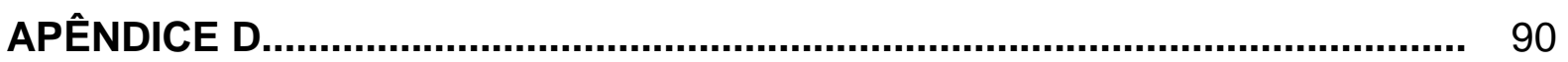

ANEXO A

ANEXO B 


\section{INTRODUÇÃO}

\subsection{APRESENTAÇÃO}

A presente dissertação de mestrado teve a finalidade de analisar o trabalho em saúde bucal na Estratégia Saúde da Família (ESF) no Brasil e no Distrito Federal. Para alcançar esse objetivo foram empregados dois diferentes tipos de estudo: (I) revisão da literatura, da qual obteve-se as principais mudanças no trabalho em saúde bucal no Brasil e (II) estudo qualitativo, de caráter descritivo, que analisou o trabalho em saúde bucal na ESF com foco na integração da equipe de saúde bucal à equipe de saúde da família.

Com o intuito de disseminar o conhecimento científico e expor os resultados do mestrado de maneira mais prática e objetiva foi optado apresentar a dissertação na forma de dois artigos científicos, sendo exibidos nos resultados e discussão da dissertação.

O Artigo 1 "Avanços e desafios no trabalho em saúde bucal após uma década de programa Brasil Sorridente" foi realizado uma revisão da literatura sobre as principais mudanças referentes ao trabalho em saúde bucal na Atenção Primária à Saúde, a partir do lançamento das Diretrizes da Política Nacional de Saúde Bucal. A elaboração desse capítulo permitiu aumentar a familiaridade ao tema, possibilitando o entendimento da maneira de realização desses estudos no Brasil.

O Artigo 2 "O trabalho em saúde bucal na Estratégia Saúde da Família: uma difícil integração?" é um estudo qualitativo do tipo descritivo que analisa o trabalho em saúde bucal na ESF no Distrito Federal, com destaque para a integração. Esse capítulo representa o tema principal de investigação realizada durante o mestrado.

As referências bibliográficas utilizadas em cada artigo, constam ao final dos mesmos seguindo as instruções de cada revista e, as referências utilizadas no restante da dissertação, estão agrupadas ao final desse documento. Apêndices e anexos estão presentes, em capítulos a parte, no final da dissertação. 


\subsection{A SAÚDE BUCAL NA ESTRATÉGIA SAÚDE DA FAMÍLIA}

Atenção Primária à Saúde (APS) apresenta-se como uma estratégia para reorientar a organização do sistema de saúde e caracteriza-se como o primeiro nível de contato dos indivíduos, da família e da comunidade a um serviço de saúde, e constitui o primeiro elemento de um processo de atenção continuada à saúde ${ }^{1,2}$. Este nível de atenção busca dar respostas antecipatórias, racionais e com base em evidências às necessidades de saúde da população, nos diferentes aspectos de promoção, proteção, tratamento, reabilitação da saúde, prevenção de doenças e agravos, com a agilidade necessária para o diagnóstico e tratamento precoce dos problemas mais comuns e relevantes ${ }^{3,4}$.

No Brasil, ao longo de mais de duas décadas, o Ministério da Saúde (MS) tem a Saúde da Família como estratégia prioritária para expansão e consolidação da APS e para promover mudanças no modelo de atenção vigente ${ }^{2,4,5}$. A Estratégia Saúde da Família (ESF) mantém os princípios constituídos no Sistema Único de Saúde (SUS), apoiada nos atributos da APS e apresenta uma proposta progressiva e gradual de transformação da realidade, com base no planejamento territorial, na ampliação dos mecanismos de participação social, na gestão com o desenvolvimento da oferta das ações e serviços, inclusão e integração das populações vulneráveis, em situação de injustiças sociais ${ }^{2,4}$.

Cada equipe de Saúde da Família é formada por um médico, um enfermeiro, um auxiliar ou técnico de enfermagem e por quatro a seis agentes comunitários de saúde (ACS). No âmbito da abrangência, cada equipe se responsabiliza pela cobertura de uma área onde residem 3 mil a, no máximo, 4 mil pessoas e cada ACS é responsável por, no máximo, 150 famílias ou 750 pessoas ${ }^{2}$. Inicialmente, os profissionais da saúde bucal não faziam parte da Saúde da Família e as suas ações caracterizavam-se pela atenção predominantemente aos escolares de 6 a 14 anos, por meio do chamado Sistema Incremental ${ }^{6}$.

Em 2000, os resultados da Pesquisa Nacional por Amostra de Domicílio (PNAD), demonstraram que 29,6 milhões de brasileiros nunca tinham ido ao cirurgião-dentista. Neste contexto, em função da necessidade de aumentar as ações de prevenção e garantir os investimentos na área curativa em procedimentos odontológicos, o MS determinou o incentivo financeiro para as ações e inserção dos 
profissionais de saúde bucal na ESF. Foram definidas duas modalidades de equipes, sendo a modalidade I composta de um cirurgião-dentista (CD) e um auxiliar de saúde bucal (ASB) e a modalidade II de um CD, um ASB e um técnico de saúde bucal (TSB). Os objetivos foram, principalmente, diminuir os índices epidemiológicos de saúde bucal e ampliar o acesso da população brasileira às ações de saúde bucal 7,8 .

As Diretrizes da Política Nacional de Saúde Bucal (PNSB), mais conhecidas como "Brasil Sorridente", são lançadas pelo MS em 2004 das quais cinco frentes de ação foram estabelecidas: ampliação do atendimento na rede de APS, criação de centros de especialidades, ações educativas, implantação de próteses e fluoretação das águas ${ }^{9}$. Houve um aumento nos incentivos financeiros federais para ampliar o acesso à saúde bucal na APS, resultando em um crescimento de $106 \%$ das equipes de saúde bucal na ESF entre dezembro de 2002 e setembro de $2004^{8}$.

Contudo, o perfil da prática odontológica, ao longo dos anos, indica que a saúde bucal foi desenvolvida à distância, predominantemente isolada, restrita à prática do $C D$ com ações eminentemente clínicas e preventivas direcionadas a escolares, que se revelaram insuficientes para responder às necessidades da população ${ }^{6,10}$. Devido à inserção tardia da saúde bucal, seis anos após a ESF, há que se considerar possíveis dificuldades na integração dos profissionais de saúde bucal às equipes de saúde da família, bem como diferentes formas de implantação das equipes de saúde bucal no país ${ }^{8}$.

Outro ponto que merece destaque é a forma que a ESF se organiza, a partir de uma equipe multiprofissional, onde cada um dos profissionais de saúde desenvolve atribuições e ações de saúde ora comuns (como as ações intersetoriais e de planejamento, visita domiciliar, entre outras), ora devendo ser preservadas as especificidades de seus núcleos de atuação e competência. Neste sentido, construir a integração e a interdisciplinaridade é um desafio posto às equipes da ESF ${ }^{6}$.

Entretanto, a inserção da equipe de saúde bucal na ESF, tem se constituído um avanço na prática odontológica, por se tratar de uma estratégia eficaz de reorganização da APS ${ }^{11}$, também, observa-se o esforço para promover uma maior integração da saúde bucal nos serviços de saúde em geral, a partir da conjugação de saberes e práticas que apontem para a promoção e vigilância em saúde e para revisão das práticas assistenciais que incorporem a abordagem familiar e a defesa da vida. A incorporação das ações de saúde bucal pelas equipes de saúde da 
família visa transpor esse modelo de organização e prática anterior, na medida em que procura integrar a prática dos profissionais da equipe ${ }^{6}$.

\subsection{A ESTRATÉGIA SAÚDE DA FAMÍLIA COMO INOVAÇÃO TECNOLÓGICA NÃO MATERIAL}

Sousa \& Hamann $(2009)^{12}$ consideram que a implementação da ESF é uma agenda inerte e incompleta, por não ter sido capaz de ampliar as condições para a superação efetiva do modelo biomédico hegemônico nas políticas públicas do setor saúde no Brasil. Entretanto, Scherer, Pires e Soratto (2014) ${ }^{13}$ enfatizam que a ESF se constitui em uma proposta contra hegemônica no sentido de mudança do modelo tradicional de assistência em saúde.

Além de proporcionar aos usuários tratamentos de determinadas doenças, a ESF também realiza um conjunto de ações de saúde, no âmbito individual e coletivo, que abrange a promoção e a proteção da saúde, a prevenção de agravos, o diagnóstico, a reabilitação, a redução de danos e a manutenção da saúde ${ }^{4}$. Essas ações visam proporcionar uma visão integral do processo saúde-doença e de seus determinantes e condicionantes, propondo articulação de saberes técnicos e populares, juntamente com a mobilização de recursos institucionais e comunitários, públicos e privados para o enfrentamento de problemas de saúde ${ }^{13}$.

O formato de equipe multiprofissional proporciona o compartilhamento das responsabilidades do cuidado entre os membros da equipe e a participação de todos, com suas competências profissionais, para a melhoria da qualidade das ações de saúde e para concepção da integralidade 4, 6, 13. Dentre as diversas atribuições comuns dos membros da equipe, pode-se destacar algumas: participação do processo de territorialização e mapeamento da área de atuação; realização da assistência em saúde à população adscrita de maneira interdisciplinar; realização da atualização do cadastramento das famílias alocadas; participação do acolhimento dos usuários por meio da escuta qualificada das necessidades de saúde; realização de reuniões a fim de discutir em conjunto o planejamento e avaliação das ações; realização de educação em saúde à população adscrita e a grupos mais vulneráveis ${ }^{4}$. 
A ESF, no campo da saúde brasileira, é a inovação tecnológica não material de maior impacto político, social e nos condicionantes de saúde. Pois, se constitui em uma nova forma de organização e gestão do trabalho em saúde que tem como resultado o serviço prestado pelas equipes multiprofissionais, que não são produtos não materiais, inseparáveis do processo de produção; e, é uma inovação com característica incremental, pois não rompe integralmente com os saberes e as práticas clínicas de cuidado mas, introduz novas práticas colaborativas, de diálogo em diferentes saberes, assume como objeto de trabalho os seres humanos em sua integralidade e coletividade cultural e socialmente determinadas; e sua aplicação possibilitou melhorias nos resultados do trabalho em saúde aperfeiçoando o modo de fazer a atenção à saúde ${ }^{13}$.

\subsection{O TRABALHO EM SAÚDE: O MODO DE OPERACIONALIZAÇÃO DAS POLÍTICAS PÚBLICAS}

Apesar dos avanços nos planos legal e institucional, que ocorreram ao longo dos anos no Brasil, passando desde a aprovação da Constituição Federal e da criação do SUS, das Diretrizes da PNSB até a publicação revisada e atual da Política Nacional de Atenção Básica (PNAB), a reorientação do processo de trabalho em saúde de acordo com os princípios do SUS continua sendo um grande desafio.

Chanlat $(2004)^{14}$, cita a presença de alguns paradoxos com os quais algumas organizações se confrontam, inclusive as organizações de saúde: a afirmação do coletivo e o desenvolvimento de práticas cada vez mais individualizadas; a preocupação de flexibilidade permanente e o desejo de estabilidade; a redução do espaço-tempo social e a afirmação da importância do coletivo; a urgência de qualidade e a realização de práticas que vão em sentido contrário.

Quando se aborda o trabalho em saúde é inevitável não abordar o modo como são operacionalizadas as políticas de saúde. Ao falar do trabalho é preciso dizer de quem trabalha, em como trabalha e em quais condições ${ }^{13}$. Como diz Schwartz $(1998)^{15}$, refletir sobre o que se transforma "no" ou "do" trabalho tem implicações políticas e éticas, porque não se trata de um campo neutro e os instrumentos utilizados na produção do conhecimento e dos produtos materiais e 
não materiais não estão separados das escolhas e julgamentos de valor implícitos nesse processo.

Peduzzi \& Schraiber $(2008)^{16}$ descrevem que o processo de trabalho em saúde diz respeito à dimensão microscópica do cotidiano do trabalho em saúde, à prática dos trabalhadores e profissionais de saúde, sendo, no entanto, necessário compreender que neste processo de trabalho que está produzida toda a intervenção e dinâmica e do trabalho humano.

Neste contexto, o trabalho não é um ato isolado, é a síntese do histórico e social daquilo que é possível ser feito, num determinado espaço e tempo, por sujeitos, segundo a relação que estes estabelecem com o meio e sua capacidade de agir, tendo por base um conjunto de normas antecedentes e de valores ${ }^{13}$. Schwartz $(1998)^{15}$, ressalta que a realização do trabalho é mediada por diferentes formas de organização e gestão orientadas pelas prescrições institucionais que são permanentemente renormalizadas pelos sujeitos do trabalho, os trabalhadores.

O trabalho coletivo em saúde, que podemos entender como trabalho em equipe na ESF, pela sua complexidade e múltiplos profissionais e trabalhadores envolvidos implica na necessidade de cooperação no trabalho entretanto, geralmente, predominam ações fragmentadas de cada área técnica por uma parte da atividade. A cooperação não pode ser prescrita, ela é fruto da busca, pelo trabalhador, da qualidade do trabalho como uma condição para ter prazer no trabalho, saúde mental e construção da sua identidade singular ${ }^{17,18}$.

O trabalho multiprofissional é condicionado pelo modelo de gestão e pelas condições materiais e organizacionais nas quais se desenvolvem. Entretanto, para se efetivar na perspectiva interdisciplinar e ser mais resolutivo o trabalho multiprofissional depende da consciência e do compromisso dos profissionais, de conhecimentos e competências, envolvendo a subjetividade e a intersubjetividade dos trabalhadores ${ }^{19}$.

Neste contexto, a inserção da saúde bucal na ESF representa uma oportunidade de mudança no processo de trabalho na APS. Para o $C D$, a integração à ESF pode significar a ruptura do isolamento profissional e o caminho para a produção de novas relações com a equipe, transformando-o em um profissional mais atuante no campo da saúde ${ }^{10}$. 


\section{OBJETIVOS}

\subsection{OBJETIVO GERAL}

Analisar o trabalho em saúde bucal na Estratégia Saúde da Família (ESF) à luz de políticas públicas nacionais após uma década de Programa Brasil Sorridente.

\subsection{OBJETIVOS ESPECÍFICOS}

- Identificar as ações de saúde bucal desenvolvidas no trabalho em saúde bucal na ESF;

- Relacionar as ações realizadas com as ações preconizadas pelas normas orientadoras do trabalho em saúde bucal na ESF;

- Identificar as mudanças efetuadas no trabalho dos profissionais de saúde bucal na atenção primária à saúde no Brasil; e,

- Analisar como a equipe de saúde bucal se integra à equipe de saúde da família. 


\section{MÉTODO}

\subsection{TIPO DE ESTUDO}

O estudo originou-se do projeto de pesquisa multicêntrico intitulado "Estratégia saúde da família - inovação tecnológica para ampliação do acesso, da qualidade e promoção de saúde bucal na atenção básica”, que possui apoio financeiro do Conselho Nacional de Desenvolvimento Científico e Tecnológico (CNPq).

Realizaram-se duas pesquisas, na primeira foi elaborada uma revisão de literatura sobre as principais mudanças referentes ao trabalho em saúde bucal na atenção primária à saúde, a partir do lançamento das Diretrizes da Política Nacional de Saúde Bucal. Na segunda investigação, foi realizado um estudo qualitativo que analisa o trabalho em saúde bucal na ESF no Distrito Federal.

\subsection{REVISÃO DE LITERATURA}

Foi realizada revisão da literatura guiada por elementos analisadores das mudanças no trabalho da saúde bucal na APS, segundo as normatizações vigentes e a partir da publicação das Diretrizes da PNSB ${ }^{4,6,9}$.

Os estudos foram coletados nas bases MEDLINE (via PubMed), Lilacs, EMBASE, SciELO, Biblioteca Virtual em Saúde e The Cochrane Library (via Bireme). Foram incluídas publicações a partir de 2000, três anos antes da publicação das Diretrizes, até 03 de novembro de 2013. Foi incluído período anterior a 2004, quando lançadas as Diretrizes da PNSB, tendo em vista esse momento ser precedido de experiências e pactuações entre os diversos atores envolvidos na temática que poderiam ter sido objeto de pesquisas publicadas em periódicos científicos.

As palavras-chaves de busca em inglês utilizadas no PubMed foram: ("primary health care" OR "family health" OR "work") AND (OR "health policy" OR "dental health services" OR "dentistry" OR "oral health") AND ("Brazil"). Nas demais 
bases, os descritores foram utilizados em inglês e português. A combinação foi realizada com a utilização dos operadores booleanos " $A N D$ " e "OR" e utilizando operadores $\mathrm{MeSH}$ ou análogos de acordo com a base pesquisada quando disponível.

A coleta de dados foi realizada por uma pesquisadora enquanto que a seleção e avaliação dos estudos pareada por duas pesquisadoras familiarizadas com o tema e com o método. Com a escolha dessas palavras-chave e descritores foram encontrados 77 artigos na MEDLINE (via Pubmed), 538 no LILACS, 4 no EMBASE, 67 no SCIELO, 338 na Biblioteca Virtual em Saúde (BVS) e 13 no The Cochrane Library (via Bireme), totalizando 1.037 artigos.

Foram incluídos os artigos de estudos que se referiam ao trabalho ou às práticas ou mudança de modelo na saúde bucal na APS descrito no título do estudo ou em seus resumos. Foram selecionados aqueles que problematizam a organização e a gestão dos processos de trabalho em saúde bucal, em especial do trabalho em equipe na APS, um dos eixos centrais da reordenação da atenção à saúde no SUS. Foram excluídos os estudos de reflexão teórica, dissertações e teses.

Foram selecionados 211 artigos, depois retirados 60 que se repetiram nas distintas bases, resultando em 52 estudos submetidos à leitura integral. Ao final, 32 artigos foram incluídos.

Nos artigos incluídos foram identificados aspectos gerais da publicação, características metodológicas e principais resultados, analisados a partir dos elementos de análise do trabalho em saúde bucal na APS. A triagem das informações foi realizada independentemente pelos pesquisadores e posteriormente comparada em reunião de consenso. Os itens consensuais foram considerados adequados e incluídos na descrição dos resultados. Estes foram agrupados em função das categorias temáticas prévias (elementos de análise) e analisados de forma descritiva. 


\subsection{ESTUDO QUALITATIVO}

\subsubsection{Local e sujeitos do estudo}

O estudo qualitativo foi realizado no contexto de duas unidades básicas de saúde (UBS) no Distrito Federal (DF). O DF é uma unidade da federação totalmente atípica e indivisível, embora compartilhe muito dos problemas que afligem as demais regiões brasileiras. Com a finalidade de facilitar a administração, o território do DF é dividido em 30 regiões administrativas ${ }^{20}$, conforme mostra a Figura1. O presente estudo foi realizado em duas dessas regiões administrativas, Fercal e Gama.

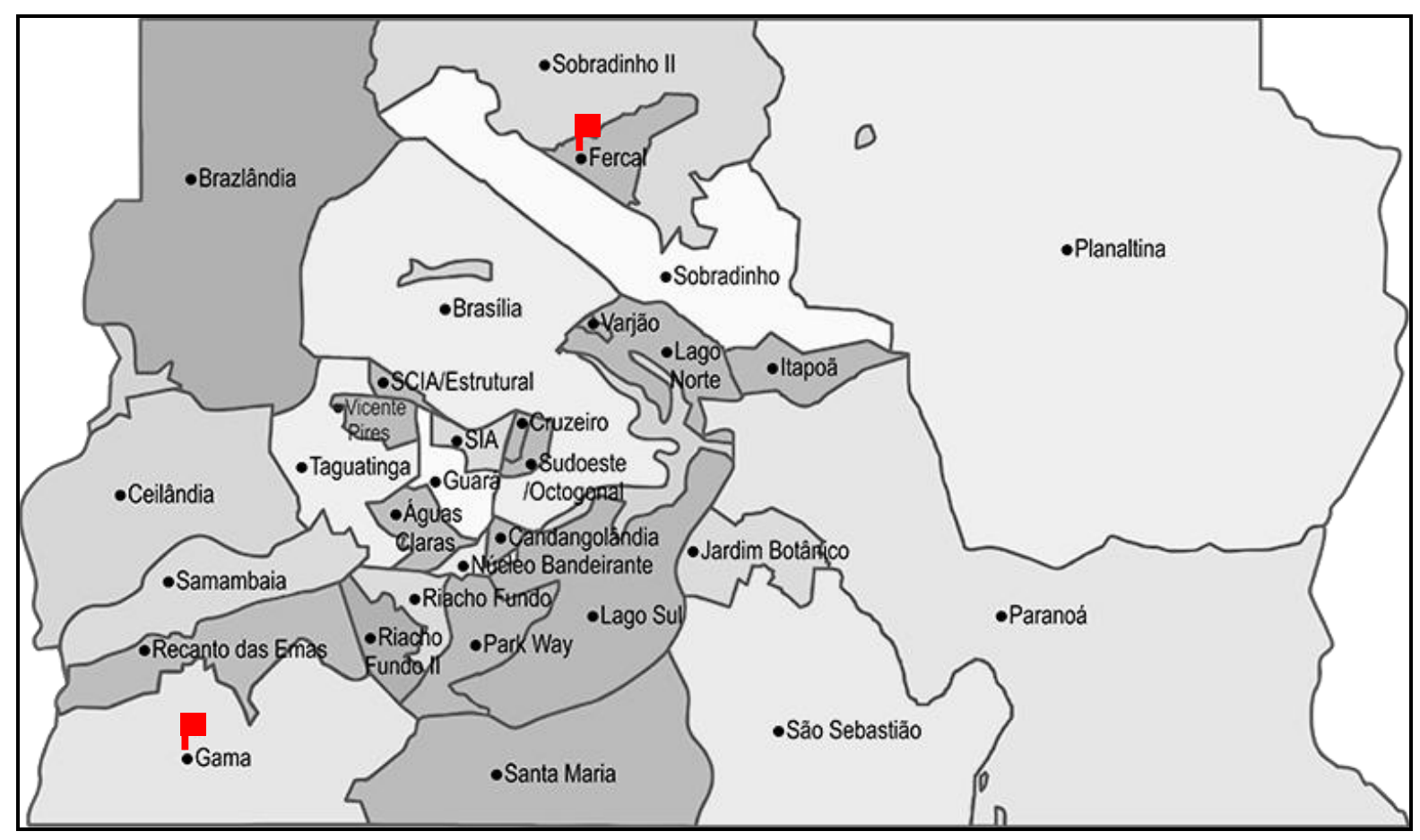

Figura 1. Regiões administrativas do Distrito Federal com destaque para os locais do estudo ${ }^{21}$.

O sistema de saúde no DF caracteriza-se pela predominância de estabelecimentos de saúde sob a administração direta da Secretaria de Saúde do Distrito Federal, que conta com 64 centros de saúde/unidade básica de saúde; 02 unidades mistas; 39 postos de saúde urbanos e rurais, além de 244 equipes de saúde da família, 70 equipes de saúde bucal modalidade II (CD e TSB), e 11 centros de especialidades odontológicas (CEO). Há 277 CD que atuam nas unidades de 
APS enquanto os demais estão distribuídos em outros pontos da rede de atenção à saúde. Segundo dados do MS ${ }^{22}$, de agosto de 2014, Brasília apresenta cobertura de APS de 54,39\%, considerando a ESF com cobertura de 30\%. A saúde bucal apresenta cobertura de $26 \%$ entretanto, considerando somente a ESF, tem-se uma cobertura de $8,47 \%$.

A escolha do local do estudo e dos participantes se deu a partir dos seguintes critérios de inclusão: a) equipes de saúde da família completas com equipe de saúde bucal, independentemente da modalidade; b) equipes de saúde da família consideradas de boa qualidade pelos gestores, tendo como referência a Política Nacional de Atenção Básica e as Diretrizes da Política Nacional de Saúde Bucal; c) equipes que, preferencialmente, tenham como referência CEO e/ou Núcleo de Apoio à Saúde da Família (NASF); e, d) equipes que participaram do $1^{\circ}$ ciclo do Programa Nacional de Melhoria do Acesso e da Qualidade (PMAQ) do Ministério da Saúde.

A amostra foi intencional e contou com 19 profissionais de saúde de duas UBS, uma localizada na região administrativa do Gama e outra, da Fercal, que conjuntamente, integram sete ACS, quatro técnicos de enfermagem (TE), dois enfermeiros $(E)$, dois $C D$, dois TSB e dois médicos $(M)$. Somente foram consideradas as entrevistas que abordaram o trabalho em saúde bucal na ESF, foco central de análise nesse estudo.

O caráter multiprofissional da amostra, incluindo equipe de saúde bucal e equipe de saúde da família, teve por objetivo abranger diferentes visões sobre o objeto de estudo, considerando que a saúde bucal não se restringe ao núcleo da odontologia, mas também abrange o campo de competências e responsabilidades de outras áreas profissionais; e, que a $\mathrm{PNAB}^{4}$ descreve aspectos norteadores do processo de trabalho e estabelece atribuições comuns, além das específicas, a todos os profissionais que atuam na ESF.

O foco central do estudo foi analisar o trabalho em saúde bucal sob a lógica da ESF. Neste sentido, o olhar do pesquisador se voltou para o trabalho em saúde bucal articulado/conjunto/integrado dos profissionais das equipes de saúde da família e de saúde bucal, sem analisar os procedimentos clínicos ou técnicos utilizados nos atendimentos assistenciais. 


\subsubsection{Coleta de dados}

Para assegurar os critérios de fidedignidade e de validade, utilizou-se da técnica da triangulação de dados, que consiste em olhar o objeto sob seus diversos ângulos, comparando e articulando os resultados das três técnicas de coleta de dados (análise documental, observação e entrevistas).

A triangulação de dados consiste em observar determinado problema sob diversos prismas, realizando comparações das informações encontradas ou colhidas através de duas ou mais técnicas ${ }^{23}$. A técnica de triangulação na coleta e análise de dados é amplamente utilizada em pesquisas qualitativas que utilizam como referencial de análise a percepção complexa dos fenômenos, por possibilitar o acesso aos dados por meio de fontes diversas, permitindo uma compreensão mais global do que é investigado ${ }^{24}$.

A coleta de dados ocorreu por meio da realização de entrevista semiestruturada, observação participante e análise documental. As entrevistas foram orientadas por um roteiro com perguntas norteadoras, gravadas e transcritas; as observações foram realizadas com auxílio de um guia de observação e um diário de campo foi utilizado para registro; e, a análise documental foi realizada por meio das atas de reunião de equipe (Apêndices $A, B$ e $C$ ).

$\mathrm{Na}$ apresentação dos resultados, os participantes de entrevista são denominados por letras que correspondem à categoria profissional (ACS: agente comunitário de saúde, CD: cirurgião-dentista, E: enfermeiro, M: médico, TE: técnico de enfermagem, TSB: técnico de saúde bucal) e números que correspondem a quantidade de entrevistados por categoria profissional, por exemplo (ACS1, ACS2, ACS3...).

Para subsidiar a observação participante, a categorização e a análise dos dados utilizou-se de uma revisão do referencial teórico ${ }^{4,6,9}$ sobre o trabalho em saúde bucal por meio da seleção de elementos de análise do trabalho em saúde bucal na APS. 


\subsubsection{Análise dos dados}

Os recursos disponíveis no software Atlas.ti (Qualitative Research and Solutions), versão 7.1.8, serviram como ferramenta para sistematizar e categorizar os dados e subsidiar a análise qualitativa. Os dados foram analisados à luz das políticas públicas nacionais vigentes: Política Nacional de Atenção Básica e as Diretrizes da Política Nacional de Saúde Bucal, articulando-os com o referencial teórico acerca do trabalho em saúde bucal.

A transcrição das entrevistas alimentou o banco de dados do Atlas.ti, constituindo a "Unidade Hermenêutica", linguagem utilizada pelo software. Os recursos do software possibilitaram a criação de códigos (codes) que indicaram os núcleos de sentido e as unidades de análise. Posteriormente, foram identificadas as verbalizações (quotations), ou, que ilustraram os códigos criados, representando as citações das falas dos sujeitos.

Após transcrição das entrevistas, na pré-análise, e durante a leitura flutuante, foi feita a exploração do material para identificar os núcleos de sentido e, por fim, sua organização e categorização conforme as categorias analíticas prévias (elementos de análise do trabalho em saúde bucal).

\subsubsection{Aspectos Éticos}

O projeto de pesquisa foi aprovado pelos Comitês de Ética em Pesquisa da Universidade de Brasília (Anexo A) e da Fundação de Ensino e Pesquisa em Ciências da Saúde (Anexo B) e seguiu as normas da Resolução oㅜ 466/12 do Conselho Nacional de Saúde. Os entrevistados foram esclarecidos sobre os objetivos da pesquisa e assinaram termo de consentimento livre e esclarecido (Apêndice D). 


\section{RESULTADOS E DISCUSSÃO}

Os resultados e discussão serão apresentados na forma de dois artigos:

Artigo 1: submetido à Revista de Saúde Pública

Avanços e desafios no trabalho em saúde bucal após uma década de Programa Brasil Sorridente.

Autores:

Charleni Inês Scherer

Magda Duarte dos Anjos Scherer

Artigo 2: a ser submetido aos Cadernos de Saúde Pública

O trabalho em saúde bucal na Estratégia Saúde da Família: uma difícil integração?

Autores:

Charleni Inês Scherer

Magda Duarte dos Anjos Scherer 


\title{
4.1 ARTIGO 1. AVANÇOS E DESAFIOS NO TRABALHO EM SAÚDE BUCAL APÓS UMA DÉCADA DE PROGRAMA BRASIL SORRIDENTE
}

\author{
ADVANCES AND CHALLENGES AT WORKING IN ORAL HEALTH AFTER A \\ DECADE OF ORAL HEALTH PROGRAM IN BRAZIL
}

\section{RESUMO}

O advento do Programa Brasil Sorridente em 2004 sinaliza um novo modelo de atenção à saúde bucal em construção, sugerindo alterações no trabalho das equipes. Foi realizada revisão da literatura sobre as principais mudanças referentes ao trabalho em saúde bucal na atenção primária à saúde, a partir do lançamento das Diretrizes da Política Nacional de Saúde Bucal. Foram pesquisadas as bases de dados MEDLINE, Lilacs, EMBASE, SciELO, BVS e The Cochrane Library, no período de 2000 a 2013, guiadas por elementos analisadores das mudanças no trabalho. Foram selecionados e analisados 32 estudos, com predomínio de estudos qualitativos, da região nordeste, com trabalhadores, sobretudo o dentista, com foco na integralidade e qualificação da assistência. Evidenciam-se avanços incipientes nas ações educativas, acolhimento, vínculo e responsabilização. A ampliação do engajamento de gestores e profissionais na compreensão do trabalho e da formação para construir mudanças segundo as singularidades locais é um caminho promissor.

DESCRITORES: Políticas Públicas de Saúde. Odontologia em Saúde Pública. Serviços de Saúde Bucal. Atenção à Saúde. Atenção Primária à Saúde. Saúde da Família. Saúde Bucal. Trabalho. Revisão.

\section{ABSTRACT}

The employment of oral health program in Brazil, called Brasil Sorridente (Smiling Brazil), in 2004, shows a new oral health care model in construction. This model suggests changes in work carried out by oral health teams. Literature review of the main changes related to the work in oral health in primary health care was performed, starting with the launch of the Guidelines of the National Oral Health Policy. The search was carried out through the following databases: MEDLINE, 
Lilacs, EMBASE, SciELO, BVS and Cochrane Library, from 2000 to 2013. The search was guided by elements that analyze changes at work. 32 studies were selected and analyzed, mostly qualitative research, conducted in the Northeast, performed with workers (mainly dentists), and focused on the integrality and qualification of care. The results show incipient advances in educational actions, hospitality, relationship and accountability. Broadening the engagement of managers and professionals in understanding the work and training to build changes according to local singularities is a promising way.

DESCRIPTORS: Health Public Policy. Public Health Dentistry. Dental Health Services. Health Care. Primary Health Care. Family Health. Oral Health. Work. Review.

\section{INTRODUÇÃO}

O Brasil avançou com a implantação do Sistema Único de Saúde (SUS) ao estabelecer a universalidade e integralidade como seus princípios, e a ampliação da cobertura da Atenção Primária à Saúde (APS), por meio da Estratégia Saúde da Família (ESF). Entretanto, ainda prevalece o modelo assistencial à saúde biomédico orientando as práticas profissionais, inclusive da odontologia, e na mentalidade da população. ${ }^{4,11,30,42,45,49,50}$

O quarto levantamento epidemiológico nacional realizado em 2010 revelou redução da cárie dentária aos 12 anos, valor $25 \%$ menor do que o encontrado em $2003^{\mathrm{a}}$ e mostra que o Brasil saiu da condição mundial de média prevalência de cárie para baixa prevalência. ${ }^{b} \mathrm{O}$ fator mais aceito como responsável por parte das reduções são os efeitos benéficos do flúor na água de abastecimento e nos dentifrícios. ${ }^{26} \mathrm{O}$ levantamento também revelou redução da necessidade de próteses em $52 \%$ nos adolescentes de 15 a 19 anos e de $70 \%$ nos adultos de 35 a 44 anos. ${ }^{28}$

Embora os resultados sejam animadores nacionalmente, chama a atenção: (a) as diferenças regionais na prevalência e gravidade da cárie são marcantes,

\footnotetext{
ainistério da Saúde (BR), Secretaria de Atenção à Saúde; Secretaria de Vigilância em Saúde, Departamento de Atenção Básica, Coordenação Geral de Saúde Bucal. Projeto SB Brasil 2010: Pesquisa Nacional de Saúde Bucal - Resultados Principais. Brasília: Ministério da Saúde, 2012. 116p.

${ }^{b}$ World Health Organization. WHO Global Oral Health Database. WHO Collaborating Centre for Education, Training and Research in Oral health; 2011 [citado 2012 abr 15]. Disponível em: http://www.mah.se/CAPP/
} 
indicando a necessidade de políticas voltadas para a equidade na atenção; (b) pouca redução da cárie na dentição decídua (18\%), e $80 \%$ dos dentes afetados continuam não tratados; (c) o déficit em idosos é significativo, apesar das necessidades de próteses terem diminuído em adolescentes e adultos; e (d) a prevalência de oclusopatia que requer tratamento é de $10 \%$ em adolescentes, indicando a necessidade de redimensionar a oferta de procedimentos ortodônticos na atenção secundária. ${ }^{28,30}$ Esses resultados estão associados ao perfil da prática odontológica, caracterizado pela realização de ações eminentemente clínicas, com ênfase em atividades restauradoras, e ações preventivas direcionadas a escolares, que se revelaram insuficientes para responder às necessidades da população. ${ }^{25}$

A saúde bucal é inseparável da saúde geral do indivíduo e componente importante de cuidados primários à saúde, entretanto, desigualdades no acesso existem a nível mundial, exigindo políticas públicas específicas que impulsionem novos modos de organizar os serviços e o trabalho dos profissionais. ${ }^{c}$

A trajetória brasileira de reorientação do modelo de atenção à saúde bucal na APS é marcada por quatro momentos, com potencial de impulsionar mudanças no processo de trabalho: $\left.1^{\circ}\right)$ da $1^{\text {a }}$ Conferência Nacional de Saúde Bucal (CNSB) em 1986, seguida da criação da Política Nacional de Saúde Bucal em 1989, e da $2^{a}$ CNSB em $19933^{8} 2^{\circ}$ ) em $2000^{15}$, da inserção dos profissionais de odontologia à ESF, enfrentando a restrição histórica de atuação junto ao grupo materno-infantil ${ }^{d}$, e do estabelecimento de incentivo financeiro federal; da criação das novas diretrizes curriculares nacionais dos cursos de graduação da área da saúde ${ }^{3}$ e, em 2001, da aprovação das normas e diretrizes de inclusão das equipes de saúde bucal na ESF; $3^{\circ}$ ) do lançamento do Programa Brasil Sorridente ${ }^{20}$ em 2004 e da $3^{\text {a }}$ CNSB, que contribuiu para a produção democrática e progressista sobre a temática; ${ }^{8} 4^{\circ}$ ) em 2006, as responsabilidades e atribuições comuns e específicas dos profissionais de saúde bucal foram inseridas na Política Nacional de Atenção Básica e reiteradas em 2011. ${ }^{f}$

\footnotetext{
' Ministério da Saúde (BR), Secretaria de Vigilância em Saúde, Departamento de Análise de Situação de Saúde. Saúde Brasil 2008: 20 anos de Sistema Único de Saúde (SUS) no Brasil. Brasília: Ministério da Saúde, 2009. 416p.

dinistério da Saúde (BR). Portaria no 613/GM, de 13 de junho de 1989. Aprova a Política Nacional de Saúde Bucal. Diário Oficial da União 1989; 13 jun.

e Ministério da Saúde (BR). Portaria no 648/GM, de 28 de março de 2006. Aprova a Política Nacional de Atenção Básica, estabelecendo a revisão de diretrizes e normas para a organização da Atenção Básica para o Programa Saúde da Família (PSF) e o Programa Agentes Comunitários de Saúde (PACS). Diário Oficial da União 2006; 29 mar

${ }^{\text {f } M i n i s t e ́ r i o ~ d a ~ S a u ́ d e ~(B R) . ~ P o r t a r i a ~ n o ~ 2.488 / G M, ~ d e ~} 21$ de outubro de 2011. Aprova a Política Nacional de Atenção Básica, estabelecendo a revisão de diretrizes e normas para a organização da Atenção Básica, para a Estratégia Saúde da Família (ESF) e o Programa de Agentes Comunitários de Saúde (PACS). Diário Oficial da União 2011; 24 out.
} 
O Programa Brasil Sorridente, em formato de Diretrizes da Política Nacional de Saúde Bucal (PNSB), ${ }^{9}$ propõe a reorganização da saúde bucal na APS, tendo o conceito do cuidado como eixo de reorientação de modelo. ${ }^{20}$ As diretrizes representam o principal marco na mudança da atenção em saúde bucal porque rompem com o modelo centrado no fazer odontológico tecnicista e curativo, orientam para a multiprofissionalidade, integralidade e intersetorialidade, tendo como finalidade a ampliação e qualificação da assistência, com foco nas necessidades de saúde da população. $8,20,26,35$

A normatização das atribuições e responsabilidades comuns dos profissionais da ESF mudam as características do processo de trabalho até então vigente. Todos devem se inserir em atividades tais como territorialização, planejamento e acolhimento, fortalecendo o vínculo e a responsabilização com a saúde da população, para além da cura da doença. ${ }^{3,25}$

A trajetória recente na atenção à saúde bucal sinaliza um novo modelo em construção no País (Figura 1).

O Programa Brasil Sorridente, maior programa público de saúde bucal do mundo, completa uma década em $2014^{\mathrm{h}}$, sugerindo que nesse espaço de tempo alterações tenham sido provocadas no trabalho das equipes de saúde bucal na APS, de forma a cumprir com os objetivos de reorientação do modelo de atenção. ${ }^{18}$

Considerando que a APS tem se constituído num espaço potencial de inovação na gestão e organização do processo de trabalho, um dos eixos centrais da reordenação da atenção à saúde no SUS, o presente artigo tem por objetivo analisar, a partir do lançamento das Diretrizes da PNSB, as mudanças efetuadas no trabalho dos profissionais de saúde bucal na APS no Brasil.

\footnotetext{
${ }^{\mathrm{g}}$ Ministério da Saúde (BR), Secretaria de Atenção à Saúde, Departamento de Atenção Básica, Coordenação Nacional de Saúde Bucal. Diretrizes da Política Nacional de Saúde Bucal. Brasília: Ministério da Saúde, 2004.16p.

${ }^{\mathrm{h}}$ Ministério da Saúde (BR). 10 anos de Brasil Sorridente: milhões de sorrisos. Revista Brasileira Saúde da Família. 2012;1(1):74-77.
} 


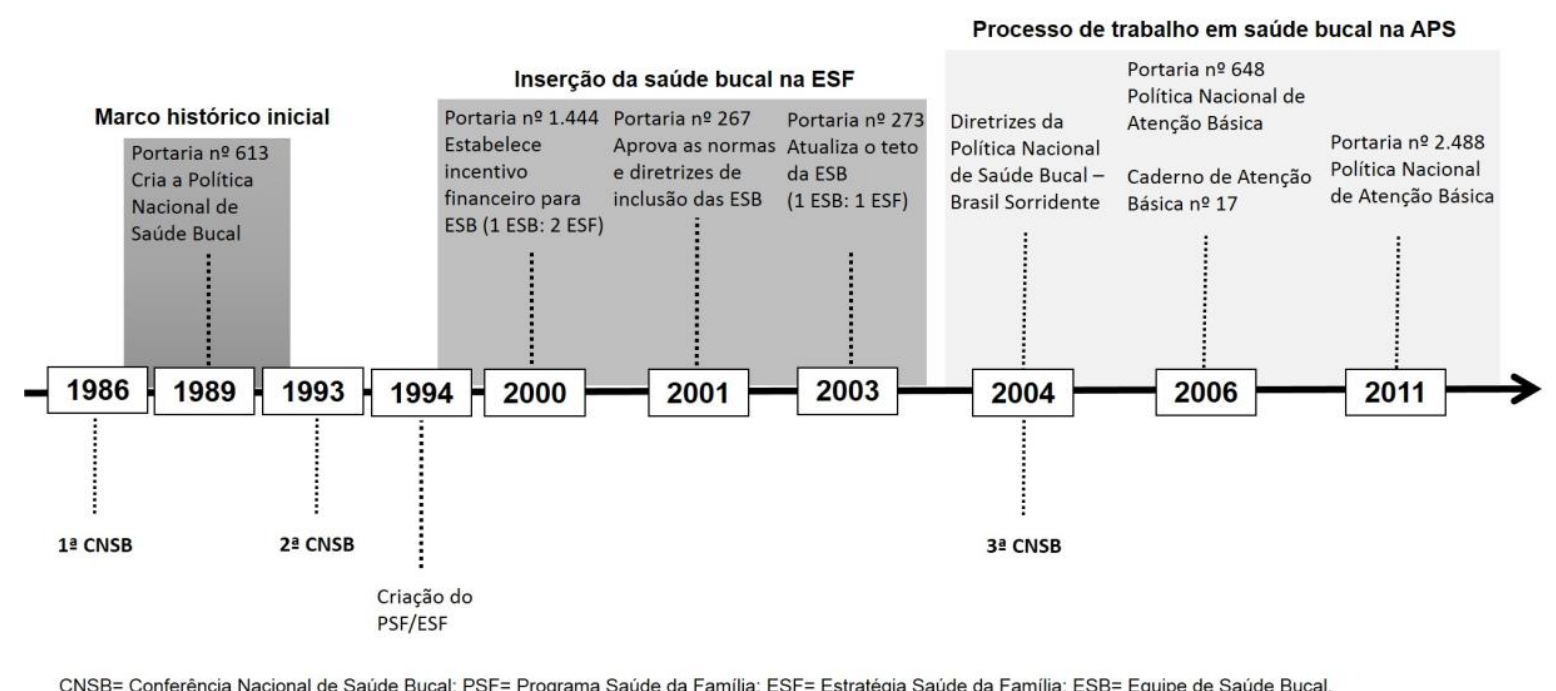

Figura 1. Linha do tempo, identificando os momentos e normatizações que marcam o incentivo à mudanças no processo de trabalho em saúde bucal na APS no Brasil.

\section{MÉTODOS}

Foi realizada revisão da literatura guiada por elementos analisadores das mudanças no trabalho da saúde bucal na APS, segundo as normatizações vigentes e,f,i e a partir da publicação das Diretrizes da PNSB ${ }^{\mathrm{g}}$ (Figura 2).

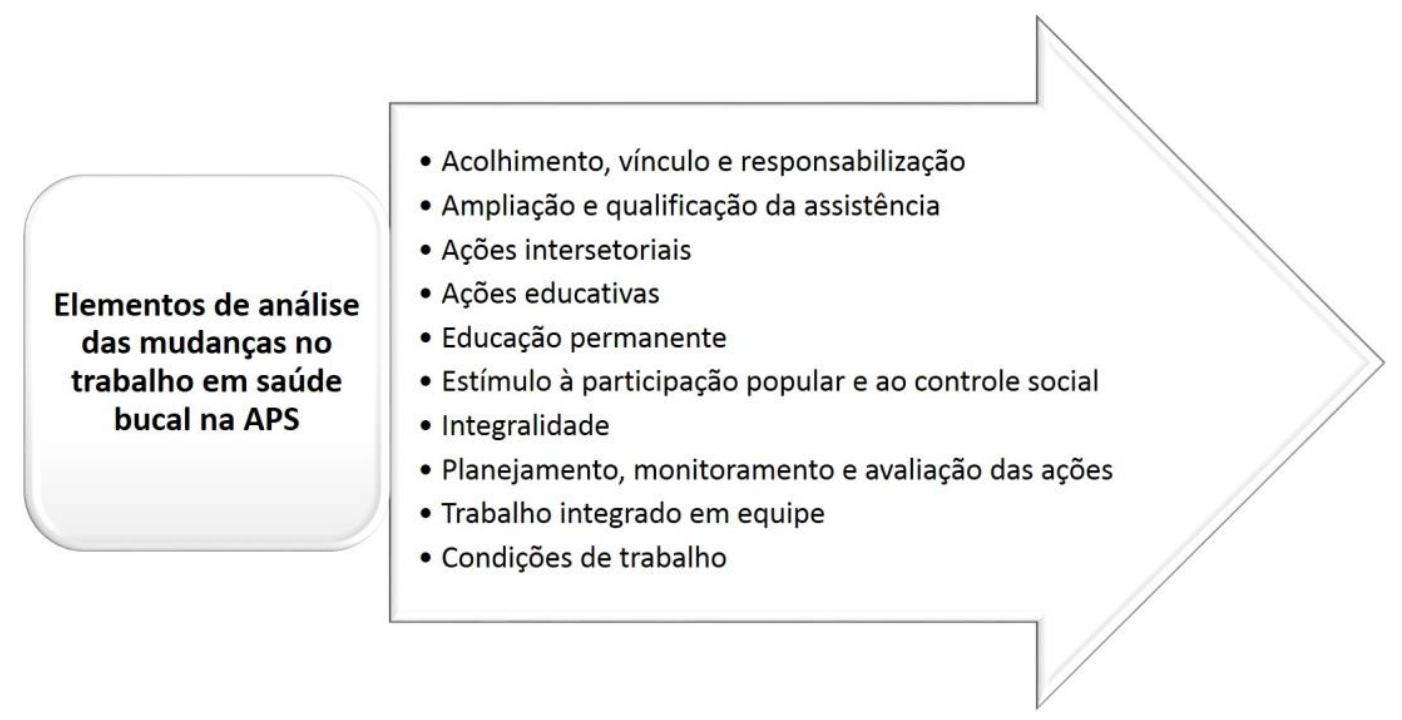

Figura 2. Elementos de análise das mudanças de concepções e práticas em saúde bucal na APS.

\footnotetext{
' Ministério da Saúde (BR), Secretaria de Atenção à Saúde, Departamento de Atenção Básica. Saúde Bucal: Cadernos de Atenção Básica, n. 17. Brasília: Ministério da Saúde, 2006. 92p.
} 
Os estudos foram coletados nas bases MEDLINE (via PubMed), Lilacs, EMBASE, SciELO, Biblioteca Virtual em Saúde e The Cochrane Library (via Bireme). Foram incluídas publicações a partir de 2000, três anos antes da publicação das Diretrizes, até 03 de novembro de 2013. Foi incluído período anterior a 2004, quando lançadas as Diretrizes da PNSB, tendo em vista esse momento ser precedido de experiências e pactuações entre os diversos atores envolvidos na temática que poderiam ter sido objeto de pesquisas publicadas em periódicos científicos.

As palavras-chaves de busca em inglês utilizadas no PubMed foram: ("primary health care" OR "family health" OR "work") AND (OR "health policy" OR "dental health services" OR "dentistry" OR "oral health") AND ("Brazil"). Nas demais bases, os descritores foram utilizados em inglês e português. A combinação foi realizada com a utilização dos operadores booleanos " $A N D$ " e "OR" e utilizando operadores $\mathrm{MeSH}$ ou análogos de acordo com a base pesquisada quando disponível.

A coleta de dados foi realizada por uma pesquisadora enquanto que a seleção e avaliação dos estudos pareada por duas pesquisadoras familiarizadas com o tema e com o método. Com a escolha dessas palavras-chave e descritores foram encontrados 77 artigos na MEDLINE (via Pubmed), 538 no LILACS, 4 no EMBASE, 67 no SCIELO, 338 na Biblioteca Virtual em Saúde (BVS APS) e 13 no The Cochrane Library (via Bireme), totalizando 1.037 artigos.

Foram incluídos os artigos de estudos que se referiam ao trabalho ou às práticas ou mudança de modelo na saúde bucal na APS descrito no título do estudo ou em seus resumos. Foram selecionados aqueles que problematizam a organização e a gestão dos processos de trabalho em saúde bucal, em especial do trabalho em equipe na APS, um dos eixos centrais da reordenação da atenção à saúde no SUS. Foram excluídos os estudos de reflexão teórica, dissertações e teses.

Foram selecionados 211 artigos, depois retirados 60 que se repetiram nas distintas bases, resultando em 52 estudos submetidos à leitura integral. Ao final, 32 artigos foram incluídos. A Figura 3 apresenta o fluxograma do processo de busca, seleção, inclusão e exclusão das referências. 


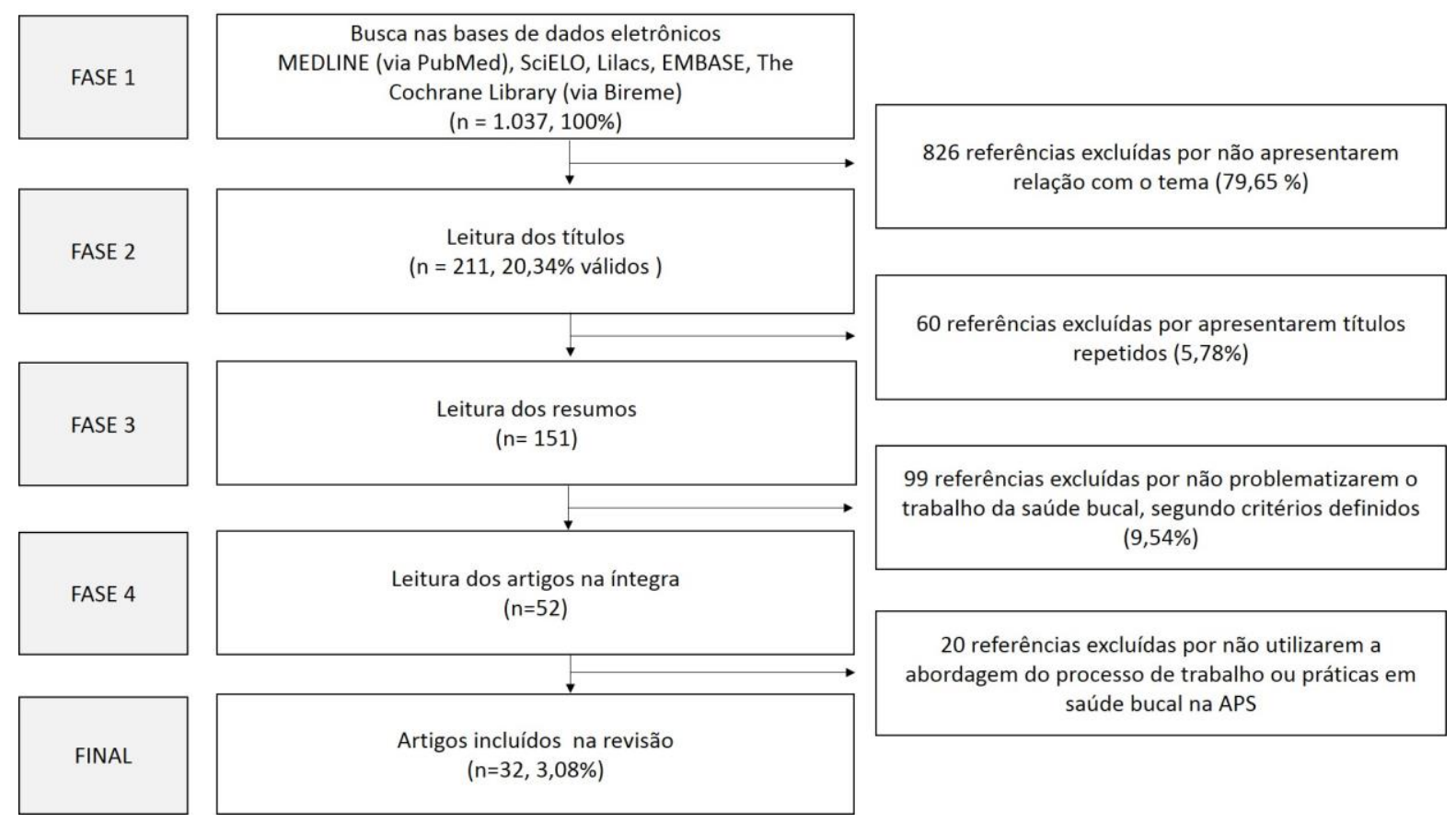

Figura 3. Busca, seleção, inclusão e exclusão dos estudos sobre o processo de trabalho na saúde bucal na APS.

Nos artigos incluídos foram identificados aspectos gerais da publicação, características metodológicas e principais resultados, analisados a partir dos elementos apresentados na Figura 2. A triagem das informações foi realizada independentemente pelos pesquisadores e posteriormente comparada em reunião de consenso. Os itens consensuais foram considerados adequados e incluídos na descrição dos resultados. Estes foram agrupados em função das categorias temáticas prévias (elementos de análise) e analisados de forma descritiva.

\section{RESULTADOS}

A maior parte das pesquisas é da região Nordeste $(n=21 ; 65,6 \%)$, Sudeste $(n=6 ; 18,7 \%)$ e Sul ( $n=3 ; 9,3 \%$ ) (Tabela 1). Foram identificados estudos qualitativos ( $n=24 ; 75 \%)$, quantitativos $(n=3 ; 9,3 \%)$, sendo que em cinco estudos $(15,6 \%)$ utilizou-se uma combinação de métodos quanti e qualitativos (Tabela 2). A maioria dos estudos tem os trabalhadores da ESF como principais participantes, com destaque para o CD, e cerca de um terço incluem gestores e usuários (Tabela 1).

Todos os estudos ( $n=32)$ abordaram um ou mais elementos de análise do trabalho, sendo que nenhum contemplou todos (Tabela 2). Apontaram algum tipo de 
mudança, mas também revelaram limitações que comprometem a implementação da política tal como preconizada nas normatizações.

Os avanços ainda incipientes no trabalho em saúde bucal situam-se: nas ações educativas; nas ações de educação permanente; no acolhimento, vínculo e responsabilização. As principais dificuldades e desafios estão relacionados à: integralidade; ampliação e qualificação da assistência; trabalho em equipe; planejamento, monitoramento e avaliação das ações; e, condições de trabalho. Poucos estudos abordam o estimulo à participação popular e ao controle social e ações intersetoriais. De um total de 12 estudos, três (25\%) não indicam dificuldades e nove (75\%) não apontam mudanças nas práticas da equipe.

\section{Integralidade}

Em relação à integralidade, dos 32 estudos, 19 abordam o tema sendo que 14 $(73,6 \%)$ apontam dificuldades para reestruturar a saúde bucal na APS, superar as práticas do modelo tradicional da odontologia escolar e criar novas possibilidades, tais como a abordagem familiar e o diagnóstico da situação de saúde. 1,9,13,29,34 Persistem as ações com foco no atendimento clínico e valorização excessiva da técnica e da especialidade e há predomínio de práticas preventivas e educativas tradicionais. ${ }^{7,13,36}$ As equipes de saúde bucal ainda encontram dificuldades para as práticas pertinentes à ESF, como visitas domiciliares pelo dentista, ações de prevenção de agravos e de promoção à saúde, bem como reuniões e ações para a articulação com a comunidade de abrangência. ${ }^{5,34}$

Algumas mudanças incipientes vinculadas à integralidade foram demonstradas em cinco estudos ${ }^{27,31}(26,3 \%)$ que relatam a introdução do atendimento centrado no usuário com espaço para o diálogo e para o encontro de saberes instituintes da saúde bucal. Ao contrário das atividades individuais, as ações em grupos e os avanços na visão preventiva e na prática de educação em saúde dos profissionais são expressivas na ESF. ${ }^{1,13,33}$ Outra mudança apontada é relativa aos Técnicos em Saúde Bucal (TSB) que têm desprendido seu tempo mais em atividades preventivas e coletivas do que em atividades assistenciais. ${ }^{40}$

\section{Trabalho Integrado em Equipe}

Somente dois estudos (14,2\%), dentre 14 que abordam o trabalho em equipe, revelam que a maioria dos cirurgiões-dentistas (CD) relata integração com a equipe, 
porém poucos participam das reuniões e utilizam prontuários únicos. ${ }^{5,17} \mathrm{O}$ trabalho do $C D$ raramente se insere em práticas partilhadas com profissionais de outras áreas, uma vez que suas ações são desenvolvidas de forma autônoma, independente e individualizadas. ${ }^{34}$

Há entraves para o trabalho em equipe também entre os profissionais da odontologia. ${ }^{11}$ Os CDs reconhecem que a relação com os TSBs é prejudicada pela desinformação sobre o processo de trabalho, pela falta de clareza sobre a responsabilidade legal dos CDs em relação às atividades desenvolvidas pelos TSBs, bem como pelo receio quanto à possibilidade dos TSBs tornarem-se dentistas práticos e tomarem seu espaço no mercado de trabalho. Por outro lado, os CDs valorizam a participação dos TSBs na reorganização do trabalho odontológico e a construção de uma relação de parceria e cooperação.

\section{Ações Intersetoriais}

As ações intersetoriais são abordadas em dois dos 32 estudos, ${ }^{13,52}$ relacionadas às ações de educação e prevenção em saúde bucal desenvolvidas na comunidade ou nas escolas. ${ }^{52} \mathrm{~A}$ intersetorialidade apresenta-se como uma prática de caráter voluntário por parte das equipes e não conduz aos impactos esperados. Tal circunstância pode levar os profissionais ao descrédito em relação à ESF, sensação de impotência, tendo em vista a incapacidade do setor saúde enfrentar isoladamente os determinantes sociais do processo saúde-doença.

\section{Ações Educativas}

As ações educativas foram evidenciadas em 9 estudos, dos quais sete $(77,7 \%)$ apontam avanços nas práticas dos profissionais em relação ao que é preconizado pelas Diretrizes da PNSB. Martelli et al ${ }^{19}$ (2010) apontaram que 92,3\% dos CDs as consideram pertinentes e que desses, $89,6 \%$ relataram realizá-las. Rodrigues et $\mathrm{al}^{37}$ (2009) identificaram que todos os CDs realizavam atividades de educação em saúde, na Unidade ou em escolas, asilos, igrejas e creches. As ações mais relatadas são as de prevenção e promoção em grupos ${ }^{1,13}$ com destaque para 0 TSB como responsável por elas, ${ }^{40}$ e as de educação em saúde estão mais presentes no cotidiano dos profissionais da ESF. ${ }^{33,37}$

Segundo Mialhe et $\mathrm{al}^{23}$ (2011), as atividades educativas em saúde bucal são realizadas de maneira esporádica e voltadas prioritariamente às gestantes, mães e 
crianças, em um modelo vertical de transmissão de informações, visando mudanças de comportamentos individuais e incorporação de hábitos saudáveis. Essa visão é compartilhada pela população, que considera as orientações de higiene bucal como uma das melhorias mais importantes. ${ }^{10}$

\section{Planejamento, monitoramento e avaliação das ações}

O planejamento, monitoramento e avaliação das ações foi relatado em 8 estudos como prática incipiente na atenção à saúde bucal. Os estudos apontam dificuldades na realização de levantamentos para reconhecer as necessidades da população, considerando as características sociais e epidemiológicas. ${ }^{33,39}$ Apesar dos avanços, a saúde bucal necessita de muito investimento, além do controle e avaliação de suas ações por meio dos sistemas de informação, fortalecendo o planejamento e a tomada de decisão. ${ }^{32}$

\section{Estimulo à participação popular e ao controle social}

O estimulo à participação popular e ao controle social é abordado em dois estudos como uma ação a ser fomentada pelas equipes. Pezatto et $a^{31}$ (2013) ressaltam que a apropriação dos temas da saúde bucal pelos espaços do controle social é um dos principais desafios para a efetiva implementação dos serviços de saúde bucal no SUS.

\section{Ampliação e qualificação da assistência}

A ampliação e qualificação da assistência em saúde bucal foram abordadas em 19 dos 32 estudos. Desses 5 (73,6\%) abordam avanços porém, as dificuldades prevalecem $(73,6 \%)$ em relação ao atendimento as demandas da população adscrita. $^{5}$ A demanda excessiva destaca-se como ponto negativo, com predominância das ações curativas pelo $\mathrm{CD} .{ }^{17}$ Mesmo com a ampliação do acesso aos serviços de saúde bucal, um nó crítico dos serviços é a organização da demanda, pois são várias portas de entrada, é grande a demanda reprimida e pouca a oferta. ${ }^{17,27,29}$ Ampliar e qualificar a assistência requer enfrentar desafios relacionados ao investimento público insuficiente; à dificuldades de encaminhamento para especialidades, principalmente ortodontia e próteses; às ações com foco no atendimento clínico com valorização excessiva da técnica e da especialidade e; a 
crescente demanda por serviços pela população, focalizadas nas ações curativas individuais. ${ }^{29}$

Apesar das dificuldades, pontos positivos foram observados nos estudos: a delimitação da clientela, possibilitando melhor acompanhamento; mudança no perfil dos procedimentos odontológicos realizados pelas equipes; a cobertura populacional de acordo com o mínimo estipulado pelo Ministério da Saúde. ${ }^{10,32,46}$

\section{Acolhimento, vínculo e responsabilização}

O estabelecimento do acolhimento, vínculo e responsabilização permite a negociação entre usuários e profissionais acerca do cuidado integral à saúde, contribuindo para que o ato terapêutico esteja centrado no profissional, mas que seja realizado pela manifestação de desejo do usuário. Esses elementos foram abordados por sete estudos e desses seis apontam mudanças: a influência das novas diretrizes curriculares nacionais na prática mais humanizada de odontólogos, reforçando o vínculo, o olhar ampliado para o território e para a comunidade; e o potencial trabalho dos ACS no estabelecimento de vínculo, acolhimento e autonomia dos usuários. ${ }^{5,41}$

\section{Condições de trabalho}

Foram identificados 11 estudos (93,6\%) de um total de 12 que abordam dificuldades relativas às condições de trabalho no SUS. São nós críticos: a precarização das relações de trabalho com baixos salários e contratações instáveis, ${ }^{5,17,19}$ com prováveis reflexos na rotatividade e na satisfação profissional, comprometendo a qualidade da assistência à saúde ${ }^{5,19}$; a dupla jornada de trabalho do CD entre o setor público e o privado, e o descumprimento da jornada semanal de 40 horas na ESF como algo pactuado entre gestores e trabalhadores. ${ }^{37,39} \mathrm{~A}$ falta de recursos financeiros, estruturais, físicos e humanos também reflete nas condições de trabalho. ${ }^{5,24}$

\section{Educação permanente em saúde}

De 15 estudos que abordam a educação permanente em saúde, oito (53,3\%) identificam dificuldades: profissionais que atuam na ESF são capacitados após inserção na estratégia, não havendo preparo prévio; ${ }^{39}$ e, ausência de processos formadores voltados à qualificação profissional em saúde bucal, de modo a tornar a 
prática do cuidado à saúde mais integral. ${ }^{16,17,23,24,34}$. Entretanto, sete estudos $(46,6 \%)$ apontaram mudanças ${ }^{5,19,34,39}$ : mais de $90 \%$ dos CDs de um estudo afirmaram ter participado de cursos de capacitação, sendo que os que não participaram tinham sido recém-contratados; outro revelou que $67,8 \%$ dos CDs possuem formação voltada para a ESF e sentem necessidade de fazer especialização em saúde pública, buscando a aptidão necessária para o trabalho na ESF. ${ }^{19}$

\section{DISCUSSÃO}

A revisão da literatura apontou que a maior parte dos estudos foi publicada a partir de 2008, indicando recente interesse na área. O aumento de estudos qualitativos nos últimos anos acrescenta uma dimensão importante à avaliação das ações na área da saúde bucal ao produzir conhecimento a partir da experiência dos profissionais.

Houve predominância de estudos da região Nordeste, indicando que os resultados caracterizam uma região e não o país em sua totalidade. Soares et al $^{49}$ (2011) também encontraram predomínio de publicações na mesma região, justificada pelo fato de ser a região com maior número de equipes de saúde da família no país.

Os elementos de análise do trabalho em saúde bucal na APS mais investigados foram a integralidade, e a ampliação e qualificação da assistência. De maneira convergente, a literatura sugere que esses são dois dos elementos mais comumente analisados que podem contribuir de maneira positiva para melhoria e orientação das políticas públicas, no sentido da superação de desigualdades no acesso aos serviços de saúde, do alcance da equidade dentro do sistema e da efetivação da integralidade relativa às práticas e ao trabalho em equipe. ${ }^{47,51}$

Apesar da significativa ampliação de cobertura de atenção à saúde bucal na APS na última década, existem barreiras de acesso que privam brasileiros dos serviços. ${ }^{21}$ De maneira convergente, observou-se que são poucos os avanços referentes à ampliação e qualificação da assistência à população e o processo de trabalho em saúde bucal pode ser prejudicado devido a permanente demanda excessiva e predomínio de ações curativas. 
Dentre os princípios e diretrizes do SUS, talvez o da integralidade seja o que é menos visível na trajetória do sistema de saúde e de suas práticas. ${ }^{21} \mathrm{O}$ estudo apontou que a integralidade é incipiente e com fragilidades a serem enfrentadas no trabalho das equipes da ESF. Essas análises podem estar associadas à polissemia e à abrangência do conceito de integralidade, visto que para a sua efetividade são necessárias clínica ampliada, integração de práticas individuais e coletivas, assim como resolutividade com garantia de acesso e articulação com outros níveis de atenção. ${ }^{21,47}$

A integralidade exige que os profissionais reconheçam as necessidades de saúde e os recursos para abordá-las. ${ }^{53}$ Para se trabalhar na ESF, são necessárias competências e habilidades, oriundos da formação, da experiência profissional, e da capacidade dos profissionais de articular escolhas do que fazer em cada situação de trabalho.

O trabalho em equipe influencia diretamente na integralidade. ${ }^{54} \mathrm{~A}$ integração dos profissionais de saúde bucal no trabalho da equipe de saúde da família está ainda limitada pelo histórico isolamento dessas categorias profissionais, associado à introdução tardia da saúde bucal na ESF, bem como a formação individualista e tecnicista dos profissionais que dificulta a abordagem integral do ser humano. ${ }^{5,40} \mathrm{~A}$ inserção da ESB em uma equipe multiprofissional, além de introduzir o "novo", afronta valores, lugares e poderes consolidados pelas práticas dos modelos que 0 antecederam. $^{17}$

Será preciso que os profissionais aprendam e reaprendam com a experiência vivida na singularidade das situações de trabalho coletivo. O trabalho é resultado de um debate de normas e de valores do trabalhador consigo mesmo, de como usar de si e de como estar em condições de gerir a complexidade de questões relacionadas ao trabalho coletivo. ${ }^{44}$ Nesse sentido, a educação permanente em saúde surge como dispositivo fundamental, mas a revisão da literatura mostrou que a formação concentra-se em capacitações, ${ }^{16}$ em geral distantes do cotidiano de trabalho e restritas à núcleos profissionais.

As ações intersetoriais e estímulo à participação popular e ao controle social foram pouco investigados, fato consonante com a literatura, ${ }^{49,51}$ e 0 caráter voluntarioso por parte de algumas equipes ou profissionais pode ser parcialmente explicado pelo fato de que atuar segundo o princípio da intersetorialidade requer disponibilidade para períodos não estabelecidos no contrato de trabalho. ${ }^{14}$ Apesar 
de existir consenso acerca da necessidade da intersetorialidade na atenção primária, ela ainda é um processo em construção na ESF. ${ }^{43}$ Um dos desafios para que ela se efetive é a formação de profissionais que oriente para a percepção da complexidade dos problemas e, por conseguinte, para o reconhecimento da necessidade de ações intersetoriais para intervir em tais problemas. ${ }^{48}$

Apesar da experiência brasileira com levantamentos epidemiológicos, de maneira geral o planejamento, monitoramento e avaliação das ações ainda estão distantes do cotidiano da equipe de saúde bucal. ${ }^{49} \mathrm{O}$ monitoramento e avaliação têm sido considerados práticas importantes quando se busca a melhoria da qualidade das ações e serviços, mas ainda é desafio que exige mobilização, engajamento e decisão de gestores e profissionais.

A melhoria das condições de trabalho no SUS está diretamente relacionada à melhoria da qualidade da assistência, mas não se trata de uma relação linear. Em contextos considerados favoráveis ao trabalho segundo os princípios da ESF as equipes centram suas práticas no atendimento a demanda espontânea ou programada. $^{22}$ Ao mesmo tempo em contextos adversos profissionais buscam alternativas para serem eficazes. ${ }^{6}$ É difícil precisar em que medida as condições de trabalho influenciam na mudança das práticas profissionais.

A revisão da literatura sinaliza que, após uma década de implantação do Programa Brasil Sorridente, os principais problemas e dificuldades no trabalho das equipes de saúde bucal não são exclusivos da odontologia, mas acompanham a realidade do trabalho das equipes da ESF como um todo, em consonância com o que apontam estudos recentes sobre o trabalho das equipes de Saúde da Família. ${ }^{2,43,51}$

Os avanços evidenciados concentram-se nas ações educativas; nas ações de educação permanente; no acolhimento, vínculo e responsabilização. Os principais desafios estão relacionados à: integralidade; ampliação e qualificação da assistência; trabalho integrado em equipe; condições de trabalho; planejamento, monitoramento e avaliação das ações; estimulo à participação popular e ao controle social; e, ações intersetoriais.

Conclui-se que, apesar do novo cenário normativo, as mudanças são incipientes no trabalho em saúde bucal. Os profissionais tendem a reproduzir o modelo biomédico dominante, sendo necessários esforços continuados no campo da gestão do trabalho, da formação e da educação permanente. Dentre as 
possibilidades para que haja substituição das práticas tradicionais exercidas e um novo jeito de se fazer saúde, está a de ampliar o engajamento dos gestores e dos profissionais num processo de compreensão da dinâmica do trabalho e da formação na perspectiva de construir mudanças significativas para as realidades locais. 
Tabela 1. Aspectos gerais dos estudos selecionados, características metodológicas e sujeitos do estudo.

\begin{tabular}{|c|c|c|c|c|c|c|c|}
\hline Ano & Local & Autor(es) & Revista & Título & \multicolumn{2}{|c|}{ Tipo de estudo e metodologia } & Sujeitos do estudo \\
\hline 2013 & $\mathrm{SP}$ & $\begin{array}{c}\text { Pezzato LM, L'Abbate S e } \\
\text { Botazzo C }\end{array}$ & $\begin{array}{l}\text { Ciência \& Saúde Coletiva, } \\
\text { 18(7):2095-2104 }\end{array}$ & $\begin{array}{l}\text { A produção de micropolíticas no processo de } \\
\text { trabalho em saúde bucal: uma abordagem sócio- } \\
\text { analítica }\end{array}$ & Qualitativo & $\begin{array}{l}\text { Abordagem sócio } \\
\text { analítica }\end{array}$ & $\begin{array}{c}\text { Trabalhadores (ESB) e } \\
\text { usuários }\end{array}$ \\
\hline 2013 & $M G$ & $\begin{array}{l}\text { Sanglard-Oliveira CA, } \\
\text { Werneck MAF, Lucas SD } \\
\text { e Abreu MHNG }\end{array}$ & $\begin{array}{l}\text { Ciência \& Saúde Coletiva, } \\
\text { 18(8):2453-2460 }\end{array}$ & $\begin{array}{c}\text { Atribuições dos Técnicos em Saúde Bucal na } \\
\text { Estratégia Saúde da Família em Minas Gerais, } \\
\text { Brasil }\end{array}$ & Qualitativo & $\begin{array}{l}\text { Estudo transversal e } \\
\quad \text { descritivo } \\
\text { Entrevista telefônica }\end{array}$ & Trabalhadores (CD) \\
\hline 2013 & $\mathrm{PI}$ & Moura MS, et al & $\begin{array}{c}\text { Ciência \& Saúde Coletiva, } \\
\text { 18(2):471-480 }\end{array}$ & $\begin{array}{l}\text { Saúde bucal na estratégia de saúde da família em } \\
\text { um colegiado gestor regional do estado do Piauí }\end{array}$ & Qualitativo & $\begin{array}{l}\text { Estudo transversal } \\
\text { Questionário }\end{array}$ & Trabalhadores (CD) \\
\hline 2012 & ES & $\begin{array}{l}\text { Esposti CDD, Oliveira AE, } \\
\text { Santos Neto ET e } \\
\text { Zandonade E }\end{array}$ & $\begin{array}{l}\text { Saúde Soc. São Paulo, } \\
\text { 21(2):372-385 }\end{array}$ & $\begin{array}{c}\text { O processo de trabalho do técnico em saúde bucal } \\
\text { e suas relações com a equipe de saúde bucal na } \\
\text { Região Metropolitana da Grande Vitória, Espírito } \\
\text { Santo, Brasil }\end{array}$ & Qualitativo & $\begin{array}{c}\text { Entrevista } \\
\text { semiestruturada }\end{array}$ & Trabalhadores (CD) \\
\hline 2012 & PE & Pimentel FC, et al & $\begin{array}{l}\text { Cad. Saúde Pública, } \\
28 \text { Sup:S146-S157 }\end{array}$ & $\begin{array}{c}\text { Caracterização do processo de trabalho das } \\
\text { equipes de saúde bucal em municípios do Estado } \\
\text { de Pernambuco, Brasil, de acordo com o tamanho } \\
\text { da população: a partir de links da comunidade para } \\
\text { a organização dos cuidados clínicos. }\end{array}$ & Qualitativo & $\begin{array}{l}\text { Questionário } \\
\text { estruturado }\end{array}$ & Trabalhadores (ESB) \\
\hline 2011 & $\mathrm{SP}$ & $\begin{array}{l}\text { Cunha BAT, Marques } \\
\text { RAA, Castro CGJ e } \\
\text { Narvai PC }\end{array}$ & $\begin{array}{l}\text { Saúde Soc, } \\
\text { 20(4):1033-1045 }\end{array}$ & $\begin{array}{l}\text { Saúde bucal em Diadema: da odontologia escolar à } \\
\text { estratégia saúde da família }\end{array}$ & Qualitativo & $\begin{array}{c}\text { Entrevista } \\
\text { semiestruturada e } \\
\text { análise documental }\end{array}$ & $\begin{array}{l}\text { Gestores e trabalhadores } \\
\text { (Prefeitos, SMS, CSB e } \\
\text { CD) }\end{array}$ \\
\hline 2011 & SP & $\begin{array}{l}\text { Mialhe FL, Lefèvre F, } \\
\text { Lefèvre AMC }\end{array}$ & $\begin{array}{l}\text { Ciência \& Saúde Coletiva, } \\
\text { 16(11):4425-4432 }\end{array}$ & $\begin{array}{c}\text { O agente comunitário de saúde e suas práticas } \\
\text { educativas em saúde bucal: uma avaliação } \\
\text { qualiquantitativa }\end{array}$ & Quali-Quanti & $\begin{array}{l}\text { Entrevista } \\
\text { semiestruturada }\end{array}$ & Trabalhadores (ACS) \\
\hline 2011 & PE & Silva SF et al & $\begin{array}{c}\text { Ciência \& Saúde Coletiva, } \\
\text { 16(1):211-220 }\end{array}$ & $\begin{array}{l}\text { Análise do avanço das equipes de saúde bucal } \\
\text { inseridas na Estratégia Saúde da Família em } \\
\text { Pernambuco, região Nordeste, Brasil, } 2002 \text { a } 2005\end{array}$ & Quantitativo & $\begin{array}{l}\text { Estudo descritivo } \\
\text { exploratório }\end{array}$ & $\begin{array}{l}\text { Dados secundários } \\
\quad \text { (SIA-SUS) }\end{array}$ \\
\hline
\end{tabular}




\begin{tabular}{|c|c|c|c|c|c|c|c|}
\hline 2011 & BA & $\begin{array}{c}\text { Rodrigues AAAO, } \\
\text { Nascimento MAA, } \\
\text { Fonsêca GS e Siqueira } \\
\text { DVS }\end{array}$ & $\begin{array}{l}\text { Rev. baiana saúde pública, } \\
\text { 35(3):695-709 }\end{array}$ & $\begin{array}{l}\text { Saúde bucal na estratégia saúde da família em um } \\
\text { município do semiárido baiano }\end{array}$ & Qualitativo & $\begin{array}{l}\text { Entrevista } \\
\text { semiestruturada e } \\
\text { observação }\end{array}$ & $\begin{array}{l}\text { Trabalhadores } \\
\text { (ESF e ESB) }\end{array}$ \\
\hline 2010 & PE & Pimentel FC, et al & $\begin{array}{l}\text { Ciência \& Saúde Coletiva, } \\
\text { 15(4):2189-2196 }\end{array}$ & $\begin{array}{l}\text { Análise da atenção à saúde bucal na Estratégia de } \\
\text { Saúde da Família do Distrito Sanitário VI, Recife } \\
\qquad \text { (PE) }\end{array}$ & Qualitativo & $\begin{array}{c}\text { Estudo descritivo } \\
\text { Entrevista } \\
\text { semiestruturada e } \\
\text { dados secundários }\end{array}$ & $\begin{array}{l}\text { Gestores e trabalhadores } \\
\text { (CSB, CD e enfermeira) }\end{array}$ \\
\hline 2010 & BA & $\begin{array}{l}\text { Rodrigues AAAO, Santos } \\
\text { AM e Assis MMA }\end{array}$ & $\begin{array}{l}\text { Ciência \& Saúde Coletiva, } \\
\text { 15(3):907-915 }\end{array}$ & $\begin{array}{l}\text { Agente comunitário de saúde: sujeito da prática em } \\
\text { saúde bucal em Alagoinhas, Bahia }\end{array}$ & Qualitativo & $\begin{array}{c}\text { Entrevista } \\
\text { semiestruturada, } \\
\text { observação e análise } \\
\text { documental }\end{array}$ & $\begin{array}{l}\text { Trabalhadores } \\
\text { (ACS e ESB) }\end{array}$ \\
\hline 2010 & CE & $\begin{array}{l}\text { Nuto SAS, Oliveira GC, } \\
\text { Andrade, JV e Maia MCG }\end{array}$ & $\begin{array}{l}\text { Rev. APS, } \\
\text { 13(4):505-509 }\end{array}$ & $\begin{array}{c}\text { O acolhimento em saúde bucal na estratégia de } \\
\text { saúde da família, Fortaleza-CE: um relato de } \\
\text { experiência }\end{array}$ & Qualitativo & Relato de experiência & $\begin{array}{l}\text { Trabalhadores (ESB e } \\
\text { ACS), usuários e } \\
\text { acadêmicos }\end{array}$ \\
\hline 2010 & $\mathrm{PI}$ & Moura MS, et al & $\begin{array}{l}\text { Ciência \& Saúde Coletiva, } \\
\text { 15(supl.1): 1487-1495 }\end{array}$ & $\begin{array}{l}\text { Perfil e práticas de saúde bucal do agente } \\
\text { comunitário de saúde em municípios piauienses de } \\
\text { pequeno porte }\end{array}$ & Qualitativo & $\begin{array}{l}\text { Estudo transversal } \\
\text { observacional } \\
\text { descritivo } \\
\text { Questionário }\end{array}$ & Trabalhadores (ACS) \\
\hline 2010 & PE & Martelli PJL, et al & $\begin{array}{l}\text { Ciência \& Saúde Coletiva, } \\
\text { 15(Supl. 2):3243-3248 }\end{array}$ & $\begin{array}{c}\text { Perfil do cirurgião dentista inserido na Estratégia de } \\
\text { Saúde da Família em municípios do estado de } \\
\text { Pernambuco, Brasil }\end{array}$ & Qualitativo & $\begin{array}{l}\text { Estudo descritivo de } \\
\text { caso exploratório e } \\
\text { transversal } \\
\text { Questionário }\end{array}$ & Trabalhadores (CD) \\
\hline 2010 & SC & $\begin{array}{l}\text { Faccin D, Sebold R e } \\
\text { Carcereri DL }\end{array}$ & $\begin{array}{l}\text { Ciência \& Saúde Coletiva, } \\
\text { 15(Supl. 1):1643-1652 }\end{array}$ & $\begin{array}{c}\text { Processo de trabalho em saúde bucal: em busca } \\
\text { de diferentes olhares para compreender e } \\
\text { transformar a realidade }\end{array}$ & Qualitativo & $\begin{array}{l}\text { Entrevista } \\
\text { semiestruturada }\end{array}$ & $\begin{array}{l}\text { Trabalhadores } \\
\text { (ESF e ESB) }\end{array}$ \\
\hline 2009 & MG & $\begin{array}{l}\text { Lourenço EC, Silva ACB, } \\
\text { Meneghin MC e Pereira } \\
\text { AC }\end{array}$ & $\begin{array}{l}\text { Ciência \& Saúde Coletiva, } \\
\text { 14(Supl. 1):1367-1377 }\end{array}$ & $\begin{array}{c}\text { A inserção dos serviços de saúde bucal no } \\
\text { Programa Saúde da Família no Estado de Minas } \\
\text { Gerais }\end{array}$ & Quali-Quanti & Questionários & $\begin{array}{l}\text { Trabalhadores } \\
\text { (ESF e ESB) }\end{array}$ \\
\hline 2009 & $\mathrm{PR} / \mathrm{SP}$ & $\begin{array}{l}\text { Nascimento AC, Moysés } \\
\text { ST, Bisinelli JC e Moysés } \\
\text { SJ }\end{array}$ & $\begin{array}{l}\text { Rev. Saúde Pública, } \\
\text { 43(3):455-62 }\end{array}$ & $\begin{array}{l}\text { Oral health in the family health strategy: a change } \\
\text { of practices or semantics diversionism }\end{array}$ & Qualitativo & Grupo Focal & Trabalhadores (CD) \\
\hline 2009 & BA & $\begin{array}{l}\text { Rodrigues AAAO, Gallotti } \\
\text { AP, Pena SFA e Ledo } \\
\text { CAS }\end{array}$ & $\begin{array}{l}\text { Rev. Baiana Saúde } \\
\text { Pública, 33(4):582-594 }\end{array}$ & $\begin{array}{c}\text { Saúde bucal no programa de saúde da família na } \\
\text { cidade de Feira de Santana (BA): o perfil do } \\
\text { cirurgião-dentista }\end{array}$ & Quantitativo & Questionário & Trabalhadores (CD) \\
\hline 2009 & $\mathrm{RN}$ & Rocha ECA e Araújo MAD & $\begin{array}{l}\text { Rev. Adm. Pública, } \\
\text { 43(2): 481-517 }\end{array}$ & $\begin{array}{c}\text { Condições de trabalho das equipes de saúde bucal } \\
\text { no Programa Saúde da Família: o caso do Distrito } \\
\text { Sanitário Norte em Natal, RN }\end{array}$ & Quali-Quanti & $\begin{array}{l}\text { Estudo exploratório } \\
\text { descritivo } \\
\text { Questionário }\end{array}$ & Trabalhadores (CD) \\
\hline 2009 & $\mathrm{RN}$ & $\begin{array}{l}\text { Holanda ALF, Barbosa } \\
\text { AAA e Brito EWG }\end{array}$ & $\begin{array}{l}\text { Ciência \& Saúde Coletiva, } \\
\text { 14(Supl. 1):1507-1512 }\end{array}$ & $\begin{array}{l}\text { Reflexões acerca da atuação do agente } \\
\text { comunitário de saúde nas ações de saúde bucal }\end{array}$ & Qualitativo & Relato de experiência & Trabalhadores (CD) \\
\hline
\end{tabular}




\begin{tabular}{|c|c|c|c|c|c|c|c|}
\hline 2008 & PR & $\begin{array}{l}\text { Koyashiki GAK, Alves- } \\
\text { Souza RA e Garanhani } \\
\text { ML }\end{array}$ & $\begin{array}{l}\text { Ciência \& Saúde Coletiva, } \\
\text { 13(4):1343-1354 }\end{array}$ & $\begin{array}{l}\text { O trabalho em saúde bucal do Agente Comunitário } \\
\text { de Saúde em Unidades de Saúde da Família }\end{array}$ & Qualitativo & Entrevista & Trabalhadores (ACS) \\
\hline 2008 & BA & $\begin{array}{l}\text { Dos Santos AM, Assis } \\
\text { MMA, Nascimento, MAA e } \\
\text { Jorge, MSB }\end{array}$ & $\begin{array}{l}\text { Rev. Saúde Pública } \\
\text { 2008;42(3):464-70 }\end{array}$ & $\begin{array}{l}\text { Vínculo e autonomia na prática de saúde bucal no } \\
\text { Programa Saúde da Família }\end{array}$ & Qualitativo & $\begin{array}{l}\text { Abordagem crítico- } \\
\text { reflexiva } \\
\text { Entrevista } \\
\text { semiestruturada e } \\
\text { observação }\end{array}$ & $\begin{array}{l}\text { Trabalhadores (ESF e } \\
\text { ESB) e usuários }\end{array}$ \\
\hline 2008 & BA & $\begin{array}{l}\text { Chaves SCL e Vieira-da- } \\
\text { Silva LM }\end{array}$ & $\begin{array}{l}\text { Health Policy } \\
86(1): 119-128\end{array}$ & $\begin{array}{l}\text { Inequalities in oral health practices and social } \\
\text { space: an exploratory qualitative study }\end{array}$ & Qualitativo & $\begin{array}{l}\text { Estudo exploratório } \\
\text { Entrevista } \\
\text { semiestruturada }\end{array}$ & $\begin{array}{c}\text { Trabalhadores e } \\
\text { gestores (CD e CSB) e } \\
\text { usuários }\end{array}$ \\
\hline 2008 & PE & Martelli PJL, et al & $\begin{array}{l}\text { Ciência \& Saúde Coletiva, } \\
\text { 13(5):1669-1674 }\end{array}$ & $\begin{array}{l}\text { Análise do modelo de atenção à saúde bucal em } \\
\text { municípios do estado de Pernambuco }\end{array}$ & Qualitativo & $\begin{array}{l}\text { Entrevista } \\
\text { semiestruturada }\end{array}$ & Gestores (CSB) \\
\hline 2008 & PE & Pimentel FC, et al & $\begin{array}{l}\text { Rev. Baiana Saúde } \\
\text { Pública, 32(2): 253-264 }\end{array}$ & $\begin{array}{l}\text { Evolução da assistência em saúde bucal na } \\
\text { estratégia de saúde da família do município do } \\
\text { Recife (PE) no período de } 2001 \text { a } 2007\end{array}$ & Quantitativo & Estudo descritivo & $\begin{array}{l}\text { Dados secundários (SIA- } \\
\text { SUS) }\end{array}$ \\
\hline 2008 & $\mathrm{RN}$ & $\begin{array}{l}\text { Almeida GC e Ferreira } \\
\text { MA }\end{array}$ & $\begin{array}{l}\text { Cad. Saúde Pública, } \\
\text { 24(9):2131-2140 }\end{array}$ & $\begin{array}{l}\text { Saúde bucal no contexto do Programa de Saúde da } \\
\text { Família: práticas de prevenção orientadas a saúde } \\
\text { individual e pública }\end{array}$ & Quali-Quanti & $\begin{array}{c}\text { Estudo exploratório } \\
\text { descritivo } \\
\text { Entrevista } \\
\text { estruturada } \\
\text { Análise documental }\end{array}$ & $\begin{array}{l}\text { Trabalhadores (CD) } \\
\text { Dados secundários } \\
\text { (SIAB e SIA-SUS) }\end{array}$ \\
\hline 2008 & PA & Emmi DT e Barroso RFF & $\begin{array}{l}\text { Ciência \& Saúde Coletiva, } \\
\text { 13(1):35-41 }\end{array}$ & $\begin{array}{l}\text { Avaliação das ações de saúde bucal no Programa } \\
\text { Saúde da Família no distrito de Mosqueiro, Pará }\end{array}$ & Qualitativo & $\begin{array}{l}\text { Estudo descritivo } \\
\text { Questionário }\end{array}$ & Usuários \\
\hline 2007 & BA & Dos Santos AM, et al & $\begin{array}{l}\text { Cad. Saúde Pública, } \\
\text { 23(1):75-85 }\end{array}$ & $\begin{array}{l}\text { Linhas de tensões no processo de acolhimento das } \\
\text { equipes de saúde bucal do Programa Saúde da } \\
\text { Família: o caso de Alagoinhas, Bahia, Brasil }\end{array}$ & Qualitativo & $\begin{array}{l}\text { Entrevista } \\
\text { semiestruturada e } \\
\text { observação }\end{array}$ & $\begin{array}{l}\text { Trabalhadores (ESF e } \\
\text { ESB) e usuários }\end{array}$ \\
\hline 2007 & BA & Chaves SCL e Silva LMV & $\begin{array}{l}\text { Ciência \& Saúde Coletiva, } \\
12(6): 1697-1710\end{array}$ & $\begin{array}{c}\text { As práticas profissionais no campo público de } \\
\text { atenção à saúde bucal: o caso de dois municípios } \\
\text { da Bahia }\end{array}$ & Qualitativo & $\begin{array}{c}\text { Entrevista } \\
\text { semiestruturada }\end{array}$ & Trabalhadores (CD) \\
\hline 2007 & RN & Souza TM e Roncalli AG & $\begin{array}{l}\text { Cad. Saúde Pública, } \\
\text { 23(11):2727-2739 }\end{array}$ & $\begin{array}{c}\text { Saúde bucal no Programa Saúde da Família: uma } \\
\text { avaliação do modelo assistencial }\end{array}$ & Qualitativo & $\begin{array}{c}\text { Entrevista } \\
\text { estruturada, } \\
\text { observação e análise } \\
\text { documental }\end{array}$ & $\begin{array}{l}\text { Gestores (CSB ou } \\
\text { responsável) e } \\
\text { trabalhadores (CD) }\end{array}$ \\
\hline 2005 & PR & $\begin{array}{l}\text { Baldani MH, Fadel CB, } \\
\text { Possamai T e Queiroz } \\
\text { MGS }\end{array}$ & $\begin{array}{l}\text { Cad. Saúde Pública, } \\
\text { 21(4):1026-1035 }\end{array}$ & $\begin{array}{l}\text { Inclusão de serviços de saúde bucal no Programa } \\
\text { Saúde da Família no Estado do Paraná }\end{array}$ & Quali-Quanti & Questionários & $\begin{array}{l}\text { Gestores (CSB ou SMS) } \\
\text { e trabalhadores (CD) }\end{array}$ \\
\hline 2005 & BA & $\begin{array}{l}\text { Rodrigues AAAO e Assis } \\
\text { MMA }\end{array}$ & $\begin{array}{l}\text { Rev. baiana saúde pública, } \\
\text { 29(2):273-285 }\end{array}$ & $\begin{array}{l}\text { Oferta e demanda na atenção à saúde bucal: o } \\
\text { processo de trabalho no Programa Saúde da } \\
\text { Família em Alagoinhas - Bahia }\end{array}$ & Qualitativo & $\begin{array}{c}\text { Entrevista } \\
\text { semiestruturada, } \\
\text { observação e análise } \\
\text { documental }\end{array}$ & $\begin{array}{l}\text { Gestores (Prefeito, SMS } \\
\text { e CSB) e trabalhadores } \\
\text { (ESF e ESB + ACS) }\end{array}$ \\
\hline
\end{tabular}

ACS= Agente Comunitário de Saúde; $C D=$ Cirurgião Dentista; $C S B=$ Coordenador de Saúde Bucal; ESB= Equipe de Saúde Bucal; ESF= Equipe de Saúde da Família; SAI-SUS= Sistema de Informações Ambulatoriais do SUS; SIAB= Sistema de Informação de Atenção Básica; SMS= Secretário Municipal de Saúde. 
Tabela 2. Estudos selecionados que abordam os elementos analisadores do trabalho em saúde bucal na APS no Brasil apontando desafios e mudanças.

\begin{tabular}{|c|c|c|c|c|c|}
\hline \multirow{2}{*}{ Região } & \multirow{2}{*}{ UF } & \multirow{2}{*}{ Ano } & \multirow{2}{*}{ Autor(es) } & \multicolumn{2}{|c|}{$\begin{array}{l}\text { Elementos analisadores presentes } \\
\text { nos estudos }\end{array}$} \\
\hline & & & & $\begin{array}{l}\text { Indica(m) } \\
\text { desafio(s) }\end{array}$ & $\begin{array}{c}\text { Aponta(m) } \\
\text { mudança(s) }\end{array}$ \\
\hline \multirow[t]{3}{*}{ Sul } & PR & 2005 & $\begin{array}{c}\text { Baldani MH, Fadel CB, Possamai T e Queiroz } \\
\text { MGS }\end{array}$ & $1,7,9$ e 10 & 4 \\
\hline & PR & 2008 & $\begin{array}{c}\text { Koyashiki GAK, Alves-Souza RA e Garanhani } \\
\text { ML }\end{array}$ & 5 e 9 & 7 \\
\hline & SC & 2010 & Faccin D, Sebold R e Carcereri DL & $1,3,7,9$ e 10 & 2 \\
\hline \multirow[t]{6}{*}{ Sudeste } & $M G$ & 2009 & $\begin{array}{c}\text { Lourenço EC, Silva ACB, Meneghin MC e } \\
\text { Pereira AC }\end{array}$ & $5,8,9$ e 10 & 1 \\
\hline & SP & 2011 & $\begin{array}{c}\text { Cunha BAT, Marques RAA, Castro CGJ e } \\
\text { Narvai PC }\end{array}$ & 1 e 7 & 4 e 5 \\
\hline & SP & 2011 & Mialhe FL, Lefèvre F, Lefèvre AMC & 2 e 5 & 0 \\
\hline & ES & 2012 & $\begin{array}{c}\text { Esposti CDD, Oliveira AE, Santos Neto ET e } \\
\text { Zandonade E }\end{array}$ & 9 & 5 e 10 \\
\hline & SP & 2013 & Pezzato LM, L'Abbate S e Botazzo C & 0 & 1 e 7 \\
\hline & $M G$ & 2013 & $\begin{array}{l}\text { Sanglard-Oliveira CA, Werneck MAF, Lucas } \\
\text { SD e Abreu MHNG }\end{array}$ & 0 & 2,4 e 7 \\
\hline \multirow{2}{*}{$\begin{array}{c}\text { Sul e } \\
\text { Sudeste }\end{array}$} & PR & \multirow{2}{*}{2009} & \multirow{2}{*}{$\begin{array}{c}\text { Nascimento AC, Moysés ST, Bisinelli JC e } \\
\text { Moysés SJ }\end{array}$} & 1,9 & 4,7 \\
\hline & SP & & & 1 & 0 \\
\hline \multirow[t]{11}{*}{ Nordeste } & BA & 2005 & Rodrigues AAAO e Assis MMA & 7 e 9 & 0 \\
\hline & BA & 2007 & Dos Santos AM, et al & 4 & 0 \\
\hline & BA & 2007 & Chaves SCL e Silva LMV & 7 & 0 \\
\hline & $\mathrm{RN}$ & 2007 & Souza TM e Roncalli AG & $1,8,9$ e 10 & 3 \\
\hline & BA & 2008 & $\begin{array}{c}\text { Dos Santos AM, Assis MMA, Nascimento, } \\
\text { MAA e Jorge, MSB }\end{array}$ & 1 e 10 & 4 \\
\hline & BA & 2008 & Chaves SCL e Vieira-da-Silva LM & 2 e 7 & 0 \\
\hline & $\mathrm{PE}$ & 2008 & Martelli PJL, et al & $1,5,8$ e 10 & 9 \\
\hline & PE & 2008 & Pimentel FC, et al & 7 e 8 & 1 \\
\hline & $\mathrm{RN}$ & 2008 & Almeida GC e Ferreira MA & 1 e 8 & 2 \\
\hline & BA & 2009 & $\begin{array}{l}\text { Rodrigues AAAO, Gallotti AP, Pena SFA e } \\
\text { Ledo CAS }\end{array}$ & 10 & 2 e 5 \\
\hline & $\mathrm{RN}$ & 2009 & Rocha ECA e Araújo MAD & 1 e 10 & 0 \\
\hline
\end{tabular}




\begin{tabular}{|c|c|c|c|c|c|}
\hline & $\mathrm{RN}$ & 2009 & Holanda ALF, Barbosa AAA e Brito EWG & 7 e 9 & 5 \\
\hline & PE & 2010 & Pimentel FC, et al & $1,6,7,8,9$ & 2 \\
\hline & BA & 2010 & Rodrigues AAAO, Santos AM e Assis MMA & 9 & 7 \\
\hline & CE & 2010 & $\begin{array}{l}\text { Nuto SAS, Oliveira GC, Andrade, JV e Maia } \\
\text { MCG }\end{array}$ & 1 & 4 e 5 \\
\hline & $\mathrm{PI}$ & 2010 & Moura MS, et al & 7 & 5 \\
\hline & PE & 2010 & Martelli PJL, et al & 1,5 e 10 & 2 \\
\hline & PE & 2011 & Silva SF et al & 7 & 1 e 5 \\
\hline & BA & 2011 & $\begin{array}{c}\text { Rodrigues AAAO, Nascimento MAA, Fonsêca } \\
\text { GS e Siqueira DVS }\end{array}$ & $5,7,8$ e 10 & 0 \\
\hline & PE & 2012 & Pimentel FC, et al & $1,5,6,7$ e 8 & 9 \\
\hline & $\mathrm{PI}$ & 2013 & Moura MS, et al & $5,7,9$ e 10 & 0 \\
\hline Norte & PA & 2008 & Emmi DT e Barroso RFF & 0 & 1 e 2 \\
\hline
\end{tabular}

1: ampliação e qualificação da assistência; 2: ações educativas; 3: ações intersetoriais 4: acolhimento, vínculo e responsabilização; 5: educação permanente em saúde; 6: estimulo à participação popular e ao controle social; 7: integralidade; 8: planejamento, monitoramento e avaliação das ações; 9: trabalho integrado em equipe; 10: valorização do trabalho; 0: Ausência de elementos analisadores no estudo.

UF: Unidade da Federação; PR: Paraná; SC: Santa Catarina; MG: Minas Gerais; SP: São Paulo; ES: Espírito Santo; BA: Bahia; PE: Pernambuco; RN: Rio Grande do Norte; PI: Piauí; PA: Pará. 


\section{REFERÊNCIAS}

1. Almeida GC, Ferreira MA. Saúde bucal no contexto do Programa de Saúde da Família: práticas de prevenção orientadas a saúde individual e pública. Cad Saude Publica. 2008;24(9):2131-40.

2. Anjos FS, Mestriner SF, Bulgarelli AF, Pinto IC, Mestriner-Jr W. Equipes de saúde bucal no Brasil: avanços e desafios. Cienc Cuid Saude. 2011;10(3): 601-7.

3. Antunes JLF, Narvai PC. Políticas de saúde bucal no Brasil e seu impacto sobre as desigualdades em saúde. Rev Saude Publica. 2010;44(2):360-5. DOI:10.1590/S0034-89102010005000002

4. Ardenghi TM, Piovesan C, Antunes JLF. Desigualdades na prevalência de cárie dentária não tratada em crianças pré-escolares no Brasil. Rev Saude Publica. 2013;47(Suppl 3):129-37.

5. Baldani MH, Fadel CB, Possamai T, Queiroz MGS. Inclusão de serviços de saúde bucal no Programa Saúde da Família no Estado do Paraná. Cad Saude Publica. 2005;21(4):1026-35. DOI:10.1590/S141381232009000800009

6. Bertoncini JH, Pires DEP, Scherer MDA. Condições de trabalho e renormalizações nas atividades das enfermeiras na saúde da família. Trab educ saude. 2011;9(suppl 1):157-73. DOI:10.1590/S198177462011000400008

7. Chaves SCL, Silva LMV. As práticas profissionais no campo público de atenção à saúde bucal: o caso de dois municípios da Bahia. Cienc Saude Coletiva. 2007;12(6):1697-1710. DOI:10.1590/S1413-81232007000600031

8. Costa JFR, Chagas LD, Silvestre RM. A política nacional de saúde bucal do Brasil: registro de uma conquista histórica. Brasília: Organização PanAmericana da Saúde, 2006. 67p.

9. Cunha BAT, Marques RAA, Castro CGJ e Narvai PC. Saúde bucal em Diadema: da odontologia escolar à estratégia saúde da família. Saude Soc. 2010; 20(4):1033-45. DOI:10.1590/S0104-12902011000400019

10.Emmi DT, Barroso RF. Avaliação das ações de saúde bucal no Programa Saúde da Família no distrito de Mosqueiro, Pará. Cienc Saude Coletiva. 2008;13(1):35-41. DOI:10.1590/S1413-81232008000100008

11.Esposti CDD, Oliveira AE, Santos Neto ET, Zandonade E. O processo de trabalho do técnico em saúde bucal e suas relações com a equipe de saúde bucal na Região Metropolitana da Grande Vitória, Espírito Santo, Brasil. Saude Soc Sao Paulo. 2012; 21(2):372-85.

12. Esposti CDD, Oliveira AE; Zorzal e Silva M; Lima RCD. Perspectivas da saúde bucal na Estratégia Saúde da Família: dificuldades e avanços. UFES Rev Odontol. 2006; 8(3):49-56.

13. Faccin D, Sebold R, Carcereri, DL. Processo de trabalho em saúde bucal: em busca de diferentes olhares para compreender e transformar a realidade. Cienc Saude Coletiva. 2010; 15(1):1643-52. DOI: 10.1590/S141381232010000700076 
14.Goncalves RJ, Soares RA, Troll T, Cyrino EG. Ser médico no PSF: formação acadêmica, perspectivas e trabalho cotidiano. Rev bras educ med. 2009;33(3):382-92. DOI:10.1590/S0100-55022009000300009

15. Jatrana S, Crampton P, Filoche S. The case for integrating oral health into primary health care. NZ Med J. 2009;122(1301):43-52.

16. Koyashiki GAK, Alves-Souza RA, Garanhani ML. O trabalho em saúde bucal do Agente Comunitário de Saúde em Unidades de Saúde da Família. Cienc Saude Coletiva. 2008;13(4):1343-54. DOI:10.1590/S141381232008000400032

17. Lourenço EC, Silva ACB, Meneghin MC, Pereira AC. A inserção dos serviços de saúde bucal no Programa Saúde da Família no Estado de Minas Gerais. Cienc Saude Coletiva. 2009;14(Suppl. 1):1367-77. DOI:10.1590/S141381232009000800009

18. Lucena EHG, Pucca JR GA, Sousa MF. A Política Nacional de Saúde Bucal no Brasil no contexto do Sistema Único de Saúde. Revista Tempus Actas de Saude Coletiva. 2011;5(3):53-63.

19.Martelli PJL, Macedo CLSV, Medeiros KR, Silva SF, Cabral APS, Pimentel FC, et al. Perfil do cirurgião-dentista inserido na Estratégia de Saúde da Família em municípios do estado de Pernambuco, Brasil. Cienc Saude Coletiva. 2010;15(Suppl 2):3243-48. DOI:10.1590/S141381232010000800029

20. Matos PES e Tomita NE. A inserção da saúde bucal no Programa Saúde da Família: da universidade aos pólos de capacitação. Cad Saude Publica. 2014;20(6):1538-44. DOI:10.1590/S0102-311X2004000600011

21. Mattos RA. A integralidade na prática (ou sobre a prática da integralidade). Cad Saude Publica. 2004;20(5):1411-16. DOI:10.1590/S0102$311 \times 2004000500037$

22. Mendonça MHM, Martins MIC, Giovanella L, Escorel S. Desafios para gestão do trabalho a partir de experiências exitosas de expansão da Estratégia de Saúde da Família. Cienc Saude Coletiva. 2010;15(5):2355-65. DOI:10.1590/S1413-81232010000500011

23. Mialhe FL, Lefèvre $F$, Lefèvre AMC. $O$ agente comunitário de saúde e suas práticas educativas em saúde bucal: uma avaliação qualiquantitativa. Cienc Saude Coletiva. 2011;16(11):4425-32. DOI:10.1590/S141381232011001200015

24. Moura MS, Ferro FEFD, Cunha NL, Nétto OBS, Lima MDM, Moura LFAD. Saúde bucal na estratégia de saúde da família em um colegiado gestor regional do estado do Piauí. Cienc Saude Coletiva. 2013;18(2):471-80. DOI:10.1590/S1413-81232013000200018

25. Moysés SJ, Pucca Jr GA, Paludetto Jr M, Moura L. Avanços e desafios à Política de Vigilância à Saúde Bucal no Brasil. Rev Saude Publica. 2013;47(Suppl 3):161-7. DOI:10.1590/S0034-8910.2013047004329

26. Narvai PC, Frazão P, Roncalli AG, Antunes JLF. Cárie dentária no Brasil: declínio, iniquidade e exclusão social. Rev Panam Salud Publica. 2006;19(6):385-93. DOI:10.1590/S1020-49892006000600004 
27. Nascimento AC, Moysés ST, Bisinelli JC e Moysés SJ. Oral health in the family health strategy: a change of practices or semantics diversionism. Rev Saude Publica. 2009;43(3):455-62. DOI:10.1590/S0034-89102009005000015

28. Nascimento AC, Moyses ST, Werneck RI, Moyses SJ. Oral health in the context of primary care in Brazil. International Dental Journal. 2013;63:237-43.

29. Nuto SAS, Oliveira GC, Andrade JV, Maia MCG. O acolhimento em saúde bucal na estratégia de saúde da família, Fortaleza-CE: um relato de experiência. Rev APS. 2010;13(4):505-9.

30.Pereira DQ, Pereira JCM, Assis MMA. A prática odontológica em Unidades Básicas de Saúde em Feira de Santana (BA) no processo de municipalização da saúde: individual, curativa, autônoma e tecnicista. Cienc Saude Coletiva. 2003;8(2):599-609. DOI:10.1590/S1413-81232003000200020

31.Pezzato LM, L'Abbate S, Botazzo C. A produção de micropolíticas no processo de trabalho em saúde bucal: uma abordagem sócio-analítica. Cienc Saude Coletiva. 2013;18(7):2095-2104. DOI:10.1590/S141381232013000700025

32. Pimentel FC, Martelli PJL, Araújo Jr JLAC, Lima AS, Santana VGD, Macedo CLSV. Evolução da assistência em saúde bucal na estratégia de saúde da família do município do Recife (PE) no período de 2001 a 2007. Rev Baiana Saude Publica. 2008;32(2): 253-64.

33. Pimentel FC, et al. Análise da atenção à saúde bucal na Estratégia de Saúde da Família do Distrito Sanitário VI, Recife (PE). Cienc Saude Coletiva. 2010;15(4):2189-96. DOI:10.1590/S1413-81232010000400033

34. Pimentel FC, Albuquerque PC, Martelli PJL, Souza WV, Acioli RML. Caracterização do processo de trabalho das equipes de saúde bucal em municípios do Estado de Pernambuco, Brasil, de acordo com o tamanho da população: a partir de links da comunidade para a organização dos cuidados clínicos. Cad Saude Publica. 2012;28(Suppl):S146-S157. DOI:10.1590/S0102-311X2012001300015

35. Pucca JR GA, Lucena EHG, Cawahisa PT. Financing national policy on oral health in Brazil in the context of the Unified Health System. Braz Oral Res. 2010;24(suppl. 1):26-32. DOI:10.1590/S1806-83242010000500005

36. Rodrigues AAAO, Assis MMA. Oferta e demanda na atenção à saúde bucal: o processo de trabalho no Programa Saúde da Família em Alagoinhas - Bahia. Rev Baiana Saude Publica. 2005;29(2):273-285.

37. Rodrigues AAAO, Gallotti AP, Pena SFA, Ledo CAS. Saúde bucal no programa de saúde da família na cidade de Feira de Santana (BA): o perfil do cirurgião-dentista. Rev Baiana Saude Publica. 2009;33(4):695-709.

38. Rodrigues AAAO, Santos AM e Assis MMA. Agente comunitário de saúde: sujeito da prática em saúde bucal em Alagoinhas, Bahia. Cienc Saude Coletiva. 2010;15(3):907-15. DOI:10.1590/S1413-81232010000300034

39. Rodrigues AAAO, Nascimento MAA, Fonsêca GS, Siqueira DVS. Saúde bucal na estratégia saúde da família em um município do semiárido baiano. Rev Baiana Saude Publica. 2011;35(3):695-709. 
40.Sanglard-Oliveira CA, Werneck MAF, Lucas SD, Abreu MHNG. Atribuições dos Técnicos em Saúde Bucal na Estratégia Saúde da Família em Minas Gerais, Brasil. Cienc Saude Coletiva. 2013;18(8):2453-60. DOI:10.1590/S1413-81232013000800030

41. Santos AM, Assis MMA, Rodrigues AAAO, Nascimento MAA, Jorge MSB. Linhas de tensões no processo de acolhimento das equipes de saúde bucal do Programa Saúde da Família: o caso de Alagoinhas, Bahia, Brasil. Cad Saude Publica. 2007;23(1):75-85. DOI:10.1590/S0102-311X2007000100009

42. Scherer MDA, Marino SRA, Ramos FRS. Rupturas e resoluções no modelo de atenção à saúde: reflexões sobre a estratégia saúde da família com base nas categorias kuhnianas. Interface - Comunic Saude Educ. 2005;9(16):5366.

43. Scherer MDA, Pires DEP, Soratto J. O trabalho na Estratégia Saúde da Família. In: Souza MF, Franco MS, Mendonça, AVM. Saúde da Família nos municípios brasileiros: os reflexos dos 20 anos do espelho do futuro. Campinas, SP: Saberes Editora, 2014. p. 521-571.

44.Schwartz, Y. Trabalho e uso de si. Pró-Posições. Campinas, v. 1, n. 5 (32), p. 34-50, jul. 2000.

45. Silva JM, Caldeira AP. Modelo assistencial e indicadores de qualidade da assistência: percepção dos profissionais da atenção primária à saúde. Cad Saude Publica. 2010;26(6):1187-93. DOI:10.1590/S0102$311 \times 2010000600012$

46. Silva SF, Martelli PJL, Sá DA, Cabral AP, Pimentel FC, Monteiro IS, et al. Análise do avanço das equipes de saúde bucal inseridas na Estratégia Saúde da Família em Pernambuco, região Nordeste, Brasil, 2002 a 2005. Cienc Saude Coletiva. 2011;16(1):211-20. DOI:10.1590/S1413-81232011000100024

47. Silvia LA, Casotti CA, Chaves SCL. A produção científica brasileira sobre a Estratégia Saúde da Família e a mudança no modelo de atenção. Cienc Saude Coletiva. 2013;18(1):221-32. DOI:10.1590/S1413-81232013000100023

48. Silva KL, Rodrigues AT. Ações intersetoriais para promoção da saúde na Estratégia Saúde da Família: experiências, desafios e possibilidades. Rev bras enferm. 2010;63(5):762-69. DOI: 10.1590/S0034-71672010000500011

49. Soares FF, Figueiredo CRV, Borges NCM, Jordão RA e Freire MCM. Atuação da equipe de saúde bucal na estratégia saúde da família: análise dos estudos publicados no período 2001-2008. Cienc Saude Coletiva. 2011;16(7): 316980. DOI:10.1590/S1413-81232011000800017

50.Sousa MF, Hamann EM. Programa Saúde da Família no Brasil: uma agenda incompleta? Cienc Saude Coletiva. 2009;14(Suppl 1):1325-35. DOI:10.1590/S1413-81232009000800002

51.Souza LGS, Menandro MCS. Atenção primária à saúde: diretrizes, desafios e recomendações. Revisão de bibliografia internacional. Physis: Rev de Saude Coletiva. 2011;21(2):517-39. DOI:10.1590/S0103-73312011000200010

52. Souza TM, Roncalli AG. Saúde bucal no Programa Saúde da Família: uma avaliação do modelo assistencial. Cad Saude Publica. 2007;23(11):2727-39. 
53.Starfield, B. Atenção primária: equilíbrio entre necessidades de saúde, serviços e tecnologia. Brasília: Unesco: Ministério da Saúde, 2002.

54.Viegas SMF, PENNA CMM. A construção da integralidade no trabalho cotidiano da equipe saúde da família. EsC Anna Nery. 2013;17(1):133-41. DOI:10.1590/S1414-81452013000100019 


\subsection{ARTIGO 2. O TRABALHO EM SAÚDE BUCAL NA ESTRATÉGIA SAÚDE DA FAMÍLIA: UMA DIFÍCIL INTEGRAÇÃO?}

THE WORK IN ORAL HEALTH INTO THE FAMILY HEALTH STRATEGY: IS IT A TOUGH INTEGRATION?

\section{Resumo}

Um dos maiores desafios para a saúde bucal na Estratégia Saúde da Família (ESF), desde sua inserção, é a integração na equipe de saúde da família. Trata-se de um estudo qualitativo que analisa o trabalho em saúde bucal na ESF. Os dados foram coletados por meio de observação, análise documental e entrevistas com dezenove profissionais que atuavam na ESF no Distrito Federal. A coleta e análise baseou-se em categorias analíticas prévias construídas a partir das políticas públicas nacionais que orientam o trabalho em saúde bucal. Os resultados mostram que no trabalho em saúde bucal na ESF predominam características do modelo biomédico hegemônico com ênfase nas ações curativas individuais que convivem com características do modelo preconizado pelas políticas com destaque para a integração dos profissionais da saúde bucal nas reuniões de equipe, nas visitas domiciliares, nas ações intersetoriais e de educação em saúde. Conclui-se que a integração da saúde bucal na equipe de saúde da família é incipiente e limitada por conflitos de normas: de um lado uma normativa que institui o campo comum de atribuições e de outro, a que institui duas equipes distintas. Uma difícil integração.

Palavras-chave: Atenção Primária à Saúde. Saúde da Família. Saúde Bucal. Trabalho. Pesquisa Qualitativa.

\section{Abstract}

One of the biggest challenges for oral health in Brazil's National Family Health Strategy (FHS), since its inception, is the integration into the family health team. It is a qualitative study that examines the work at oral health in FHS. Data were collected through observation, document analysis and interviews. The study was carried out with nineteen professionals who worked in FHS from Federal District. Data collection and analysis were based on previous analytical categories, which were established 
from national public policies that guide the oral health work. The results show that at work in oral health into the FHS predominate characteristics of the hegemonic biomedical model, with emphasis on individual curative actions that deal with the characteristics of the model recommended by policies, especially on the integration of oral health professionals in staff meetings, home visits, intersectoral actions and health education. It is concluded that the integration of oral health in the family health team is incipient and limited by conflict on regulations: on one side, an instruction establishing the common field assignments and on the other, another instruction establishing two different teams - a tough integration.

Keywords: Primary Health Care. Family Health. Oral Health. Work. Qualitative Research.

\section{Introdução}

No Brasil, a Atenção Primária à Saúde (APS) apresenta três importantes características que a diferencia dos modelos de outros países: a responsabilidade das equipes multiprofissionais por territórios geográficos e população adscrita; a presença singular dos agentes comunitários de saúde; e, a inclusão da saúde bucal no sistema público de saúde ${ }^{1}$.

O fortalecimento da APS tem sido um processo gradativo, por intermédio da implantação da Estratégia de Saúde da Família (ESF) com ênfase na reformulação dos processos de trabalho segundo os princípios do Sistema Único de Saúde (SUS) $2-7$.

A inserção da saúde bucal e das práticas odontológicas no SUS, ao longo dos anos, deu-se de forma paralela à organização dos demais serviços de saúde ${ }^{2}$. Iniciou-se de forma isolada em Curitiba/PR e no Distrito Federal (DF) em 1995 e Camaragibe/PE em $1998{ }^{4,5}$. A inclusão da saúde bucal na ESF em nível nacional ocorreu apenas em 2000, por meio do estabelecimento de incentivo financeiro para a reorganização da atenção à saúde bucal prestada nos municípios, o que resultou em um grande impulso de sua expansão pelo Brasil ${ }^{3,8,9}$.

Em 2004, foram publicadas as Diretrizes da Política Nacional de Saúde Bucal (PNSB), intituladas Programa Brasil Sorridente, que apontam para uma reorganização da atenção em saúde bucal em todos os níveis de atenção e para 
readequação do processo de trabalho na saúde bucal, por meio da interdisciplinaridade e multiprofissionalismo; integralidade da atenção; intersetorialidade; ampliação e qualificação da assistência; discussões das condições de trabalho e de parâmetros para orientar o processo de trabalho ${ }^{2}$. Destacam-se, dentre as atribuições comuns a todos os profissionais que atuam na ESF, a realização em conjunto da territorialização e do planejamento local de saúde, priorizando ações de acordo com as necessidades de uma área adscrita ${ }^{6}$.

Dados do Ministério da Saúde (MS) ${ }^{10}$, demonstram aumento substancial no número de equipes de saúde bucal desde a sua implantação. Em 2002 a cobertura populacional era de $15 \%$ da população brasileira e em julho de 2014 passou a 37\%, o que corresponde atualmente a 74,2 milhões de pessoas.

Para além da ampliação do acesso, a inclusão da saúde bucal na ESF tem se constituído possibilidade de romper com a prática odontológica excludente baseada no curativismo, tecnicismo e biologicismo e representa uma oportunidade de mudança no processo de trabalho, por se tratar de uma estratégia eficaz de reorganização da APS ${ }^{3,11-14}$. Nesse contexto, a integração da equipe de saúde bucal com a de saúde da família para a realização de um trabalho em conjunto tem sido um dos maiores desafios para a saúde bucal ${ }^{3,15,16}$.

Após uma década de Programa Brasil Sorridente, torna-se oportuno analisar o trabalho em saúde bucal na ESF e como a equipe de saúde bucal se integra à equipe de saúde da família que é o objetivo do presente artigo.

\section{Método}

O estudo originou-se do projeto de pesquisa multicêntrico intitulado "Estratégia saúde da família - inovação tecnológica para ampliação do acesso, da qualidade e promoção de saúde bucal na atenção básica", que possui apoio financeiro do Conselho Nacional de Desenvolvimento Científico e Tecnológico (CNPq).

Trata-se de estudo qualitativo no Distrito Federal (DF) sobre o trabalho da saúde bucal na ESF no contexto de duas unidades básicas de saúde (UBS), em duas regiões administrativas, Fercal e Gama. O território do DF é dividido em 30 regiões administrativas ${ }^{17}$.

Segundo dados do $\mathrm{MS}^{18}$, de agosto de 2014, Brasília apresenta cobertura de APS de 54,39\%, considerando a ESF com cobertura de 30\%. A saúde bucal 
apresenta cobertura de $26 \%$ entretanto, considerando somente a ESF, tem-se uma cobertura de $8,47 \%$.

A escolha do local do estudo e dos participantes se deu a partir dos seguintes critério de inclusão: a) equipes de saúde da família completas com equipe de saúde bucal, independente da modalidade; b) equipes de saúde da família consideradas de boa qualidade pelos gestores, tendo como referência a Política Nacional de Atenção Básica e as Diretrizes da Política Nacional de Saúde Bucal; c) equipes que, preferencialmente, tenham como referência CEO e/ou Núcleo de Apoio à Saúde da Família (NASF); d) equipes que participaram do 1ำ ciclo do Programa Nacional de Melhoria do Acesso e da Qualidade (PMAQ) do Ministério da Saúde; e, e) equipes que concordem em participar do estudo.

Participaram do estudo 19 profissionais de saúde: sete agentes comunitários de saúde (ACS), quatro técnicos de enfermagem (TE), dois enfermeiros (E), dois cirurgiões-dentistas (CD), dois técnicos de saúde bucal (TSB) e dois médicos (M).

O caráter multiprofissional da amostra teve por objetivo abranger diferentes visões sobre o objeto de estudo, considerando que a saúde bucal não se restringe ao núcleo da odontologia, mas também abrange o campo de competências e responsabilidades de outras áreas profissionais ${ }^{6}$.

O foco central do estudo foi analisar o trabalho em saúde bucal sob a lógica da ESF. Neste sentido, o olhar do pesquisador se voltou para o trabalho em saúde bucal articulado/conjunto/integrado dos profissionais das equipes de saúde da família e de saúde bucal, sem analisar os procedimentos clínicos ou técnicos utilizados nos atendimentos assistenciais.

Os dados foram coletados e analisados guiados por categorias analíticas previas construídas a partir de uma revisão do referencial teórico ${ }^{2,6,11}$, articulandoos com o referencial teórico acerca do trabalho em saúde bucal, conforme Figura 1. 


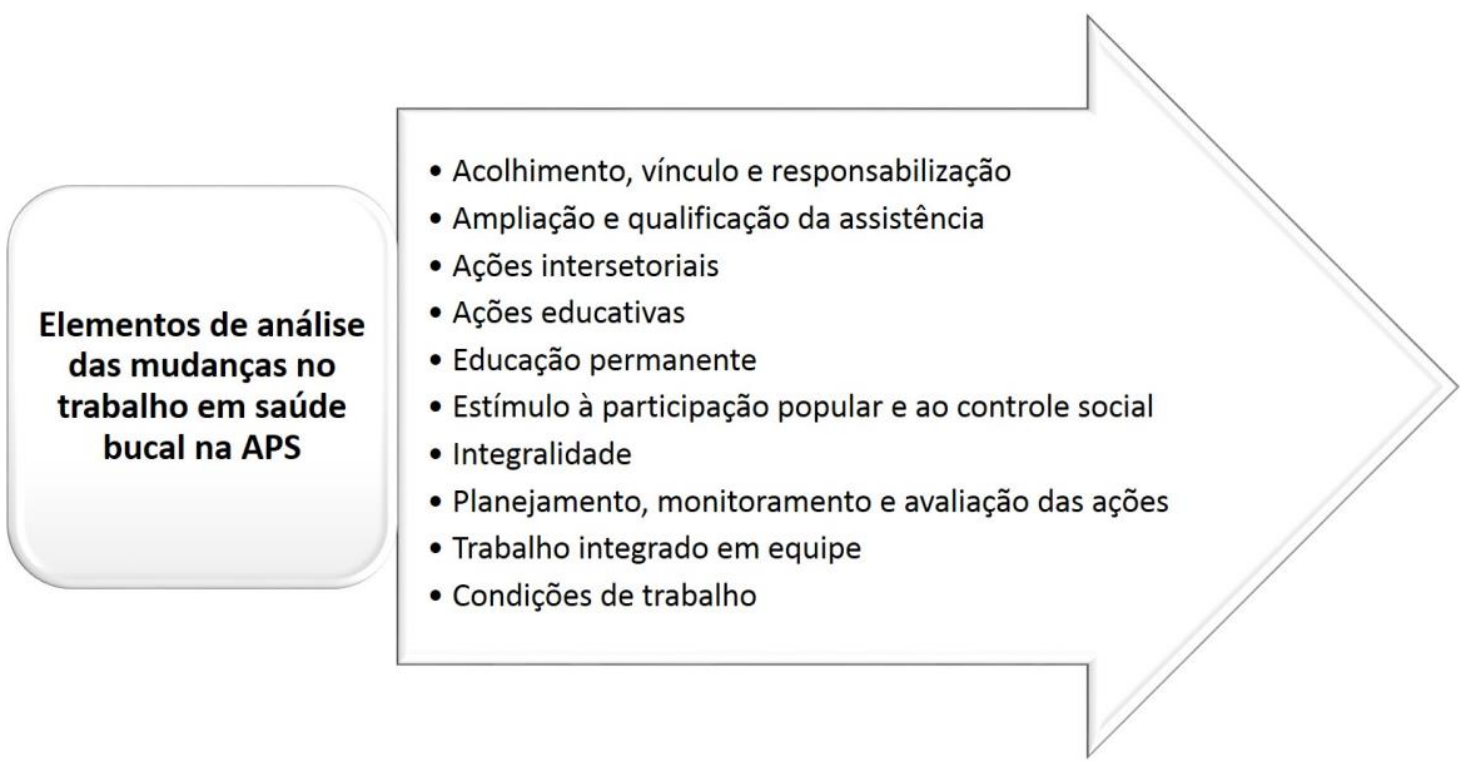

Figura 1. Elementos de análise das mudanças no trabalho em saúde bucal na APS.

A coleta de dados ocorreu por meio de entrevistas semiestruturadas, observação participante e análise documental. As entrevistas foram orientadas por um roteiro com perguntas norteadoras, gravadas e transcritas; as observações foram realizadas com auxílio de um guia de observação e um diário de campo; e, a análise documental foi realizada por meio das atas de reunião de equipe. $\mathrm{Na}$ apresentação dos resultados, os participantes de entrevista são denominados por letras que correspondem à categoria profissional (ACS: agente comunitário de saúde, CD: cirurgião-dentista, E: enfermeiro, M: médico, TE: técnico de enfermagem, TSB: técnico de saúde bucal) e números que corresponde a quantidade de entrevistados por categoria profissional, por exemplo (ACS1, ACS2, ACS3...). Somente foram consideradas as entrevistas que abordaram sobre o trabalho em saúde bucal na ESF, foco central de análise nesse estudo.

Os recursos disponíveis no software Atlas.ti (Qualitative Research and Solutions), versão 7.1.8, serviram como ferramenta para sistematizar e categorizar os dados e subsidiar a análise qualitativa (Figura 3). 


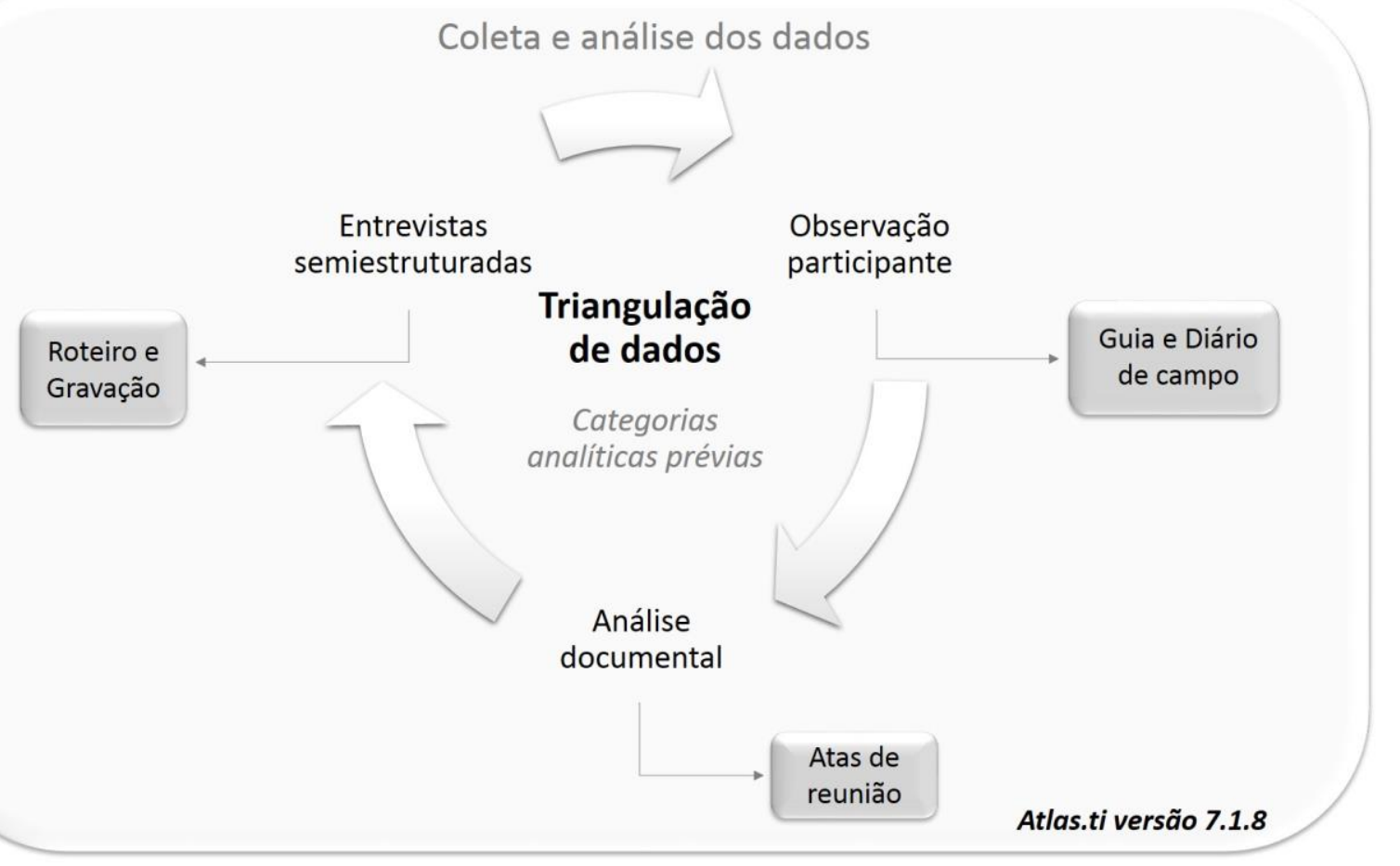

Figura 2. Síntese do percurso metodológico.

Para assegurar os critérios de fidedignidade e de validade, utilizou-se da técnica da triangulação de dados, que consiste em olhar o objeto sob seus diversos ângulos, comparando e articulado os resultados das três técnicas de coleta de dados (análise documental, observação e entrevistas) ${ }^{19,20}$.

Uma dificuldade percebida no percurso metodológico foi a de "separar" o que é "inseparável" para o estudo do trabalho em saúde. Ou seja, para realizar a coleta e análise dos dados as categorias analíticas prévias conduziram o olhar do pesquisador para compreender a realidade do trabalho mas, ao mesmo tempo, com essa conduta corremos um risco de mutilar a singularidade e a subjetividade dos sujeitos e das relações que estes estabelecem com o meio e sua capacidade de agir, tendo por base um conjunto de normas antecedentes e de valores ${ }^{21}$.

O projeto de pesquisa foi aprovado pelos Comitês de Ética em Pesquisa da Universidade de Brasília e da Fundação de Ensino e Pesquisa em Ciências da Saúde e seguiu as normas da Resolução no 466/12 do Conselho Nacional de Saúde. 


\section{Resultados e discussão}

O trabalho é resultado de um debate de normas e de valores do trabalhador consigo mesmo, de como usar de si e de como estar em condições de gerir a complexidade de questões relacionadas ao trabalho coletivo ${ }^{22}$.

Os resultados mostram que no trabalho em saúde bucal na ESF predominam características do modelo biomédico hegemônico, com ênfase nas ações curativas individuais, que convivem com características do modelo preconizado pelas políticas. Os profissionais das equipes de saúde bucal e equipes de saúde da família se deparam com conflitos de normas que dificultam a integração, de um lado uma normativa que institui o campo comum de atribuições e de outro, a que institui duas equipes distintas.

Refletir sobre o que se transforma "no" ou "do" trabalho tem implicações políticas e éticas, porque não se trata de um campo neutro e os instrumentos utilizados na produção do conhecimento e dos produtos materiais e não materiais não estão separados das escolhas e julgamentos de valor implícitos nesse processo ${ }^{23}$.

Por meio das categorias analíticas prévias foi possível visualizar as fortalezas e as fragilidades presentes no cotidiano de trabalho das equipes, ora revelando a integração e ora revelando a fragmentação (Quadro 1).

Quadro 1. Fortalezas e fragilidades na integração da equipe de saúde bucal à equipe de saúde da família, segundo as categorias analíticas prévias.

\begin{tabular}{|c|c|c|c|}
\hline \multicolumn{2}{|r|}{ Categorias analíticas e fortalezas } & \multicolumn{2}{|r|}{ Categorias analíticas e fragilidades } \\
\hline 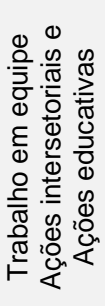 & $\begin{array}{l}\text { Participação e colaboração dos profissionais da } \\
\text { equipe, inclusive do médico, com destaque para } \\
\text { os ACS, nas ações educativas de SB (com foco } \\
\text { na prevenção) realizadas na escola. } \\
\text { Articulação e reconhecimento dos profissionais } \\
\text { da saúde pelos profissionais da educação. } \\
\text { Identificação de parceiros e recursos na } \\
\text { comunidade para ações intersetoriais. }\end{array}$ & 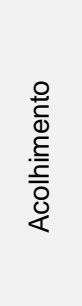 & $\begin{array}{l}\text { Dúvidas quanto ao acolhimento e a forma de } \\
\text { organização do serviço usuário-centrada. } \\
\text { Fragmentação do acolhimento na UBS, } \\
\text { profissionais de SB isolados dos demais } \\
\text { profissionais da equipe saúde da família. }\end{array}$ \\
\hline 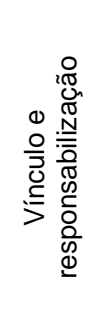 & $\begin{array}{l}\text { ACS como sujeito promotor do vínculo com a } \\
\text { comunidade e capaz de contribuir com a } \\
\text { autonomia e ampliação do cuidado à SB. } \\
\text { Visita domiciliar do CD como instrumento para o } \\
\text { vínculo e responsabilização do usuário. }\end{array}$ & 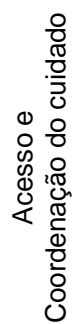 & $\begin{array}{l}\text { Barreiras no acesso à atenção à SB, modo de } \\
\text { marcação de consulta por lista de espera e o } \\
\text { acolhimento à demanda espontânea pouco } \\
\text { estruturado. } \\
\text { Obstáculos na coordenação do cuidado na rede } \\
\text { de atenção à saúde bucal, com destaque para } \\
\text { referência às especialidades do CEO. }\end{array}$ \\
\hline
\end{tabular}




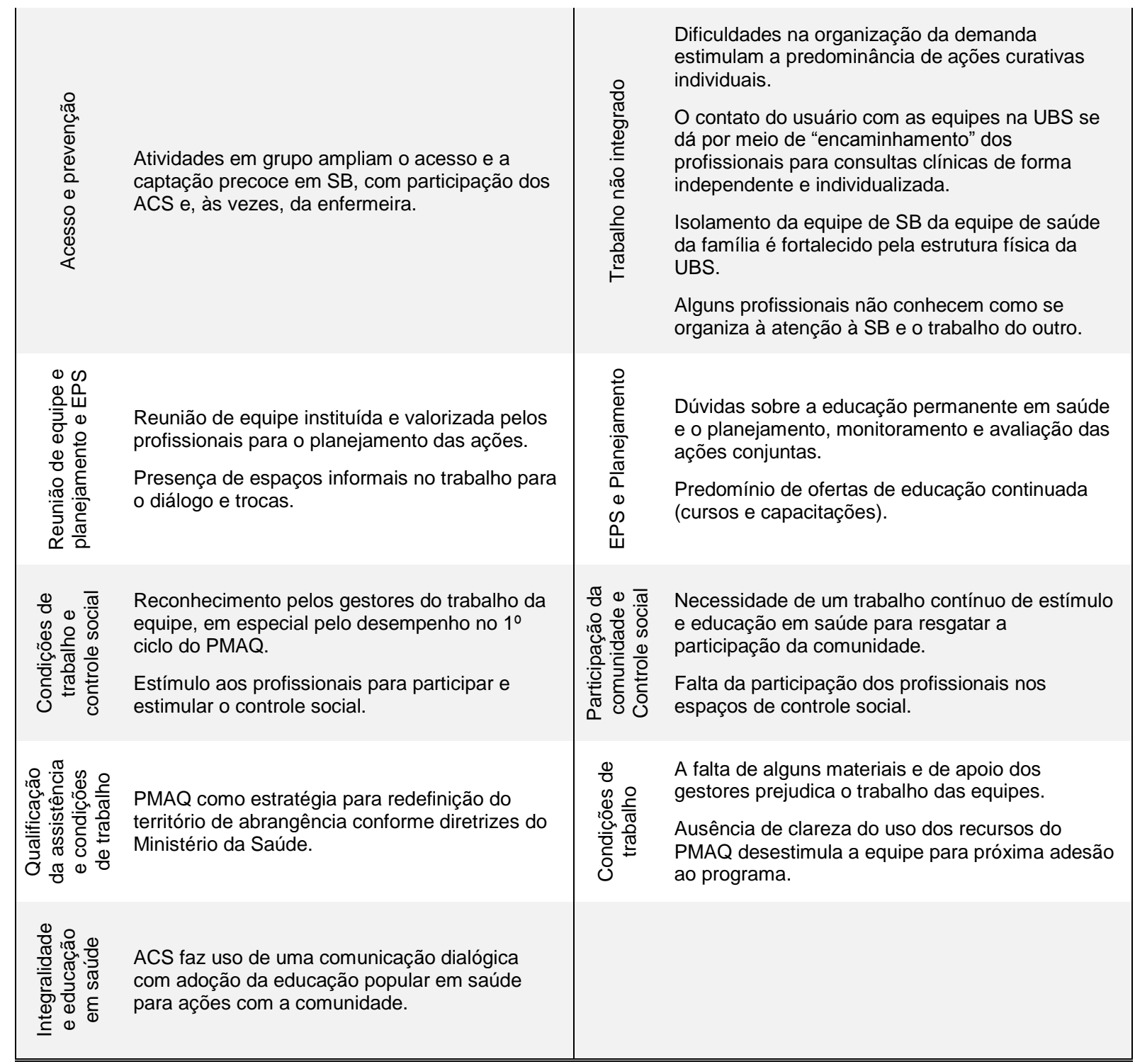

EPS: Educação Permanente em Saúde.

A observação em campo e a produção dos dados por meio da entrevista e análise documental trouxeram diferentes olhares para o processo de trabalho em saúde bucal. Numa primeira aproximação visualizou-se o distanciamento físico existente, devido ao arranjo arquitetônico da UBS, entre a equipe de saúde da família e a equipe de saúde bucal, sugerindo distanciamento também no modo de trabalhar:

"Na verdade é a gente aqui e eles, lá dentro. Então não temos muito envolvimento com eles. Não temos muito contato. Não ajudamos praticamente nada" (TE1).

"[...] a gente fica meio que pra cá né, a gente não tem muito contato com pessoal de lá" (TSB2). 
"Quando eu cheguei e ainda era Centro de Saúde, a odonto era como se fosse um serviço à parte do posto. Entrar lá? A gente nem entrava. Era como se fosse secreta, a sensação que eu tinha, era como se fosse só deles” (TE3).

"O único contato que eu tenho com eles quando chego na unidade é quando eu pergunto para o paciente o que ele está aguardando e ele responde que é o dentista ai, eu peço pra aguardar porque ele está atendendo" (TE4).

Conhecer o trabalho do outro é um dos elementos para o trabalho integrado da equipe e para a construção conjunta de uma agenda comum de trabalho, com as atividades que são comuns e específicas, possibilitando momentos de trabalho que, quando articulados, têm potência para promover a integralidade da atenção à saúde. Nesta pesquisa, contraditoriamente, para alguns profissionais da saúde bucal todos os membros da equipe conhecem o trabalho que cada um realiza, enquanto para outros o contrário também é verdadeiro:

"Todo mundo conhece o trabalho de todo mundo" (TSB1).

"A dentista tem um sistema diferenciado de marcação, não sei te explicar com detalhes como funciona" (TE2).

Os resultados sugerem que a baixa integração é um problema dos profissionais técnicos, mas segundo Pimentel et al $(2012)^{7}$, o trabalho do CD raramente se insere em práticas partilhadas com profissionais de outras áreas, uma vez que suas ações são desenvolvidas de forma autônoma, independente e individualizadas.

Momentos de integração entre a equipe de saúde bucal e a equipe de saúde da família são percebidos pelos profissionais em ações coletivas pontuais, especialmente nas ações intersetoriais, desenvolvidas por iniciativas da equipe de saúde bucal no ambiente escolar:

"Com a equipe de saúde bucal, todo evento que o dentista realiza nós fazemos parte. Nós já fizemos teatro, a gente faz a marcação de consulta, as escovações nas escolas, primeiro ele ensina a gente e depois passa para os alunos junto com ele" (ACS4).

"Teve a semana odontológica e eu participei. O dentista se empenhou bastante. Fez teatro e tudo. No que a gente podia ajudar, não necessariamente na área médica, na logística mesmo" (M2). 
"No ano passado teve duas ações na escola e uma delas foi direcionada para a parte odontológica e eu fui lá colaborar. Não participei diretamente, mas colaborei" (M1).

O trabalho integrado em equipe é como uma via de mão dupla, em que ambos os lados precisam estar dispostos à integração no cotidiano do trabalho ${ }^{13}$. $\mathrm{O}$ desenvolvimento conjunto de ações comuns, que demandam maior contato e engajamento, ainda é um desafio posto às equipes de saúde da família e de saúde bucal. A relação entre os profissionais, segundo eles, restringe-se ao diálogo de dúvidas clínicas e de atendimento à grupos prioritários:

"Liberdade total, qualquer dúvida eu posso entrar na sala de qualquer um e perguntar qualquer coisa. Ver a agenda deles. No dia das gestantes eu pergunto "deixa eu ver quem são as gestantes?". Ah já vieram ou não vieram. E elas também "dá uma olhada nesse menino aqui", ou "a mãezinha quer falar com você". Então com o médico também, às vezes medicação no pré-operatório. Principalmente hipertenso e diabético, pode conversar. Pelo menos, com os que passaram por aqui, nunca teve restrição, nenhum obstáculo pra conversar com eles" (CD2).

No trabalho das equipes predominam tanto atividades fragmentadas como atividades integradas de aproximação e trocas entretanto, ainda estão mais presentes as ações individuais realizadas no consultório:

"Sempre no atendimento de crescimento e desenvolvimento da criança, quando é a primeira consulta, a gente orienta a passar no dentista para ele dar as orientações" (M1).

"Sempre passa por um ou pelo outro. Já teve um caso, mas é um caso ou outro. Teve um câncer bucal que o médico viu e me chamou: "olha isso aqui". Aí que eu liguei para o especialista do HRAN e encaminhamos juntos" (CD2).

$\mathrm{Na}$ observação do trabalho da equipe percebeu-se momentos de oportunidade e fortalecimento da integração. O encaminhamento do usuário de um profissional da equipe de saúde da família ao CD da equipe de saúde bucal poderia se tornar um atendimento conjunto ou uma interconsulta:

"No meu próprio atendimento eu orientava, eu olhava se havia alguma deformação de palato, alguma má formação na dentição, nisso já encaminhava para o dentista, às vezes conversava com ele, se tivesse que encaminhar a gente encaminhava e até crianças maiores, na hora do exame físico, se eu identificasse cárie ou alguma coisa assim eu questionava a mãe porque estava acontecendo, se 
realizava escovação, uso do fio-dental. Mas, de qualquer maneira, eu já encaminhava para o dentista dar uma avaliada" (M1).

Existem algumas barreiras a serem rompidas para que haja a mudança do modelo em saúde bucal, pois o CD e sua equipe estão basicamente envolvidos em consultas clínicas, de forma independente e individualizadas, que privilegiam as características da prática hegemônica, não tendo tempo de atuar com o território, a família e a comunidade. Nesse sentido, alguns fatores contribuem para tal organização do processo de trabalho, como o processo histórico de inserção da saúde bucal na ESF, os aspectos estruturais e as concepções dos profissionais acerca do processo saúde-doença ${ }^{5,13}$.

Uma das percepções mais presentes nos discursos dos sujeitos é de que a população enfrenta grandes dificuldades de acesso para atenção à saúde bucal. $\mathrm{Na}$ observação foi possível perceber a fragilidade da estratégia de marcação utilizada pelas equipes, por meio de lista de espera e pelo ACS como interlocutor, que resulta em uma grande lista e, segundo os entrevistados, em desresponsabilização do usuário:

"Aí eu falo para o dentista que tem pessoas há 2 anos na fila. Já teve um caso de um camarada falar que precisava ir ao dentista, aí eu disse que ia colocar o nome dele na lista, aí passou tanto tempo, mas nesse caso a falha foi dele, porque ele foi chamado para uma consulta e não veio. Aí teve outra, ele não veio. Depois de muito tempo eu passei lá e ele disse que tinha que arrumar outra maneira de consertar os dentes. Os dentes já tinham caído e ele precisava de uma dentadura" (ACS2).

Os profissionais reconhecem que o tempo de espera para acesso à atenção à saúde bucal é longo e acreditam que a população está acostumada com tal situação:

"Alguns casos são mais rápidos, como as crianças e gestantes. Mas para um adulto eu não tenho ideia, eu sei que é muito tempo. O dentista nos informou que a lista de espera é aproximadamente de 5 anos" (ACS7).

De maneira convergente com a literatura ${ }^{15,24,25}$ um nó crítico dos serviços é a organização da demanda pois, é grande a demanda reprimida e pouca, a oferta. A demanda excessiva, por sua vez, estimula a predominância das ações curativas pelo $C D$, de maneira isolada e fragmentada da equipe.

O ACS aparece como um facilitador para o acesso do usuário à saúde bucal, em especial por ser o elo entre equipe e comunidade. No entanto, os ACS relatam 
dificuldades nessa função de "porta de entrada" para a marcação de consulta de saúde bucal:

"Então eu vou passando nas casas e nem pergunto mais, porque é uma parte tão sensível de lidar. Eu espero eles me procurarem e explico que vou botar o nome na lista" (ACS6).

A partir da dificuldade de acesso, criam-se diferentes modelos de organização da demanda que priorizam determinados grupos, segundo critérios de problemas de saúde (hipertensão e diabetes) e por ciclos de vida, notadamente as crianças e gestantes. Há desafios na incorporação de outras parcelas da população:

"Geralmente os escolares e o Cárie Zero a gente já vai chamando pela nossa lista. O dia da gestante, por exemplo, a gente passa para os ACS. Adulto, adolescente e hiperdia são com os ACS também. Aí a gente passa as vagas e eles falam "oh, tem tantas vagas para gestante amanhã", por exemplo. Aí eles mandam para a gente. No caso, a gente não sabe quem vai vir" (TSB2).

Além das dificuldades encontradas para acesso na marcação de consulta programática, a população também enfrenta obstáculos para acolhimento da demanda espontânea na saúde bucal que, durante a observação, mostrou-se pouco estruturada e pouco utilizada.

Chanlat $(2004)^{26}$, cita a presença de alguns paradoxos com os quais algumas organizações de saúde se confrontam. No contexto, da pesquisa os profissionais das equipes de saúde bucal e equipes de saúde da família se deparam com conflitos de normas. De um lado, eles são orientados para organizar o serviço de forma fragmentada, por ciclos de vida e agravos, e de outro, as diretrizes nacionais orientam um cuidado integral, organizando o serviço segundo as necessidades de saúde. Há, também, o reforço das ações coletivas e ao mesmo o estímulo para o desenvolvimento de práticas cada vez mais individualizadas.

O modo de organização de encaminhamento dos usuários para especialidades também é um dos desafios que precisam ser enfrentados ${ }^{25}$. Observa-se dificuldade dos profissionais, em especial do $C D$, para a continuidade e coordenação do cuidado na rede de atenção à saúde:

"Eles mandam as vagas mensais, endodontia, periodontia, cirurgia, pacientes com necessidades especiais, aí eles já mandam o código com o número de vagas e a gente tem uma lista das necessidades dos pacientes, e vai encaminhando para eles todo fim de mês. Todo mundo tem que ir segunda-feira pela manhã no hospital 
assistir a palestra, todos no mesmo horário. Depois eles mandam a contrarreferência para continuar aqui a manutenção. Se você não assistiu a palestra ali, você perdeu a vaga" (CD2).

A atividade com grupos apareceu como uma estratégia de ampliação do acesso à saúde bucal e captação precoce:

"Tinha cineminha com pipoca e pintura de rosto, palestra sobre prevenção de câncer de boca e depois eu fiz o exame em todo mundo e se precisou eu já encaminhei" (CD1).

O acesso e o acolhimento são elementos essenciais para avaliação do processo de trabalho e da qualidade dos serviços de saúde, pois contribuem para a procura pelo usuário ${ }^{27}$.

De acordo com as Diretrizes da PNSB ${ }^{11}$, o acolhimento pressupõe que 0 serviço de saúde seja organizado de forma usuário-centrada, garantido por uma equipe multiprofissional, nos atos de receber, escutar, orientar, atender, encaminhar e acompanhar. Ou seja, significa a base da humanização das relações e caracteriza o primeiro contato do usuário com o serviço, contribuindo para uma atenção integral e resolutiva a toda população.

$\mathrm{Na}$ observação do trabalho dos profissionais na UBS, os técnicos de enfermagem ficam como referência da "sala de acolhimento" e realizam a escuta inicial e a triagem com classificação de risco para atendimento clínico. Talvez a existência desse espaço, com a identificação de "sala de acolhimento" fragmente ainda mais as ações da equipe e 0 isolamento da saúde bucal, que não se reconhece como parte dessa atribuição. Entretanto, os profissionais expressam dúvidas sobre como realizar o acolhimento:

"Eu faço muito acolhimento, orientação, alguns pacientes me procuram para conversar, na maioria das vezes eu não fico no consultório atendendo paciente, talvez isso que deveria ser o certo, não sei, e muita coisa, antes de passar pelo médico, passa por mim, porque às vezes a paciente quer renovar uma receita de anticoncepcional ou alguma dúvida que não precisa passar pelo médico" (E2).

$\mathrm{O}$ vínculo é um dos resultados esperados das ações de acolhimento e, principalmente, da qualidade da resposta, clínica ou não, recebida pelo usuário. Nas entrevistas e nas observações do trabalho, os ACS compreendem a importância de morar na comunidade e de conhecê-la para o fortalecimento do vínculo: 
"[...] morar na microárea que você trabalha e conhecer a comunidade, isso facilita bastante". "[...] quando acontecer qualquer coisa ali, fala pra gente, porque às vezes alguém vem e conversa no acolhimento e, às vezes, a gente não tá sabendo daquele problema" (ACS5).

De maneira convergente com outros achados ${ }^{28,29}$, o estudo mostra que os ACS são sujeitos fundamentais para gerar uma relação de confiança e cumplicidade que se estende aos demais trabalhadores, potencializando o acolhimento, o vínculo, a responsabilização dos usuários. Eles se monstram promotores do vínculo com a comunidade.

Nas observações percebeu-se que o CD vai aos domicílios com o ACS para a marcação de consultas, considerando que assim criará vínculo e comparecerá à consulta:

"A oferta de saúde bucal se organiza através de uma lista, quando chega a vez dela de marcação, o dentista ou me dá para eu ir lá na residência marcar o dia e a hora para começar a fazer o tratamento ou o dentista vai comigo ou ele vai sozinho" (ACS4).

A literatura ${ }^{13,28}$ aponta que o CD no domicílio para atenção à saúde bucal, só faz sentido se estiver pautada em uma necessidade explícita e que os profissionais demonstram fragilidades sobre como desempenhar essa ação no território.

A forma como se organiza o trabalho na ESF convida o profissional de saúde bucal para sair do isolamento e procurar ser um profissional mais atuante no campo da saúde na busca da integralidade da atenção ${ }^{13}$ :

"A gente tenta mostrar para eles que a boca faz parte do corpo inteiro. Que não é para tratar só a boca. E aí quando a gente vai abordar a higiene bucal, a gente já fala da higiene geral. Quando as pessoas sentam na cadeira, a gente vê um piolhinho e fala 'mãe oh tem um piolhinho aqui, vamos pentear o cabelo, passa na médica e pega um shampoozinho'. 'Corta a unha do menino'. Alimentação, a gente sempre está falando para ter uma alimentação saudável. Do açúcar também, não só para prevenir a cárie mas para a diabetes na infância" (CD2).

"Eu tenho vontade de estar abordando essa questão, não só odontológica, mas na saúde mental, psicológica, toda a parte que compõe as necessidades do ser humano, em geral" (TE3).

Dentre os princípios e diretrizes do SUS, talvez a integralidade seja o que é menos visível na trajetória do sistema de saúde e de suas práticas. A integralidade é 
a compreensão ampliada das necessidades, mas principalmente a habilidade de reconhecer a adequação das ofertas ao contexto específico da situação, no qual se dá o encontro do sujeito com a equipe ${ }^{30,31}$.

Ao mesmo tempo, o estudo revelou concepções dos profissionais de saúde sobre o processo de saúde-doença que colocam o usuário como relativamente "culpado" pelos seus problemas de saúde e dificuldades de acesso aos serviços. Partem do pressuposto de que as informações educativas não se traduzem em comportamentos saudáveis por falta de interesse, de responsabilidade e de autocuidado:

"Aqui tem lista de 3 anos, porque a população é extremamente pobre, hábitos de higiene não existem, apesar de ser uma população jovem, mas que não tem aquele cuidado. Então a fila é grande porque a demanda é sempre muito grande. É uma demanda que não pára porque a população não quer mudar os hábitos. É uma população totalmente carente de informação. Eles não conseguem mudar muitas vezes o consumo de açúcar, que é muito alto" (E1)

"São encaminhados os pacientes, mas a dificuldade é eles não irem na consulta. Aí eles acabam abaixando as nossas vagas. Se mandava cinco vagas antes para fazer canal, hoje eles mandam uma ou duas. Porque nossos pacientes não vão. Então não se completa o tratamento. $E$ as radiografias às vezes tem essa dificuldade, porque a maioria das radiografias são feitas nas regionais, Asa Sul, Asa Norte, Taguatinga. Para encaminhar para periodontia, precisa de radiografia. Alguns não tem condições de fazer. Então não faz" (CD2).

Conhecer o itinerário dos usuários e as razões das "escolhas" e "possibilidades" pode ser caminho para reorientar os serviços e ampliar o acesso.

Faccin et al $(2010)^{13}$ perceberam que é essencial que os profissionais compreendam que o processo saúde-doença sofre influência de múltiplas dimensões, inerentes ao viver. Desta maneira, pode-se ampliar o processo de intervenção sobre um problema que antes estava exclusivamente sob responsabilidade do $C D$.

Para além da clínica, a prevenção de doenças e a promoção da saúde, estão entre as atribuições comuns à todos os profissionais da equipe. Para que essas se efetivem a identificação de parceiros e recursos na comunidade é preconizado como forma de potencializar as acões intersetoriais: 
"A ACS conversou com o responsável pela escolinha de futebol e explicou que queríamos fazer uma parceria, e eles adoraram, então nós não estamos fazendo nada de cima para baixo, estamos fazendo junto com os pais porque senão isso não vai dar certo" (E2).

"Então a gente foi ver o que a gente podia fazer, aí vamos fazer uma parceria com o projeto da escolinha de futebol, fazer uma união com eles e vê o que a gente pode oferecer pra eles. Então a gente viu que a gente pode oferecer o quê? As consultas de clínica médica aqui na nossa unidade de saúde e o acompanhamento odontológico que, pra muitos isso é um sonho distante porque eles lá não tem a menor chance de ter" (ACS5).

De acordo com os entrevistados, além das ações intersetoriais caracterizarem-se pela manutenção de tais práticas tradicionais, como o atendimento individual curativo, o trabalho preventivo nas escolas também destacase e a questão da vulnerabilidade mostra-se como uma dificuldade:

"Fora da unidade a gente tem o PSE, Programa Saúde na Escola. Mas assim, esse PSE é mais uma questão assim de educação da saúde, em relação a lavar as mãos, a escovar os dentes, questão de piolho, não tem essa parte de vulnerabilidade. Apesar de que a gente sabe pelos professores se a criança tem alguma vulnerabilidade, nessa parte fica até difícil de intervir" (M2).

Um avanço ainda necessário é ir além da prevenção e da cura da doença, compreender os aspectos da promoção da saúde e diagnosticar no território áreas de risco, de maior vulnerabilidade e buscar estratégias de intervenção, conhecer os determinantes e condicionantes da saúde, e identificar na comunidade outros dispositivos sociais para potencializar e promover suas ações com olhar ampliado sobre o processo saúde-doença e para a integralidade do cuidado.

Estudo realizado com dentistas ${ }^{29}$ revelou que, ao serem questionados sobre os tipos de procedimentos executados pela equipe, eles relataram que a falta de ações preventivas e de promoção de saúde se dá pela precariedade socioeconômica da população que necessita de numerosos tratamentos, e os profissionais sentem a necessidade de adequar a oferta dos serviços à realidade local para melhoria do acesso.

A presença do CD na escola para ações puramente curativas é reconhecida como uma atividade antiga, entretanto, a articulação e integração entre os profissionais da educação e da saúde é uma conquista recente que necessita de 
fortalecimento e continuidade para o planejamento e execução conjunta das ações de prevenção de doenças e promoção de saúde. No ambiente escolar, os profissionais da saúde percebem que são reconhecidos e que suas ações são valorizadas e potencializadas pelos profissionais da educação:

"Uma professora disse assim, a gente trabalhando na escola: olha! Eu gostaria que vocês trabalhassem esse tema. Então isso é importante, porque ela tá com os alunos no dia-a-dia, ela vê a necessidade dos alunos" (ACS5).

Souza \& Roncalli $(2007)^{3}$ também verificaram, em uma pesquisa com gestores e dentistas no Rio Grande do Norte, que as atividades intersetoriais mais citadas se referem às ações de educação e prevenção em saúde bucal desenvolvidas na comunidade ou nas escolas.

Para que o trabalho de educacão em saúde seja mais sensível às necessidades subjetivas e culturais dos usuários, faz-se necessário abandonar estratégias comunicacionais informativas e adotar uma comunicação dialógica, a educação popular em saúde, que valoriza os saberes, o conhecimento prévio da população e não somente o conhecimento científico ${ }^{32,33}$. Os profissionais percebem essa necessidade de agir com olhar ampliado para tocar o usuário e promover à saúde:

"Qual o tema que nós vamos falar amanhã? Ah! Nós vamos falar sobre amamentação, então ali eu ia pesquisar sobre amamentação, ver o que eu podia falar, transformar aquela linguagem para mais popular possível para as mães entenderem" (ACS5).

Mialhe et al $(2011)^{34}$ verificaram que as atividades educativas em saúde bucal são realizadas de maneira esporádica e voltadas prioritariamente às gestantes, mães e crianças, em um modelo vertical de transmissão de informações, visando mudanças de comportamentos individuais e incorporação de hábitos saudáveis.

Entretanto, as ações educativas em saúde bucal são, também, um momento para fomentar a criatividade dos profissionais de saúde e inovar na atenção e no cuidado à saúde bucal junto a outros setores da comunidade, por meio de relações horizontais entre educador e educando, além de reforçar a integração entre os profissionais da saúde e da educação:

"Não gosto de chegar na escola e ficar fazendo palestra. Cada vez que eu vou na escola eu levo alguma coisa diferente, ou é um filme, ou é um jogo, ou algo pra pintar, eu gosto disso" (CD1). 
Alguns entrevistados trouxeram outra visão sobre o trabalho de educação em saúde, mostrando a presença do pensamento hegemônico médico-centrado, em que a concepção dos usuários e a noção no trabalho cotidiano reforça o predomínio da atenção clínica:

"Sempre convidávamos outra pessoa para dar palestras, porque uma hora a gente pensou que nossas palestras iam ser interessantes né? E não vinha ninguém, aí começamos a chamar outras pessoas e não vinham. Antes de eu vir pra cá, eles já não tinham essa motivação. Eles gostam é de consulta, então às vezes isso desmotiva" (CD2).

Os profissionais percebem que há dificuldade de mobilizar a comunidade, também, para as atividades coletivas de saúde bucal na UBS e relacionam a presença do usuário à garantia de consulta clínica:

"Tem quase que implorar para entrar aqui dentro da UBS para assistir uma palestra. Só vem porque ganha consulta. Aqui nem dando escova, motiva” (CD1).

Outros profissionais percebem que é necessário um trabalho contínuo de convencimento e educação em saúde para mobilizar a comunidade:

"As pessoas, às vezes, não são tão receptivas quando a gente faz as palestras. Mas, os poucos, trazem coisas boas e são bem participativas. E eu acho que é um trabalho de formiguinha porque não é fácil mudar as pessoas” (TE4).

Estudo realizado com pais de escolares usuários $S \mathrm{~S}^{35}$, aponta para a relevância de se repensar as práticas educativas em saúde bucal como processos de promoção de saúde, que contemplem a dimensão social e política da saúde.

A rotina de trabalho das equipes de saúde da família inclui processos de conhecimento do território e da população, que se constituem em subsídios valiosos para o planejamento, monitoramento e avaliação das ações ${ }^{2,36}$. A finalidade e a importância das reuniões com a participação de todos os profissionais para o planejamento, é reconhecida pelos profissionais da equipe:

"Nós temos um período de reunião, onde toda a equipe está presente. Nessa reunião, a gente coloca o que realizou, a dificuldade que teve na semana, a gente procura respostas, procura soluções conjuntas e planeja o que podemos fazer" (ACS4).

Os profissionais identificam que para planejar é necessário realizar uma discussão conjunta e também avaliar as ações:

"Nas reuniões de equipe, é aonde nós planejamos, discutimos, avaliamos as 
ações realizadas" (E2).

Nas observações e entrevistas, constatou-se que a carga horária dos técnicos de enfermagem e técnicos de saúde bucal é diferenciada dos demais membros da equipe e afeta a organização do processo de trabalho da equipe e a atenção integral à saúde da população Um exemplo é a dificuldade que os técnicos apresentam para realizar ações conjuntas com os demais profissionais, como a participação regular das reuniões de equipe.

Entretanto, percebeu-se que há fragilidade no planejamento de algumas ações comuns da equipe que englobam a atenção à saúde bucal, como por exemplo, a criação de critérios para definição das visitas domiciliares:

"Olha, eu vou ser sincera, isso ai quem faz é o dentista. Então não sei te falar ainda o método que ele utiliza para fazer" (TSB2).

Os profissionais percebem que a periodicidade das visitas domiciliares é prejudicada devido à falta de logística para a equipe:

"Infelizmente, nem sempre nos dias das visitas a gente sai para fazer visita, o que eu não me oponho, porque nem sempre tem carro disponível" (M2).

Alguns profissionais reconhecem a importância dos levantamentos epidemiológicos para o diagnóstico do território e planejamentos das ações entretanto, recordam que o mesmo foi realizado pela equipe anterior:

"Foi feito um trabalho pela antiga equipe de odontologia para saber o porquê do índice de cárie em crianças menores de 5 anos ser tão alto, e foi constatado que pelo fato da água aqui não ser tratada e ser extraída do solo, não tem flúor" (ACS7).

Entretanto, na observação, notou-se que a equipe de saúde bucal organiza seu trabalho e planeja suas ações por meio dos resultados de levantamentos epidemiológicos. As crianças e escolares são classificados por condição de risco para atendimento clínico e também por registro em ata e divisão por microárea do ACS. Contudo, isso é realizado de forma isolada da equipe de saúde da família de maneira que essas informações não são utilizadas para o planejamento, monitoramento e avaliação de outras ações, como as de promoção da saúde.

Pimentel et al $(2010)^{36}$, de maneira divergente, concluíram no estudo realizado em Pernambuco, que os $C D$ não realizam planejamento sistemático das atividades de saúde bucal. Verificaram, também, que algumas práticas (indispensáveis para o planejamento e a organização das ações em saúde bucal), têm dificultado a obtenção de uma adequada assistência odontológica à população. 
Outros profissionais relatam o impacto nos resultados de indicadores de saúde monitorados, devido à falta de materiais permanentes e equipamentos para ações coletivas de prevenção:

“O nosso escovódromo a gente já pediu várias vezes e não fizeram. E é até um dos indicadores do PMAQ: Quantas escovações coletivas? Antes eu até contava todos que eu fazia, mas agora... E o que deu? O DF ficou com os menores índices de escovação coletiva” (CD2).

Nas observações e entrevistas, constatou-se que outros espaços, além da reunião de equipe, são utilizados para o planejamento das ações:

"A gente vai ali naquela mesinha (copa da UBS), e planeja. Aí nossa equipe planeja dizendo que vai ter alguma coisa tal dia” (ACS2).

"Geralmente é na copa, algumas coisas mais simples se conversa durante o expediente. Se for algo mais complicado se deixa para quando são realizadas as reuniões de equipe" (ACS7).

Os espaços informais nem sempre são visíveis à todos os profissionais da equipe e acabam desconsiderados nas avaliações. Na observação, percebeu-se a presença de um espaço potente para o diálogo e problematização sobre o trabalho, uma oportunidade para a produção da educação permanente, um caminho promissor para qualificação da atenção à saúde.

Falkenberg et al $(2014)^{33}$ destacam que na educação na saúde deve-se enfatizar a educação permanente, por meio de ações direcionadas à qualificação dos processos de trabalho considerando as especificidades locais e as necessidades do trabalho real. O desafio da educação permanente é estimular o desenvolvimento da consciência nos profissionais sobre o seu contexto, pela sua responsabilidade em seu processo permanente de capacitação. As observações possibilitaram visualizar que as principais ações de cursos e capacitações, notadamente para os ACS, com baixa inclusão da equipe de saúde bucal.

"[...] a maioria é voltada para médico e enfermeiro, poucos para odontologia" (TSB1).

"O que eu percebo na verdade é que, quando eles (gestão) vão fazer esses cursos de atualização é assim, chama o médico e o enfermeiro. Isso é próprio da secretaria" (M2). 
Alguns profissionais percebem momentos pontuais e isolados de educação permanente em saúde bucal, com a presença somente da área odontológica e fora da UBS:

"Uma vez ao ano todos da odontologia nos reunimos. Não existe outro movimento de saúde bucal. Abordam atendimento humanizado, procedimentos, como agir em emergência, são coisas mais básicas da odontologia, voltado para o atendimento humanizado mesmo" (TSB1).

Os profissionais questionam a demora de ofertas mas, elogiam os cursos que participaram:

"Da odonto demora muito pra ter. Mas teve um curso de farmacologia que foi muito legal. Fizeram um congresso de odontopediatria em outubro do ano passado, foi muito bom" (CD1).

Os profissionais técnicos também demonstram que estão distantes e esquecidos dos processos formativos:

"Eu sinto falta dessas capacitações. Porque eu acho que seria interessante, conseguiríamos nos aprofundar, aprender mais" (TSB1).

Por outro lado, nos registros de reunião de equipe, os profissionais relatam que experiências de aproximação com instituições de ensino os fortalecem e propiciam transformações nas suas práticas, bem como motivam o crescimento da equipe. Um exemplo disso é a parceria com estudantes de graduação de enfermagem para auxílio nas atividades do PSE.

As condicões de trabalho nem sempre são adequadas. Os profissionais enfrentam, às vezes, dificuldades devido à falta de materiais e de apoio dos gestores:

"Um apoio maior da gestão com relação as pequenas coisas, às vezes, a falta de material ou, às vezes, a falta até de apoio mesmo, de respaldo que você não tem" (ACS5).

Contudo, na análise documental percebeu-se que os gestores reconhecem o trabalho da equipe e o seu desempenho no $1^{\circ}$ ciclo do PMAQ, participam de algumas reuniões de equipe e enfatizam a conquista de novas tecnologias, como o matriciamento e a ferramenta do telessaúde para a ampliação das ações e qualificação da equipe assim como, para fomentar possíveis avanços na organização e nas condições de trabalho.

Os profissionais percebem que as dificuldades em relação às condições de 
trabalho são comuns à outras equipes de saúde bucal e que procedimentos assistenciais são prejudicados pela falta de equipamentos:

"As extrações ficam para as equipes e nenhum dentista está querendo fazer extração, porque todo mundo alega que não tem uma bomba à vácuo; os consultórios não estão preparados” (CD1).

Os profissionais procuram alternativas e outras estratégias para tentar enfrentar a falta de materiais e evitar problemas durante os atendimentos clínicos:

"A dificuldade maior que eu tenho no atendimento é em questão do material mesmo. Às vezes a gente pede e não vem. Mas a gente vai dando um jeito com o que tem" (TSB2).

$\mathrm{Na}$ análise documental, identificou-se a insatisfação dos profissionais por não receberem nenhum tipo de gratificação profissional referente ao incentivo financeiro do PMAQ, pela falta de transparência da gestão quanto a utilização dos recursos financeiros do referido programa e, pela ausência de melhorias nas condições de trabalho na UBS.

Os profissionais ao assumirem a responsabilidade por todos os problemas de saúde da população de um determinado espaço geográfico, percebem por meio da adesão da equipe ao PMAQ uma estratégia para a redefinição do território de abrangência e da população adscrita, possibilitando melhorias na organização do processo de trabalho:

"A gente participa do $P M A Q$, graças a Deus, porque pelo menos a nossa área de abrangência diminuiu. Porque antes eu tinha mais de 10 mil pessoas em cima de mim, e isso é humanamente impossível, e agora que a gente tá conseguindo se organizar melhor" (CD1).

Outro estudos ${ }^{37,38,39}$, também apontaram avanços, apesar das dificuldades, como a delimitação da clientela, possibilitando melhor acompanhamento pela equipe de saúde bucal e a cobertura populacional de acordo com o mínimo estipulado pelo Ministério da Saúde.

A participação popular e o controle social no setor saúde constituem-se em princípios fundamentais para a melhoria da qualidade de vida da sociedade ${ }^{35}$. Dentre as ações comuns aos profissionais da saúde da família está a promoção à mobilização e participação da comunidade para a efetivação do controle social ${ }^{6}$.

"O presidente da associação de moradores é muito ativo quanto a essa questão, e ele procura participar, mesmo ele não sendo membro do conselho, mas 
ele participa de algumas reuniões. Então ele sempre traz para a gente alguma informação e a gente sempre tem essa troca de experiência com ele" (ACS5).

Outros profissionais percebem que existe um distanciamento com a comunidade, falta de estímulo e de disponibilidade deles para a mobilização da população para o controle social:

"Com a comunidade a gente nunca teve uma parceria, de chamar a comunidade, tipo: há nós vamos fazer um evento, e o que vocês acham da gente fazer isso? Vocês podem ajudar com que? A gente nunca teve” (ACS4).

"Já recebi vários convites para participar pois, acho que se a pessoa assumir algo assim ela tem que assumir com responsabilidade, e eu não me vejo com tempo e responsabilidade para assumir algo assim" (ACS3).

Entretanto, percebe-se o estímulo dos gestores, nos registros em atas das reuniões de equipe, para a participação dos profissionais no Conselho Local de Saúde e mobilização para divulgação à comunidade.

Pezatto et al $(2013)^{40}$ ressaltam que a apropriação dos temas da saúde bucal pelos espaços do controle social é um dos principais desafios para a efetiva implementação dos serviços de saúde bucal no SUS.

\section{Considerações finais}

No trabalho em saúde bucal na ESF houve predomínio das características do modelo biomédico hegemônico, com ênfase nas ações curativas individuais, que convivem com características do modelo preconizado pelas políticas.

O presente estudo aponta fortalezas e fragilidades presentes no trabalho cotidiano das equipes, ora revelando a integração, ora revelando a fragmentação. Para avanços no trabalho em saúde bucal na ESF e uma atuação integrada de toda a equipe, faz-se necessário que os profissionais busquem a troca de conhecimentos, reconheçam as habilidades e competências de cada membro e tenham atitudes para a construção coletiva de intervenções. Os valores e a forma como cada profissional compreende as normas orienta suas escolhas e a maneira de agir, com consequências no trabalho coletivo.

O trabalho não se resume a adequação às prescrições, entretanto, quando falamos do trabalho em saúde também falamos do modo como são operacionalizadas as políticas de saúde. As formas de organização e gestão do trabalho na ESF são orientadas pelas prescrições institucionais que são 
permanentemente renormalizadas pelos sujeitos do trabalho. Este estudo procurou ir além das prescrições, procurou falar de quem trabalha, em como trabalha e em quais condições.

O estudo evidenciou que o trabalho em saúde bucal na ESF para se efetivar na perspectiva da integração, da integralidade e ser mais resolutivo, depende da postura e atitudes dos profissionais, de conhecimento das habilidades e competências, envolvendo a subjetividade e intersubjetividade de todos atores envolvidos (profissionais, gestores, usuários). Para compreender o trabalho na ESF, os atores precisam investir em momentos de educação permanente e se debruçar e refletir sobre o que impede ou faz o trabalho acontecer e buscar pactuações $e$ ajustes de acordo com as necessidades locais.

Os profissionais trabalham em meio a prescrições que apresentam contradições que limitam a atuação integrada da equipe de saúde bucal com a da saúde da família: de um lado são prescritas atribuições comuns a todos os profissionais das equipes e ao mesmo tempo eles constituem duas equipes distintas, ou seja, segundo as normativas os profissionais de saúde bucal não compõem a equipe de saúde da família, podendo ser incluídos ou não segundo a decisão dos gestores locais.

Conclui-se que a integração da saúde bucal na equipe de saúde da família é incipiente, limitada por conflitos de normas e pela forma com que se organiza o trabalho na ESF no contexto estudado e devido às condições de trabalho, falta de materiais e equipamentos para a atenção à saúde com qualidade e resolutividade. Trata-se de uma difícil integração. Difícil porque não conseguiu ampliar as condições para a superação do modelo biomédico hegemônico e efetivar o trabalho integrado em equipe, por meio do reconhecimento e inclusão dos profissionais de saúde bucal para constituir a equipe de saúde da família.

\section{Colaboradores}

C. I. Scherer elaborou o projeto, desenvolveu a pesquisa e análise dos dados e elaborou o texto do artigo e M. D. A. Scherer contribuiu na concepção do projeto, orientou o estudo e revisou o artigo. 


\section{Agradecimentos}

Nossos agradecimentos aos gestores da Secretaria de Saúde que permitiram a nossa pesquisa e principalmente ao acolhimento que a pesquisadora responsável recebeu das equipes de Saúde da Família e de Saúde Bucal do Distrito Federal, Brasil.

\section{Referências}

1. Mendonça, CS. Sistema Único de Saúde: um sistema de saúde orientado pela Atenção Primária. In: Organização Pan-americana da Saúde. Inovando o papel da Atenção Primária nas Redes de Atenção à Saúde: resultados do laboratório de inovação em quatro capitais brasileiras. Brasília: Organização Pan-Americana da Saúde, 2011. p. 23-36.

2. Brasil. Ministério da Saúde. Secretaria de Atenção à Saúde, Departamento de Atenção Básica. Saúde Bucal: Cadernos de Atenção Básica, n. 17. Brasília: Ministério da Saúde, 2006. 92p.

3. Souza TM, Roncalli AG. Saúde bucal no Programa Saúde da Família: uma avaliação do modelo assistencial. Cad Saude Publica. 2007;23(11):2727-39.

4. Martelli PJL, Macedo CLSV, Medeiros KR, Silva SF, Cabral APS, Pimentel FC, et al. Perfil do cirurgião-dentista inserido na Estratégia de Saúde da Família em municípios do estado de Pernambuco, Brasil. Cienc Saude Coletiva. 2010; 15(Suppl 2):3243-48. DOI:10.1590/S141381232010000800029

5. Silva SF, Martelli PJL, Sá DA, Cabral AP, Pimentel FC, Monteiro IS, et al. Análise do avanço das equipes de saúde bucal inseridas na Estratégia Saúde da Família em Pernambuco, região Nordeste, Brasil, 2002 a 2005. Cienc Saude Coletiva. 2011;16(1):211-20. DOI:10.1590/S1413-81232011000100024

6. Brasil. Ministério da Saúde. Portaria oㅡ 2.488, de 21 de dezembro de 2011. Aprova a Política Nacional de Atenção Básica, estabelecendo a revisão de diretrizes e normas para a organização da Atenção Básica, para a Estratégia Saúde da Família (ESF) e o Programa de Agentes Comunitários de Saúde (PACS). Diário Oficial da União, Brasília, 24 de outubro de 2011.

7. Pimentel FC, Albuquerque PC, Martelli PJL, Souza WV, Acioli RML. Caracterização do processo de trabalho das equipes de saúde bucal em municípios do Estado de Pernambuco, Brasil, de acordo com o tamanho da população: a partir de links da comunidade para a organização dos cuidados clínicos. Cad Saude Publica. 2012; 28(Suppl):S146-S157. DOI:10.1590/S0102-311X2012001300015

8. Brasil. Ministério da Saúde. Portaria no 1.444 de 28 de dezembro de 2000. Estabelece incentivo financeiro para a reorganização da atenção à saúde bucal prestada nos municípios por meio do Programa de Saúde da Família. Diário Oficial da União 2000; 29 dez. 
9. Rodrigues AAAO, Nascimento MAA, Fonsêca GS, Siqueira DVS. Saúde bucal na estratégia saúde da família em um município do semiárido baiano. Rev Baiana Saude Publica. 2011;35(3):695-709.

10.Brasil. Ministério da Saúde. Departamento de Monitoramento e Avaliação. Sala de Apoio à Gestão Estratégica. Redes e Programas. [Online]. Brasília: Ministério da Saúde. 2014; [citado em 2014 Out 3]. Disponível em: http://189.28.128.178/sage/

11.Brasil. Ministério da Saúde. Diretrizes da Política Nacional de Saúde Bucal. Ministério da Saúde: Brasília, 2004.

12. Cericato GO, Garbin D, Fernandes APS. A inserção do cirurgião-dentista no PSF: uma revisão crítica sobre as ações e os métodos de avaliação das Equipes de Saúde Bucal. RFO. 2007; 12(3):18-23.

13. Faccin D, Sebold R, Carcereri, DL. Processo de trabalho em saúde bucal: em busca de diferentes olhares para compreender e transformar a realidade. Cienc Saude Coletiva. 2010; 15(1):1643-52. DOI: 10.1590/S141381232010000700076

14. Lucena EHG, Pucca JR GA, Sousa MF. A Política Nacional de Saúde Bucal no Brasil no contexto do Sistema Único de Saúde. Revista Tempus Actas de Saude Coletiva. 2011;5(3):53-63.

15. Nascimento AC, Moysés ST, Bisinelli JC e Moysés SJ. Oral health in the family health strategy: a change of practices or semantics diversionism. Rev Saude Publica. 2009;43(3):455-62. DOI:10.1590/S0034-89102009005000015

16. Moura MS, Ferro FEFD, Cunha NL, Nétto OBS, Lima MDM, Moura LFAD. Saúde bucal na estratégia de saúde da família em um colegiado gestor regional do estado do Piauí. Cienc Saude Coletiva. 2013;18(2):471-80. DOI:10.1590/S1413-81232013000200018

17.Secretaria de Estado da Saúde do Distrito Federal. Plano Distrital de Saúde 2012 a 2015. [Internet]. Brasília: Secretaria de Estado da Saúde do Distrito Federal; 2012 Jun; [citado em 2014 Out 3]. Disponível em: http://www.saude.df.gov.br/images/Conselho\%20de\%20Saude\%20do\%20DF/ planodesaude_2012_2015\%201.pdf

18. Sistema de Nota Técnica do DAB. [Internet]. Brasília: Ministério da Saúde. 2014 Set [citado em 2014 Set 15]. Disponível em: http://dab2.saude.gov.br/dab/sistemas/notatecnica/frmListaMunic.php

19. Minayo MCS. O desafio do conhecimento: pesquisa qualitativa em saúde. $12^{\mathrm{a}}$ ed. São Paulo: Hucitec, 2010. 407p.

20.Triviños ANS. Introdução à pesquisa em ciências sociais: a pesquisa qualitativa em educação. São Paulo: Atlas; 1987. 175p.

21.Durrive L. A atividade humana, simultaneamente intelectual e vital: esclarecimentos complementares de Pierre Pastré e Yves Scwartz. Trab Educ Saúde. 2011; 9(supl. 1): 47-67.

22.Schwartz, Y. Le paradigme ergologique ou un métier de philosophe. Octares editions, 2000, 763p. 
23.Schwartz, Y. (Org.). Reconnaissances du travail: pour une approche ergologique. 2. Ed. Paris: PUF, 1998.

24. Lourenço EC, Silva ACB, Meneghin MC, Pereira AC. A inserção dos serviços de saúde bucal no Programa Saúde da Família no Estado de Minas Gerais. Cienc Saude Coletiva. 2009;14(Suppl. 1):1367-77. DOI:10.1590/S141381232009000800009

25.Nuto SAS, Oliveira GC, Andrade JV, Maia MCG. O acolhimento em saúde bucal na estratégia de saúde da família, Fortaleza-CE: um relato de experiência. Rev APS. 2010;13(4):505-9.

26. Chanlat JF. Quelles sont les conditions de la production commune dans les organizations? Soin Cadres - la Revue de L'encadrement et de la formation, no 49 revue trimestrale, 2004. p. 18-21.

27. Ramos DD, Lima MADS. Acesso e acolhimento aos usuários em uma unidade de saúde de Porto Alegre, Rio Grande do Sul, Brasil. Cad Saúde Pública. 2003, 19(1):27-34.

28. Santos AM, Assis MMA, Nascimento MAA, Jorge MSB. Vínculo e autonomia na prática de saúde bucal no Programa Saúde da Família. Rev Saúde Publica. 2008;42(3):464-70.

29. Baldani MH, Fadel CB, Possamai T, Queiroz MGS. Inclusão de serviços de saúde bucal no Programa Saúde da Família no Estado do Paraná. Cad Saude Publica. 2005;21(4):1026-35. DOI:10.1590/S141381232009000800009

30. Mattos RA. A integralidade na prática (ou sobre a prática da integralidade). Cad Saude Publica. 2004; 20(5):1411-16.

31. Mattioni FC, Budo MLD, Schimith MD. O exercício da integralidade em uma equipe da estratégia saúde da família: saberes e práticas. Enferm. 2011; 20(2):263-71.

32. Alves VS. Um modelo de educação em saúde para o Programa Saúde da Família: pela integralidade da atenção e reorientação do modelo assistencial. Interface (Botucatu). 2005; 9(16):36-48.

33. Falkenberg MB, Mendes TPL, Moraes EP, Souza, EM. Educação em saúde e educação na saúde: conceitos e implicações para a saúde coletiva. Cienc Saude Coletiva. 2014; 19(3):847-52.

34. Mialhe FL, Lefèvre $F$, Lefèvre AMC. O agente comunitário de saúde e suas práticas educativas em saúde bucal: uma avaliação qualiquantitativa. Cienc Saude Coletiva. 2011;16(11):4425-32. DOI:10.1590/S141381232011001200015

35. Silveira JLG, Campos ML, Berndt RLE. Educação em saúde como estratégia para o controle social em saúde bucal. Pesq Bras Odontoped Clin Integr. 2006; 6(1):29-34.

36. Pimentel FC, et al. Análise da atenção à saúde bucal na Estratégia de Saúde da Família do Distrito Sanitário VI, Recife (PE). Cienc Saude Coletiva. 2010;15(4):2189-96. DOI:10.1590/S1413-81232010000400033 
37.Emmi DT, Barroso RF. Avaliação das ações de saúde bucal no Programa Saúde da Família no distrito de Mosqueiro, Pará. Cienc Saude Coletiva. 2008;13(1):35-41. DOI:10.1590/S1413-81232008000100008

38. Pimentel FC, Martelli PJL, Araújo Jr JLAC, Lima AS, Santana VGD, Macedo CLSV. Evolução da assistência em saúde bucal na estratégia de saúde da família do município do Recife (PE) no período de 2001 a 2007. Rev Baiana Saude Publica. 2008;32(2): 253-64

39. Silva SF, Martelli PJL, Sá DA, Cabral AP, Pimentel FC, Monteiro IS, et al. Análise do avanço das equipes de saúde bucal inseridas na Estratégia Saúde da Família em Pernambuco, região Nordeste, Brasil, 2002 a 2005. Cienc Saude Coletiva. 2011;16(1):211-20. DOI:10.1590/S1413-81232011000100024

40.Pezzato LM, L'Abbate S, Botazzo C. A produção de micropolíticas no processo de trabalho em saúde bucal: uma abordagem sócio-analítica. Cienc Saude Coletiva. 2013;18(7):2095-2104. DOI:10.1590/S141381232013000700025 


\section{CONCLUSÃO}

O escopo da presente dissertação de mestrado foi analisar o trabalho em saúde bucal na ESF à luz de políticas públicas nacionais após uma década de Programa Brasil Sorridente. Para se alcançar esse objetivo, realizaram-se dois estudos, os quais foram apresentados nos resultados e discussão.

A revisão da literatura apontou que, após uma década de implantação do Brasil Sorridente, os principais problemas e dificuldades no trabalho das equipes de saúde bucal não são exclusivos da odontologia, mas acompanham a realidade do trabalho das equipes da ESF como um todo. Os avanços evidenciados concentramse nas ações educativas; nas ações de educação permanente; no acolhimento, vínculo e responsabilização. Os principais desafios foram relacionados à: integralidade; ampliação e qualificação da assistência; trabalho integrado em equipe; condições de trabalho; planejamento, monitoramento e avaliação das ações; estimulo à participação popular e ao controle social; e, ações intersetoriais.

Dentre as possibilidades para que haja substituição das práticas tradicionais exercidas e um novo jeito de se fazer saúde, está a de ampliar o engajamento dos gestores e dos profissionais num processo de compreensão da dinâmica do trabalho e da formação, na perspectiva de construir mudanças significativas para as realidades locais, por meio de esforços continuados no campo da gestão do trabalho, da formação e da educação permanente.

No Distrito Federal, os resultados mostram-se semelhantes à revisão de literatura. No trabalho em saúde bucal na ESF predominam características do modelo biomédico hegemônico com ênfase nas ações curativas individuais que convivem com características do modelo preconizado pelas políticas, entretanto, com integração dos profissionais da saúde bucal nas reuniões de equipe, nas visitas domiciliares, nas ações intersetoriais e de educação em saúde.

O trabalho em saúde bucal na ESF para se efetivar na perspectiva da integração, da integralidade e ser mais resolutivo, depende da postura e atitudes dos profissionais, de conhecimento das habilidades e competências, envolvendo a subjetividade e intersubjetividade de todos atores envolvidos (profissionais, gestores, usuários). Para compreender o trabalho na ESF, os atores precisam investir em momentos de educação permanente e se debruçar e refletir sobre o que impede ou 
faz o trabalho acontecer e buscar pactuações e ajustes de acordo com as necessidades locais.

A realização da presente dissertação de mestrado permitiu conhecer 0 trabalho em saúde bucal na ESF para além das normatizações e perceber que as normas não são suficientes para superar o desafio de reorientação do processo de trabalho dos profissionais de saúde de acordo com os princípios do SUS. Contudo, essas normas são necessárias para os sujeitos do trabalho que, permanentemente, as renormalizam para atender as necessidades do trabalho e, de valores, que irão estabelecer a capacidade de agir dos trabalhadores e de dar respostas as necessidades de saúde da população.

O trabalho é resultado de um debate de normas e valores que determinam a capacidade do profissional atuar integrado com toda a equipe. Ou seja, a atividade humana como um entrecruzamento de normas antecedentes (as prescrições, procedimentos, contraintes, relações de autoridade, de poder, mas também os saberes científicos, técnicos, as regras jurídicas, as experiências acumuladas, tudo que antecipa a atividade de trabalho), e de tentativas de renormalização, na relação com o meio de vida, onde ocorre um debate permanente de valores que resultam em escolhas feitas pelos indivíduos e pelos grupos.

Neste contexto, a integração da saúde bucal na equipe de saúde da família é incipiente e limitada por conflitos de normas: de um lado uma normativa institui o campo comum de atribuições, e de outro, a que institui duas equipes distintas. Assim, no campo comum de atribuições estão as ações que dependem do comprometimento dos profissionais para um trabalho integrado em equipe, entretanto, a norma institui uma equipe de saúde da família e uma equipe de saúde bucal, ou seja, os profissionais de saúde bucal ainda não compõem a equipe mínima de saúde da família, são equipes distintas com o desafio da integração. Uma difícil integração porque não conseguiu ampliar as condições para a superação de fato do modelo biomédico hegemônico e efetivar o trabalho integrado em equipe, por meio da compreensão do trabalho e do reconhecimento e inclusão dos profissionais de saúde bucal para constituir a equipe de Saúde da Família. 


\section{REFERÊNCIAS}

1. Starfield B. Atenção Primária: equilíbrio entre necessidades de saúde, serviços e tecnologia. Brasília: UNESCO, Ministério da Saúde, 2002.

2. Sousa MF. A reconstrução da saúde da família no Brasil: diversidade e incompletude. In: Souza MF, Franco MS, Mendonça AVM. Saúde da família nos municípios brasileiros: os reflexos dos 20 anos do espelho do futuro. Campinas, SP: Saberes Editora, 2014. p. 521-71.

3. OMS - Organização Mundial de Saúde. Relatório Mundial da Saúde 2008: Cuidados de Saúde Primários - Agora mais que nunca. [Online]. Genebra: OMS, 2008. [citado em 2014 Out 5] Disponível em: http://www.who.int/whr/2008/whr08_pr.pdf

4. Brasil. Ministério da Saúde. Portaria № 2.488, de 21 de dezembro de 2011. Aprova a Política Nacional de Atenção Básica, estabelecendo a revisão de diretrizes e normas para a organização da Atenção Básica, para a Estratégia Saúde da Família (ESF) e o Programa de Agentes Comunitários de Saúde (PACS). Diário Oficial da União, Brasília, 24 de outubro de 2011.

5. Pereira CRS, Patrício AAR, Araújo FAC, Lucena EES, Lima KC, Roncalli AG. Impacto da Estratégia Saúde da Família com equipe de saúde bucal sobre a utilização de serviços odontológicos. Cad. Saúde Pública. 2009; 25(5): 98596.

6. Brasil. Ministério da Saúde. Secretaria de Atenção à Saúde, Departamento de Atenção Básica. Saúde Bucal: Cadernos de Atenção Básica, n. 17. Brasília: Ministério da Saúde, 2006. 92p.

7. Brasil. Ministério da Saúde. Portaria no 1.444 de 28 de dezembro de 2000. Estabelece incentivo financeiro para a reorganização da atenção à saúde bucal prestada nos municípios por meio do Programa de Saúde da Família. Diário Oficial da União 2000; 29 dez.

8. Lourenço EC, Silva ACB, Meneghin MC, Pereira AC. A inserção dos serviços de saúde bucal no Programa Saúde da Família no Estado de Minas Gerais. Cienc Saude Coletiva. 2009;14(Suppl. 1):1367-77. 
9. Brasil. Ministério da Saúde. Diretrizes da Política Nacional de Saúde Bucal. Ministério da Saúde: Brasília, 2004.

10.Faccin D, Sebold R, Carcereri, DL. Processo de trabalho em saúde bucal: em busca de diferentes olhares para compreender e transformar a realidade. Cienc Saude Coletiva. 2010; 15(1):1643-52.

11.Souza TM, Roncalli AG. Saúde bucal no Programa Saúde da Família: uma avaliação do modelo assistencial. Cad Saude Publica. 2007;23(11):2727-39.

12.Sousa MF, Hamann EM. Programa Saúde da Família no Brasil: uma agenda incompleta? Ciência \& Saúde Coletiva, 14(Supl.1):1325-1335, 2009.

13.Scherer MDA, Pires DEP, Sorrato J. O trabalho na estratégia saúde da família. In: Souza MF, Franco MS, Mendonça AVM. Saúde da família nos municípios brasileiros: os reflexos dos 20 anos do espelho do futuro. Campinas, SP: Saberes Editora, 2014. p. 521-71.

14. Chanlat JF. Quelles sont les conditions de la production commune dans les organizations? Soin Cadres - la Revue de L'encadrement et de la formation, no 49 revue trimestrale, 2004. p. 18-21.

15.Schwartz Y. (Org.). Reconnaissances du travail: pour une approche ergologique. 2. Ed. Paris: PUF, 1998.

16.Peduzzi MP, Schraiber LM. Processo de Trabalho em Saúde. Dicionário da educação profissional em saúde / Isabel Brasil Pereira e Júlio César França Lima. 2.ed. rev. ampl. Rio de Janeiro: EPSJV, 2008. 478 p.

17.Pires DEP. Reestruturação produtiva e trabalho em saúde no Brasil. 2. ed. São Paulo: Anna Blume, 2008.

18. Scherer MDA, Pires DEP, Schwartz Y. Trabalho coletivo: um desafio para a gestão em saúde. Rev Saude Publica. 2009; 43(4):721-25.

19.Scherer MDA, Pires DEP, Jean R. A construção da interdisciplinaridade no trabalho da Equipe Saúde da Família. Cienc saúde coletiva. 2013; 18(11):3203-12.

20.Secretaria de Estado da Saúde do Distrito Federal. Plano Distrital de Saúde 2012 a 2015. [Internet]. Brasília: Secretaria de Estado da Saúde do Distrito 
Federal; 2012 Jun; [citado em 2014 Out 3]. Disponível em: http://www.saude.df.gov.br/images/Conselho\%20de\%20Saude\%20do\%20DF/ planodesaude_2012_2015\%201.pdf

21.Secretaria de Meio Ambiente e Recursos Hídricos do Distrito Federal. Regiões administrativas do Distrito Federal. [mapa]. Brasília: Secretaria de Meio Ambiente e Recursos Hídricos do Distrito Federal; 2014; [citado em 2014 Out 3]. Disponível em: http://www.semarh.df.gov.br/qualiar/mapa.html

22. Sistema de Nota Técnica do DAB. [Internet]. Brasília: Ministério da Saúde. 2014 Set [citado em 2014 Set 15]. Disponível em: http://dab2.saude.gov.br/dab/sistemas/notatecnica/frmListaMunic.php

23. Minayo MCS. Análise qualitativa: teoria, passos e fidedignidade. Cienc Saude Coletiva. 2012; 17(3):621-26.

24. Triviños ANS. Introdução à pesquisa em ciências sociais: a pesquisa qualitativa em educação. São Paulo: Atlas; 1987. 175p. 


\title{
APÊNDICE A - ROTEIRO DA ANÁLISE DOCUMENTAL
}

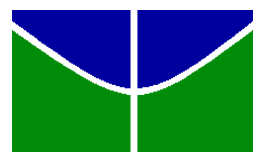 \\ UNIVERSIDADE DE BRASÍLIA \\ FACULDADE DE CIÊNCIAS DA SAÚDE \\ PROGRAMA DE PÓS-GRADUAÇÃO EM SAÚDE COLETIVA \\ ROTEIRO DA ANÁLISE DOCUMENTAL
}

Documentos orientadores:

Política Nacional de Atenção Básica (PNAB);

Diretrizes da Política Nacional de Saúde Bucal; e,

Caderno de Atenção Básica no 17: Saúde Bucal do Ministério da Saúde.

Documentos para a análise documental:

Registros diários de atividades;

Atas de reunião da equipe e sobre as atividades que incluem a equipe de saúde bucal;

Dados a serem identificados na análise documental (ter como base as categorias analíticas prévias):

Ações de saúde bucal desenvolvidas no trabalho em saúde bucal na ESF; e, Como a equipe de saúde bucal se integra à equipe de saúde da família. 


\title{
APÊNDICE B - ROTEIRO DA OBSERVAÇÃO PARTICIPANTE
}

\author{
$\checkmark$ \\ UNIVERSIDADE DE BRASÍLIA \\ FACULDADE DE CIÊNCIAS DA SAÚDE \\ PROGRAMA DE PÓS-GRADUAÇÃO EM SAÚDE COLETIVA
}

ROTEIRO DA OBSERVAÇÃO PARTICIPANTE

Acompanhar a rotina geral das equipes de Saúde Bucal e anotar em um diário de campo.

\section{Lembretes}

Partir da observação com a ESB;

Relatar toda a observação ao final do dia em documento Word para após inserir no Atlas Ti;

Correlacionar o que a PNAB e PNSB traz e o que está na Lei do exercício profissional;

* Anotar a ação realizada (tipo e descrição), quem da equipe participa e o que cada um faz.

A observação das atividades de rotina deve ser feita com foco:

Na composição da equipe;

No processo de trabalho (a atividade em si e as atividades voltadas para a promoção da saúde; os instrumentos de trabalho utilizados; como o trabalho é realizado; como o trabalho é dividido na equipe de saúde e dentro de cada profissão; tomada de decisão, entre outros);

* No fluxo da assistência (livre demanda, demanda organizada, de que forma UBS é acessada) e serviços ofertados pela unidade e pela Rede de Atenção à Saúde (CEO, NASF, entre outros);

* Na organização da UBS (horário de funcionamento, horário de chegada e saída dos profissionais, agenda de marcação de consultas da saúde bucal como é feita, se articula com outras agendas, onde fica -, como é o prontuário - é eletrônico; UBS é informatizada -, Existe acolhimento, Visita domiciliar, Interconsulta/consulta compartilhada, entre outros);

* Na existência de reuniões da equipe, da UBS; de espaços para planejamento das ações;

Nas relações interpessoais (profissionais $x$ profissionais; profissionais $x$ usuários; profissionais $x$ gestores); Como é a relação da coordenação da UBS com a equipe; Elementos de cooperação entre os profissionais; relações de poder e conflito;

* Nas atividades diárias de cada um dos profissionais da ESF (como o profissional lida no cotidiano com o inusitado);

* Nas manifestações (verbais e não verbais que revelam satisfação e insatisfação);

$\mathrm{Na}$ Infraestrutura (da UBS e equipamentos). 


\title{
APÊNDICE C - ROTEIRO DE ENTREVISTA SEMIESTRUTURADA COM PROFISSIONAIS
}

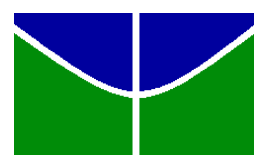 \\ UNIVERSIDADE DE BRASÍLIA \\ FACULDADE DE CIÊNCIAS DA SAÚDE \\ PROGRAMA DE PÓS-GRADUAÇÃO EM SAÚDE COLETIVA
}

ROTEIRO DE ENTREVISTA SEMIESTRUTURADA (a ser aplicada aos profissionais de saúde das Equipes de Saúde Bucal - ESB)

\section{Parte I - IDENTIFICAÇÃO DO SUJEITO}

1. Identificação/codinome:

2. Idade:

3. Sexo:

4. Fale da sua trajetória profissional (onde estudou, sua formação/escolaridade, profissão e qualificação profissional, escolhas, motivações e justificativas).

6. Fale sobre o seu tempo de experiência profissional (na profissão, na Atenção Primária à Saúde/Saúde da Família e na ESB).

Parte II - ENTREVISTA

Pense sobre o seu trabalho cotidiano, sobre o que acontece habitualmente em um dia de trabalho para responder as questões abaixo.

1. Motivação para trabalhar na Atenção Primária à Saúde (Por que você está trabalhando na Saúde da Família?).

2. Como é para você trabalhar na Saúde da Família?

3. Como é o seu dia de trabalho? (Me dê exemplos, me explique. Todo dia é igual, o que acontece de novo, como lida com o imprevisto).

4. Como é seu trabalho com a equipe de saúde bucal?

5. Quais ações de saúde bucal você realiza?

6. Como se organiza a atenção à saúde bucal na UBS? (quem, como, quando, como é feita a marcação).

7. Quais ações de promoção da saúde você desenvolve?

7.1 Você desenvolve estas ações com quem?

7.2 Em quais espaços?

8. Existem ações específicas de promoção de saúde bucal? Você desenvolve estas ações com quem? Em quais espaços?

8. 1 Como se dá a articulação com o Centro de Especialidades Odontológicas (CEO)?

8. 2 Como se dá a articulação com o Núcleo de Apoio à Saúde da Família (NASF)?

8. 3 Que ações são realizadas em parceria com outras organizações públicas e privadas (como por exemplo: igreja, escola, universidade, empresas, Organizações Não Governamentais - ONGs.)?

9. Como essas ações são planejadas? (quem planeja, quando, como, para quem, buscar, como são tomadas as decisões, quem participa da execução).

10. Como se dá a participação da comunidade nas ações desenvolvidas pela Unidade Básica de Saúde (UBS)?

11. De que ações de capacitação voltadas para a Promoção da Saúde você participou?

12. Quais as principais facilidades e dificuldades para a realização de ações de promoção de saúde? 


\title{
APÊNDICE D - TERMO DE CONSENTIMENTO INFORMADO PARA ENTREVISTA DOS PROFISSIONAIS DAS EQUIPES DA ESTRATÉGIA SAÚDE DA FAMÍLIA
}

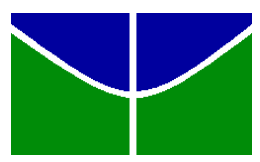 \\ UNIVERSIDADE DE BRASÍLIA \\ FACULDADE DE CIÊNCIAS DA SAÚDE \\ PROGRAMA DE PÓS-GRADUAÇÃO EM SAÚDE COLETIVA
}

O Sr.(a) está sendo convidado (a) para participar da pesquisa intitulada 'Estratégia Saúde da Família - Inovação Tecnológica para Ampliação do Acesso, da Qualidade e Promoção de Saúde Bucal na Atenção Básica - Estudo Multicêntrico", desenvolvida pelo Departamento de Saúde Coletiva da Faculdade de Ciências da Saúde da Universidade de Brasília que está pesquisando as formas de organização do processo de trabalho e as ações de promoção da saúde bucal das equipes da Estratégia Saúde da Família, a fim de melhorar a qualidade dos serviços ofertados e facilitar o acesso.

Assumo o compromisso de que toda a informação que o Sr.(a) irá me fornecer permanecerá estritamente confidencial. O seu nome não aparecerá em nenhuma parte do relatório ou investigação ou qualquer outro documento que possa ser produzido a partir dela como artigos ou relatórios. Os dados publicados serão apresentados de forma que seu nome jamais será identificado. Asseguramos que a pesquisa não apresenta qualquer tipo de risco ou constrangimento para você.

Sua participação nessa pesquisa consistirá em conceder uma entrevista sobre a organização do processo de trabalho da sua equipe/UBS e a sua atuação profissional e é de fundamental importância para gerar informações capazes de resultar na melhoria da qualidade do cuidado prestado aos usuários do Sistema Único de Saúde. Porém, ela é inteiramente voluntária. Caso, o Sr.(a) esteja de acordo, a entrevista poderá ser gravada para transcrição posterior, visando facilitar o processamento do material. A qualquer momento você poderá desistir de continuar a entrevista e só responderá as perguntas que desejar, podendo, inclusive, solicitar interrupção da gravação sem nenhum prejuízo da relação com o pesquisador.

Todo o material de pesquisa ficará sob a guarda do pesquisador e será mantido e arquivado no prazo recomendado pelo comitê de Ética em Pesquisa.

Assinatura pesquisadora

Declaro estar ciente de que entendo os objetivos e condições de participação na pesquisa 'Estratégia Saúde da Família - Inovação Tecnológica para Ampliação do Acesso, da Qualidade e Promoção de Saúde Bucal na Atenção Básica - Estudo Multicêntrico", desenvolvida pelo Departamento de Saúde Coletiva da Faculdade de Ciências da Saúde da Universidade de Brasília e aceito dela participar. 


\title{
ANEXO A - APROVAÇÃO NO COMITÊ DE ÉTICA EM PESQUISA DA UNB
}

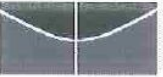 \\ Universidade de Brasilia \\ Faculdade de Ciências da Saúde \\ Comitê de Ética em Pesquisa - CEP/FS \\ DECLARAĊ̃̃O DE APROVACÃO DE PROTOCOLO DE PESOUISA
}

Título do Projeto: "ESTRATÉGIA SAÚDE DA FAMÍLIA - INOVAÇÃO

TECNOLÓGICA PARA AMPLIAÇĀO DO ACESSO, DA QUALIDADE E

PROMOÇĂO DE SAÚDE BUCAL NA ATENÇÃO BÁSICA".

Pesquisador Responsável: MAGDA DUARTE DOS ANJOS SCHERER

CAAE: 20539213.6.1001.0030

Com base na Resolução 466/12, do CNS/MS, que regulamenta a ética em pesquisa com seres humanos, o Comitê de Ética em Pesquisa com Seres Humanos da Faculdade de Ciências da Saúde da Universidade de Brasília, após análise dos aspectos éticos e do contexto técnico-científico, resolveu APROVAR o projeto intitulado "ESTRATÉGIA SAÚDE DA FAMÍLIA - INOVAÇÃO TECNOLÓGICA PARA AMPLIAÇÃO DO ACESSO, DA QUALIDADE E PROMOÇÃO DE SAÚDE BUCAL NA ATENÇÃO BÁSICA", em parecer No. 491.461, de 27 de novembro de 2013.

O pesquisador (a) responsável fica, desde já, notificado (a) da obrigatoriedade da apresentação de relatórios parcial semestral e final do projeto de pesquisa, contados a partir da data de aprovaçăo do protocolo de pesquisa, conforme Resolução 466/12 CNS, ítens X.1.3.b. e XI.2.d.

Brasília, 03 de novembro de 2014.

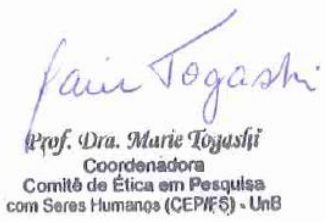

Comitê de Ética cm Pcsquisa com Seres Humanos - Faculdade de Ciências da Saúde Universidade de Brasília - Campus Universitário Darcy Ribeiro - CEP: 70.910-900

Telefone: (61)-3107-1947 Email: cepfsunb@gmail.com 


\section{ANEXO B - APROVAÇÃO NO COMITÊ DE ÉTICA EM PESQUISA DA FEPECS}

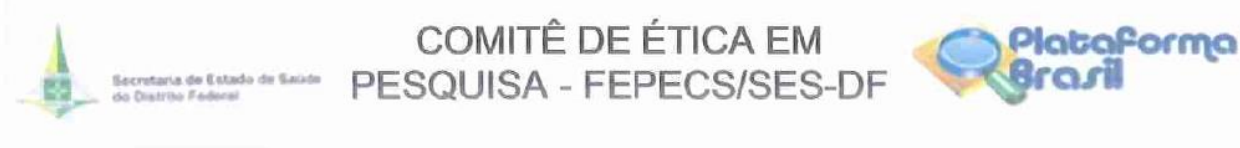

\section{PARECER CONSUBSTANCIADO DO CEP}

\section{DADOS DO PROJETO DE PESQUISA}

Titulo da Pesquisa: Inovação tecnológica na promoção da saúde bucal no trabalho da Estratégia de Saúde da Familia

Pesquisador: Charleni Inês Scherer

Área Temática:

Versão: 1

CAAE: 22866513.3.0000.5553

Instituição Proponente: Subsecretaria de Atenção Primária à Saúde

Patrocinador Principal: Financiamento Próprio

\section{DADOS DO PARECER}

Número do Parecer: 459.739

Data da Relatoria: $21 / 10 / 2013$

\section{Apresentação do Projeț:}

Considerando-se a Estratégia de Saúde da Familia (ESF) como modelo de inovação tecnológica presente na rede de Atenção Primária à Saúde(APS) no país, e que a forma de organização do trabalho tem implicaçăo direta no acesso e na qualidade das açöes de saúde, a presente pesquisa pretende analisar de que maneira o trabalho na ESF no Distrito Federal produz inovações na promoção da saúde bucal.

Trata-se de um estudo qualitativo, a ser desenvolvido no Distrito Federal, junto a profissionais que atuam na ESF, que fará uma análise transversal a partir de dados obtidos

em cenários políticos-institucionais diversos.

Busca caracterizar as ações de saúde bucal desenvolvidas pela equipe de Saúde da Família, contextualizando-as no cenário institucional e histórico-social;

Identificar os aspectos de inovação tecnológica na promoção da saúde bucal

constantes nas práticas, na composição das equipes, nas relações, na organização e na gestão do trabalho da ESF; e, Identiiicar em que sentido os aspectos de inovaçăo tecnológica na promoção da saúde bucal tem contribuido para a melhoria das ações de promoção da saúde bucal na ESF, na percepção dos profissionais e gestores.Tendo como referencial a ergologia, as diretrizes da Politica Nacional de Saúde Bucal e a Política Nacional de Atenção Básica.

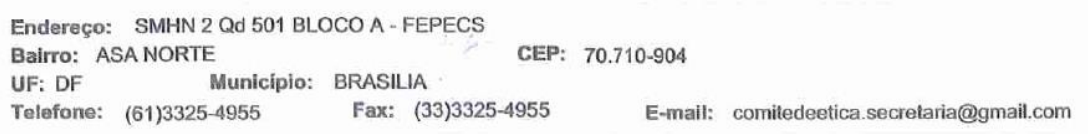




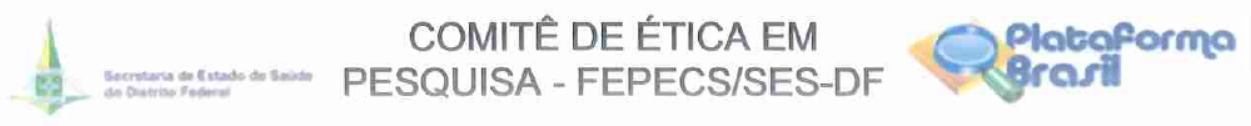

Conlinuaçẵo do Parecer: 459.739

Objetivo da Pesquisa:

Objetivo Primário:

Analisar em que medida o trabalho na ESF no Distrito Federal produz inovaçōes na promoção da saúde bucal.

Objefivo Secundário:

a)Caracterizar as ações de saúde bucal desenvolvidas pela Equipe de Saúde da Família, contextualizandoas no cenário institucional e históricosocial;

b)Identificar os aspectos de inovação tecnológica na promoçăo da saúde bucal constantes nas práticas, na composição das equipes, nas relaçöes, na organização e na gestão do trabalho da ESF;c)ldentificar em que sentido os aspectos de inovação tecnológica na promoção da saúde bucal tem contribuido para a melhoria das açỏes de promoção da saúde bucal na ESF, na percepção dos profissionais e gestores.

\section{Avaliação dos Riscos e Benefícios:}

O pesquisador assume o compromisso de garantir o sigilo que assegure o anonimato e a privacidade dos sujeitos da pesquisa e a confidencialidade dos dados coletados. Os dados obtidos na pesquisa deverão ser utilizados exclusivamente para a finalidade prevista no seu protocolo, que só poderá iniciar após aprovação pelo CEPIFEPECS.

O pesquisador deverá encaminhar relatório final ao término da pesquisa

\section{Comentários e Considerações sobre a Pesquisa:}

Estudo qualitativo.O cenário da pesquisa será a APS/Estratégia Saúde da Familia do Distrito Federal na sua relação com o sistema de saúde de cada local. A populaçấo do estudo será composta por profissionais que atuam na gestão e na assistência na Saúde da Família. A inclusão dos locais e sujeitos será feita por amostragem intencional, que consiste em uma amostragem não probabilística que seleciona um subgrupo que possa ser considerado representativo da população de estudo. A inclusăo dos sujeitos se dará pelo preenchimento dos seguintes critérios:

a) Unidades Básicas de Saúde com equipes de Saúde da Família completas incluindo equipe de Saúde Bucal, independente da modalidade;

b) Equipes de Saúde da Família consideradas de boa qualidade pelos gestores municipais e/ou distritais, tendo como referência a Política Nacional de Atenção Básica e Política Nacional de Saúde Bucal;

Endereço: SMHN 2 Qd 501 BLOCO A - FEPECS

Bairro: ASA NORTE

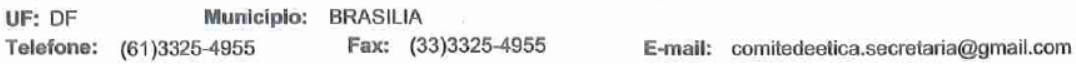

CEP: $70.710-904$ 


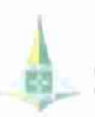

\section{COMITÊ DE ÉTICA EM PESQUISA - FEPECS/SES-DF}

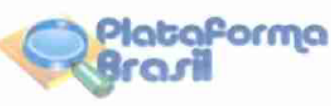

Continuaçâo do Parecer, 459.739

c) Serão consideradas, preferencialmente, equipes que tenham Centro de

Especialidades Odontológicas e Núcleo de Apoio à Saúde da Familia como referência;

d) Equipes que fizeram adesão ao $1^{\circ}$ ciclo do PMAQ; e,

e)Equipes que concordem em participar da pesquisa.

A amostra contará com no mínimo duas equipes em um município em cada região participante. Os dados serão analisados concomitantemente à coleta e a amostra será ampliada ou considerada suficiente pelo critério de saturação dos dados. Serão realizados quatro encontros entre o grupo de pesquisadores das três regiōes envolvidas no estudo.

O primeiro com objetivo de realizar balizamento teórico-metodológico e construção dos instrumentos de pesquisa entre os pesquisadores; o segundo e terceiro com objetivo de analisar e reorientar, se necessário, a atividade de campo; e o quarto para avaliação do processo.

A captura das dimensões da realidade exige uma triangulação de dados, utilizando-se de registros escritos,dados de observação e depoimentos. A técnica de triangulação na coleta de dados é amplamente utilizada em pesquisas qualitativas que utilizam como referencial de análise a percepção complexa dos fenômenos, por possibilitar o acesso aos dados por meio de fontes diversas, permitindo uma compreensäo mais global do que é investigado.

Tamanho da Amostra no Brasil: 20

Considerações sobre os Termos de apresentação obrigatória:

Folha de rosto: Apresentada. Assinada

Requerimento para parecer (CEP): Apresentado

Termo de Concordância: Apresentado

Curriculum Vitae do(s) pesquisador(es): Apresentados

TCLE: Apresentou.

Cronograma da Pesquisa: Apresentado.

Planilha de orçamento: Apresentada.

\section{Recomendações:}

O pesquisador assume o compromisso de garantir o sigilo que assegure o anonimato e a privacidade dos sujeitos da pesquisa e a confidencialidade dos dados coletados. Os dados obtidos na pesquisa deverão ser ut́ilizados exclusivamente para a finalidade prevista no seu protocolo, que só poderá iniciar após aprovação pelo CEP/FEPECS.

O pesquisador deverá encaminhar relatório final ao término da pesquisa.

Endereço: SMHN 2 Qd 501 BLOCO A - FEPECS

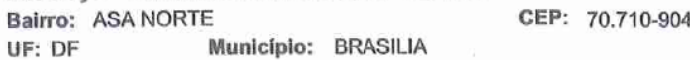


a.

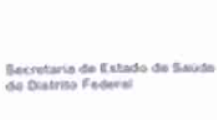

\section{COMITÊ DE ÉTICA EM PESQUISA - FEPECS/SES-DF}

Continuaçấo do Parecer: 459.739

Conclusōes ou Pendências e Lista de Inadequaçōes:

Aprovado

Situação do Parecer:

Aprovado

Necessita Apreciação da CONEP:

Não

Consideraçöes Finais a critério do CEP:

BRASILIA, 18 de Novembro de 2013

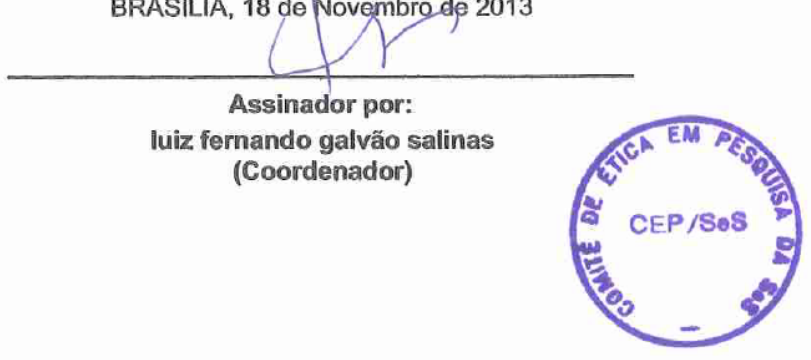

Endereço: SMHN 2 Qd 501 BLOCO A - FEPECS

BairTo: ASANORTE

CEP: $70.710-904$

UF: DF Municipio: BRASILIA

Telefone: (61)3325-4955 Fax: (33)3325-4955

E-mail: comitedeetica.secrelaria@gmail.com 